\title{
II. Die Abgeordnetenkammer zwischen Wahlsieg und Scheitern des Cartel des Gauches
}

Der Wahlsieg des Cartel des Gauches leitete für die Abgeordnetenkammer das Experiment eines linksbürgerlich-sozialistischen Regierungslagers ein, wie es in dieser Form in der Dritten Republik noch nie bestanden hatte ${ }^{1}$. Politische Praxis und Scheitern dieses Experiments wurden in der französischen Geschichtsschreibung zusammen mit den Erfahrungen der Volksfront von 1936/37 in einen größeren Zusammenhang linker Regierungsbildung gestellt, der wiederum als historische Folie für die Linksregierungen der letzten Jahrzehnte diente ${ }^{2}$. So anregend und aufschlußreich derartige Interpretationslinien sein können, eine grundsätzlichere parlamentarismusgeschichtliche Ebene blieb dabei weitgehend unbeachtet: Beide Anläufe zu einer Linksregierung bildeten auch erste Versuche zu einer stärker parteipolitisch definierten Koalitionsbildung ${ }^{3}$ und zu einer durch Parteidisziplin gesicherten Erfüllung der regierungstragenden Funktion der Abgeordnetenkammer. Sie waren daher, trotz ihres vordergründigen Scheiterns, auch Marksteine im allmählichen Wandel des klassischen französischen Parlamentarismus in ein modernes parteiengestütztes System.

Die wichtigsten Indizien dieses Prozesses und die Frage, warum eine derartige Modernisierung des parlamentarischen Systems in den Jahren 1924-26 nicht durchzusetzen war, werden im Laufe des folgenden Kapitels zu klären sein. Daneben ist aber auch auf die beiden anderen großen Optionen eines Verfassungswandels zu achten, die am Ende des vorigen Kapitels unterschieden wurden: die Möglichkeit der Reaktivierung eines parlamentarisch-präsidentiellen Mischsystems und die teils an der Tradition orientierte, teils aber auch darüber hinausgehende Stärkung eines vom Anspruch her überparteilich agierenden Ministerpräsidenten. Stehen damit vor allem Fragen der regierungstragenden Funktion im Mittelpunkt, so sind doch auch die wesentlichen Entwicklungen der übrigen parlamentarischen Funktionen von Interesse. In besonderer Weise gilt dies für den 1924 begonnenen Prozeß der legislativen Funktionsabgabe an die Regierung. Im Juli 1926 legte das Kabinett Briand-Caillaux ein umfangreiches Ermächtigungsprojekt vor. Die damit verbundenen Vorgänge, die - ähnlich wie bei der Ermächtigung vom März 1924 - in engem Zusammenhang mit der Währungskrise standen, sollen gegen Ende dieses Kapitels ausführlich behandelt werden.

1 Zum eher locker gefügten und politisch erheblich weiter in der Mitte stehenden Vorläufer des Bloc des Gauches von 1902 vgl. oben S. 34.

2 Charakteristische aktualisierende Deutung v.a. in Jeanneney, Leçon; Halimi, Sisyphe est fatigué. Weitere grundlegende Literatur zum Cartel des Gauches: Soulié, Cartel des Gauches (nur zur Anfangsphase); Berstein, Histoire 1, S. 390-436; Judt, French Socialists.

3 Berstein, Histoire 1, z.B. S. 390, spricht zwar von einer "coalition de gauche“, thematisiert aber kaum das Neuartige de Situation. Betont sei daß es sich nur um eine Annäherung an eine Koalitionsbildung im deutschen Sinne handelt. Der deutsche Koalitionsbegriff ist für das Cartel des Gauches daher problematisch. 


\section{1. „L'espoir de 1924“ - und die brüchige Grundlage des Wablergebnisses vom 11. Mai}

„Die Hoffnung von 1924“, so übertitelte Joseph Paul-Boncour ein Kapitel seiner politischen Lebenserinnerungen ${ }^{4}$ und verwies damit auf die Aufbruchstimmung, die unmittelbar nach den Kammerwahlen in Teilen der französischen Öffentlichkeit ausgebrochen war ${ }^{5}$. Ein Bericht der deutschen Botschaft spricht sogar von einem "Siegestaumel der Linken“, die nach den Erfolgen Poincarés in den letzten beiden Monaten vielfach gar nicht mehr an einen Wahlsieg geglaubt hätten ${ }^{6}$. Die seit Formierung der breiten Union sacrée von 1914 betriebene nationale Konsenspolitik war immer mehr in ein rechtsliberal-konservatives Fahrwasser geraten. Nun schien die Stunde einer regenerierten linksrepublikanischen Alternative zu schlagen. Gleichzeitig war die Chance gekommen, endlich die als Sackgasse empfundene Außen-, Reparations- und Finanzpolitik der Regierung Poincaré zu verlassen. All dies erzeugte eine Stimmungslage, die in kleinerem Maßstab bereits auf die große Euphorie nach dem Wahlsieg der Volksfront von 1936 vorauswies.

Indirekt wirft Paul-Boncours Kapitelüberschrift in ihrer rückblickenden Perspektive aber auch die Frage auf, warum diese Hoffnung schon bald enttäuscht wurde, warum sie letztlich auf einige Monate im Jahr 1924 beschränkt blieb. Wenn nun zunächst das Wahlergebnis und die daraus folgende Bildung einer Linksregierung betrachtet werden, so ist diese Frage sofort präsent. Die Suche nach Ansatzpunkten für den politischen Mißerfolg des Linkskartells und für die damit verbundenen schweren funktionalen Probleme, die der französische Parlamentarismus in den Jahren 1924 bis 1926 durchmachte, muß bereits in dieser Phase einsetzen.

An den Kammerwahlen vom 11. Mai 1924 beteiligten sich rund $83 \%$ der wahlberechtigten französischen Männer7. Noch nie in der Dritten Republik hatte es so eine hohe Wählermobilisierung gegeben. Im Vergleich zu den Wahlen von 1919 (etwa $71 \%$ Beteiligung) war ein massiver Zuwachs zu verzeichnen ${ }^{8}$. Die in weiten Teilen des Landes bestehende Polarisierung zwischen einem Links- und einem Rechtsblock und die damit verbundene Alternative eines Machtwechsels hatten offenbar stark aktivierend gewirkt ${ }^{9}$, zumal die Themen der Außen- und Reparationspolitik, der Steuerpolitik, der Währungskrise und der Teuerung erhebliche Aufmerksamkeit auf sich zogen ${ }^{10}$.

4 Paul-Boncour, Entre deux guerres 2, S. 85.

5 Vgl. Präfektenberichte, z. B. Bericht vom 15. 5. 1924 aus der Charente Inférieure. In der Bevölkerung würden große Erleichterung und große Hoffnungen dominieren, es gebe „illusions puériles“. AN Paris, F1c III, Nr. 1126. Allgemein zum Phänomen auch Soulié, Herriot, S. 141.

6 Botschaftsbericht-Paris (Hoesch), Tel. Nr. 277, 15. 5. 1924; PA AA Berlin, R 70715.

7 Zum Wahlsystem vgl. oben S. 50. Vgl. zum folgenden v.a. Bonnefous, Histoire 3, S. 434-437; Mayeur, Vie politique, S. 275-277; Wileman, What the Market Will Bear; Maier, Recasting Bourgeois Europe, S. $475 f$.

8 Lachapelle, Elections législatives du 11 mai 1924, S. $35 \mathrm{f}$.

9 In diese Richtung geht auch der bei Bonnefous, Histoire 3, S. 434, zu findende Erklärungsansatz: „Cette exceptionelle participation électorale s'explique par l'effort considérable du Cartel des gauches pour rallier à lui les abstentionnistes.“ Mayeur, Vie politique, S. 275, spricht allgemein von einem „indice de l'intensité de la lutte et de l'intégration croissante de la population à la politique“.

10 Vgl. z.B. Analyse nach den Wahlen im „rapport mensuel“ vom 14.5. 1924 des Präfekten des Departement Hautes-Alpes. AN Paris, F 1c III, 1125. 
Das Wahlergebnis brachte im Vergleich zu 1919 einen deutlichen Linksruck. Als wichtigste Ursachen hierfür wurden zeitgenössisch vor allem ein breites Unbehagen an der zuletzt betriebenen Außen- und Reparationspolitik sowie Protest gegen die Steuererhöhung des double-décime gesehen. Möglicherweise hatte, wie Le Temps meinte, auch die Furcht der Beamten vor dem drohenden Stellenabbau mittels décrets-lois eine wahlentscheidende Wirkung ${ }^{11}$. Allerdings blieb das Ergebnis des Linkskartells hinter manchen zu Beginn des Jahres geäußerten Erwartungen zurück. Offenbar hatte der Erfolg der Regierung in der Bekämpfung der Währungskrise eine nicht unerhebliche Wirkung gezeigt ${ }^{12}$. Poincarés Manöver der Kabinettsumbildung und der damit verbundene Verzicht auf eine klare Lagerbildung dürften dagegen ambivalente Folgen gehabt haben: Zum einen trugen sie dazu bei, die Hoffnung auf einen geschlossenen Linksblock zu dämpfen, zum anderen könnten sie aber auch im eigenen rechtsliberal-konservativen Wählerspektrum für eine gewisse Verunsicherung gesorgt haben ${ }^{13}$. Möglicherweise zeigte auch, wie deutsche Politiker im Vorfeld befürchtet hatten ${ }^{14}$, der eine Woche zuvor bei den Reichstagswahlen erfolgte Rechtsruck gewisse Auswirkungen.

Die personelle Kontinuität zwischen alter und neuer Abgeordnetenkammer lag 1924 höher als beim Wechsel von 1919, war doch der jetzige Linksrutsch bei weitem nicht so stark wie die Verschiebungen nach rechts beim grandiosen Wahlsieg des Bloc national viereinhalb Jahre zuvor. Dennoch schieden zahlreiche Parlamentarier, die bisher dem Regierungslager angehört hatten, aus der Kammer aus. Darunter befand sich auch eine Reihe prominenter Namen wie etwa Tardieu, der offenbar ein Opfer seiner Aktivitäten gegen die Regierung Poincaré geworden war ${ }^{15}$, der einstige Finanzminister de Lasteyrie ${ }^{16}$ oder der junge Paul Reynaud, dessen rhetorische Brillanz in den letzten Monaten des Bloc national für Aufsehen gesorgt hatte ${ }^{17}$.

In Mandaten ergab sich ein knapper Sieg des Cartel: 266 Sitze fielen an Kandidaten, die auf dessen Listen bzw. innerhalb rein sozialistischer Wahlvorschläge angetreten waren, 229 an Repräsentanten von Mitte-rechts-Listen, 47 an Vertreter von Listenverbindungen der linken Mitte und 26 an Kommunisten ${ }^{18}$. Nach Abschluß der Fraktionsbildung in der neuen Abgeordnetenkammer Mitte Juni verfügte die SFIO über 104 Abgeordnete, die radikale Fraktion über 139 und die

1 LT, 14. 5. 1924, S. 1, "Causes et conséquences“. Der Artikel sah drei Hauptgründe für die Niederlage der Regicrung: "décrets-lois", „double-décime " und die verwirrende Regierungsumbildung im März. Der letztgenannte Aspekt ist allerdings sehr fragwürdig und spiegelt eher die Vorliebe von Le Temps für ein klar konturiertes Mitte-rechts-Lager.

12 Vorausgesagt etwa von Botschaftsbericht-Paris (Hoesch), A 1140, Nr. 18. 3. 1924, S. 3f.; PA AA Berlin, R 70697.

13 So erneut LT, 14.5. 1924, S. 1, "Causes et conséquences“: „Le remplacement brusque de certain ministres, qui depuis deux ans, avaient fidèlement suivi la politique gouvernementale, par d'autres qui l'avaient combattue, avait créé dans ces milieux un malaise indéniable. La prime de récompense à l'opposition, un des maux dont souffre le parlementarisme, n'avait pas paru comme un des moyens les plus sûrs de désarmer cette même opposition. Et elle avait, par une puissance cumulative, désorienté, désaxé une majorité qui avait toujours suivi le précédent ministère.“

14 Vgl. oben S. 334, Anm. 584.

15 So Bonnefous, Histoire 3, S. 435, Anm. 1. Zum Wiedereinzug 1926 vgl. unten S. 482.

$16 \mathrm{Zu}$ den Ursachen des Mißerfolgs im Departement Corrèze vgl. Kittel, Provinz, S. 470.

17 Vgl. auch - mit weiteren Namen - Bonnefous, Histoire 3, S. 436; Reynaud, Mémoires 1, S. 175185. Zum weiteren politischen Werdegang Reynauds vgl. Grüner, Reynaud.

18 Vgl. Bonnefous, Histoire 3, S. 436. 
Républicains-socialistes über 44 (vgl. auch Tab. 4.5 im Anhang). Alle drei linken Fraktionen hatten somit ihre Mandatszahl deutlich steigern können, wobei die Sozialisten (zuletzt 50 Abgeordnete) den größten Sprung machten. Die insgesamt 286 Sitze des linken Wahlkartells lagen jedoch knapp unter der rechnerischen Mehrheit aller Mandate (293 von jetzt 584). Bleibt man in der - für den französischen Parlamentarismus immer nur bedingt aussagefähigen - fraktionellen Logik, dann wurde die nach einer vierjährigen Unterbrechung erneut formierte ${ }^{19}, 40 \mathrm{Ab}$ geordnete starke Gauche radicale nun zum Zünglein an der Waage. Diese unabhängige Gruppierung, politisch im fließenden Bereich zwischen Radicaux und Modérés einzuordnen, rekrutierte sich zum überwiegenden Teil aus Wahlverbindungen der linken Mitte ${ }^{20}$, die meist in bewußter Abgrenzung vom Konzept eines Linkskartells entstanden waren und z.B. Namen wie Union républicaine oder Concentration républicaine trugen.

In der abgelaufenen Legislaturperiode hatten die jetzt zur Gauche radicale zusammengeschlossenen Abgeordneten, soweit sie bereits in der Kammer vertreten waren, überwiegend den Fraktionen der Républicains de Gauche und vor allem der Gauche républicaine démocratique und somit dem rechtsliberalen Spektrum angehört, darunter mit Louis Loucheur auch ein Minister der letzten Regierung Poincaré21. Hinzu kamen einzelne Dissidenten aus der radikalen Fraktion - wie etwa der im März anläßlich seiner Berufung in die Regierung Poincaré III aus dem Parti radical ausgetretene Daniel-Vincent. Insgesamt aber handelte es sich weit eher um eine Gruppe von „Überläufern“ aus dem bisherigen Regierungslager als um eine Absplitterung vom rechten Rand des Parti radical. Ein gewisser Opportunismus und das Streben nach politischen Ämtern mögen bei diesem Seitenwechsel ebenso beteiligt gewesen sein wie inhaltliche Motive. Nicht zufällig hatte gerade Loucheur als engagierter Vertreter einer kooperativen Reparationspolitik ${ }^{22}$ in der Endphase des Kabinetts Poincaré II, bevor er dann selber in das Kabinett Poincaré III eintrat, zu den schärfsten informellen Kritikern der bisherigen Regierungspolitik gehört. Die konkreten Hintergründe der Fraktionsbildung der Gauche radicale liegen jedoch im Dunkeln ${ }^{23}$.

Durch die Abhängigkeit der Kartellkräfte von dieser diffusen Gruppierung entstand eine paradoxe Situation: Das Experiment einer koalitionsähnlichen, parteiengestützten Regierungsallianz der Linken wurde erst durch das Mitwirken einer

19 Über die Motive der Gründung ist kaum etwas bekannt. In der Literatur wird diese Frage bislang offenbar nicht behandelt. LT, 2.6. 1924, S. 4, „La gauche radicale“, erwähnt nur kurz die Bildung aus Abgeordneten der bisherigen Fraktionen der Républicains de Gauche und der Gauche républicaine démocratique. Als Initiatoren werden hier Eugène Raynaldy, Hector Molinié und André Fallières genannt.

20 Bereits vor dem Ersten Weltkrieg hatte es eine gleichnamige Gruppe gegeben.

21 Nach Schulthess 1924, S. 224, wurde die neue Fraktion von Loucheur gegründet. Loucheur, Carnets secrets, bleibt hierzu allerdings ohne Angaben; ebenso Carls, Loucheur. Von 30 Abgeordneten der Gauche radicale, die bereits 1919-24 ein Kammermandat besaßen, hatten 16 der Gauche républicaine démocratique, je fünf den Républicains de Gauche und der Fraktion des Parti radical angehört. Je einer stammte aus den Reihen der Action républicaine et sociale, der Républicains-socialistes und sogar der Entente républicaine démocratique, einer war fraktionslos gewesen. Berechnet mit Hilfe der Angaben zur Fraktionszugehörigkeit in den Annexes zu Roussellier, Phénomène.

22 Generell hierzu Carls, Loucheur.

23 Möglicherweise könnten hier spezielle biographische Recherchen sowie eine breite Erfassung von Pressemeldungen weiterhelfen. 
parteiunabhängigen Fraktion möglich, die gleichsam aus den archaischen Tiefen der parlamentarischen Tradition Frankreichs stammte.

Nur wenn man die am 11. Mai erzielten Ergebnisse jener Mitte-links-Wahlbündnisse, aus denen die Gauche radicale weitgehend hervorging ${ }^{24}$, einem fiktiven Gesamtergebnis des ehemaligen Bloc national zuschlägt, ergibt sich im übrigen die in der Literatur gerne angeführte Mitte-rechts-Mehrheit nach absoluten Stimmen ${ }^{25}$. Eine derartige Rechnung aber erscheint angesichts der Entscheidung der Gauche radicale für das Linkskartell unzulässig. Bei differenzierter Betrachtung der Wahlbündnisse unterscheiden sich deren Stärkeverhältnisse in abgegebenen Stimmen (3,2 Millionen für Mitte-rechts-Listen, 3,4 für Kartell- bzw. SFIOListen, 1 Million für die linke Mitte) nicht allzu sehr von der späteren Mandatsverteilung zwischen dem Mitte-rechts-Spektrum, den drei ursprünglichen Kartellparteien und der Gauche radicale. Die in der Literatur allgemein verbreitete und bereits zeitgenössisch vom liberal-konservativen Temps übellaunig vertretene ${ }^{26}$ Auffassung, das Linkskartell wäre dem Mitte-rechts-Lager nach absoluten Stimmen eigentlich unterlegen und hätte seinen Sieg nur dem Wahlsystem zu verdanken, ist daher in dieser Form zurückzuweisen.

Allerdings, dies sei eingeräumt, wären die Mehrheitsverhältnisse bei einem konsequenten Verhältniswahlrecht noch knapper und unübersichtlicher gewesen, was freilich vor allem an einer erhöhten Mandatszahl der isoliert angetretenen Kommunisten gelegen hätte ${ }^{27}$. Die kommunistische Fraktion erreichte 1924 eine Stärke von 26 Abgeordneten - immerhin eine Verdoppelung gegenüber der zurückliegenden Legislaturperiode; bei einem reinen Verhältniswahlsystem wären es allerdings 56 gewesen. Die bestehende Komponente des Mehrheitswahlsystems im geltenden Wahlrecht sorgte damit für eine Dämpfung des Radikalisierungsschubes, der - in geringerem Maße als in Deutschland und beschränkt auf die extreme Linke - 1924 auch in den französischen Kammerwahlen festzustellen war.

Die ehemaligen Träger des Bloc national in seiner zuletzt bestehenden verengten Form kamen zusammen lediglich auf 185 Sitze, davon 104 für die Union républicaine démocratique (die frühere Entente républicaine démocratique) sowie 43 für die Gauche républicaine démocratique und 38 für die Républicains de Gauche, den beiden nach den Wahlen noch bestehenden Fraktionen im Umfeld der Alliance ${ }^{28}$. Berücksichtigt man zudem die 14 Abgeordneten der neugebildeten christdemokratischen Fraktion der Démocrates ${ }^{29}$ sowie die 28 Abgeordneten der Gruppe "Aucun groupe“, die politisch meist auf der äußersten Rechten standen, dann ergibt sich eine Summe von 227 Parlamentariern, die einem oppositionellen Mitterechts-Lager zuzuweisen sind. Selbst wenn sich die Fraktion der Gauche radicale

24 Von 40 Abgeordneten kamen 6 von Kartellisten und 34 von Mitte-links-Listen. Auszählung nach Angaben in Normand, Tout le Parlement.

25 Genaue Zahlen nach Lachapelle, Elections législatives 1924, S. 28 f.: 4539063 zu 4270228 (inclusive 875812 kommunistische Stimmen). Ähnlich auch Bonnefous, Histoire 3, S. 435; Mayeur, Vie politique, S. 275 f.; Delporte, III' République 3, S. 96.

26 LT, 14. 5. 1924, S. 1, „Causes et conséquences“.

27 Lachapelle, Elections législatives 1924, S. $26 \mathrm{f}$.

28 Die Action républicaine et sociale hatte sich nicht mehr formiert. Allerdings bildete sich $1926-$ ebenfalls im Bereich der Modérés - die Gauche indépendante. Vgl. auch Tab. 4.5 im Anhang.

29 Vorläufer des Ende 1924 gegründeten Parti démocrate populaire. 
von Anfang an in dieses Spektrum eingefügt hätte, wäre es von einer eigenen Mehrheitsbildung noch weit entfernt gewesen.

Die Voraussetzungen für eine stabile linke Regierungsbildung waren bereits durch die Schlüsselrolle, in welche jetzt die Gauche radicale gelangte, eher ungünstig. Berücksichtigt man ferner die konzeptionellen Unklarheiten der am Kartell beteiligten Parteien, dann bildeten die knappen Mehrheitsverhältnisse eine äußerst unsichere Basis. Le Temps meinte denn auch am Abend des 12. Mai halb drohend, halb prophetisch: „Si [...] il apparaît [...] que les forces de gauche approchent la majorité et donc du pouvoir, on peut leur prédire que pour elles l'ère des difficultés commence." 30

\section{Entscheidungskampf der Kartellmebrheit gegen Millerand und Bildung der Regierung Herriot}

Kaum war das Wahlergebnis bekannt, stand neben einer den neuen Mehrheitsverhältnissen angepaßten Regierungsbildung noch ein zweites Thema auf der politischen Tagesordnung. Sofort setzte in großen Teilen der linken Presse eine heftige und zum Teil äußerst rüde Kampagne ein ${ }^{31}$, die den Rücktritt des Staatspräsidenten zum Ziel hatte. Dies eröffnete einen in seiner Tragweite noch immer unterschätzten $^{32}$ Verfassungskonflikt, der zwischen Millerand und der neuen Kammermehrheit ausgefochten wurde und der schließlich mit der Kapitulation des Präsidenten endete. In gewisser Hinsicht bedeutete dieser Konflikt die Fortführung und den Abschluß des parlamentarisch-präsidentiellen Kampfes von 1877. Beide Themen - Regierungsbildung und Zukunft des Staatspräsidenten - gingen nun eine enge politische Verbindung ein. Neben dem Umstand, daß die Regierungsbildung erstmals in der Dritten Republik eine stark parteipolitische Prägung erhielt, war dies ein wesentlicher Grund dafür, daß sich die Formierung des neuen Kabinetts ungewöhnlich lange verzögerte.

Die politische Entwicklung in jenen fünf Wochen zwischen den Wahlen zur Abgeordnetenkammer und der Bildung der Kartellregierung Herriot war derart ereignisreich und vielschichtig, dazu voller fiebriger Emotionen, Spekulationen und Gerüchte - mancher Zeitgenosse zog sogar den Vergleich zu den revolutionären Tagen des Nationalkonvents ${ }^{33}$-, daß ihre Darstellung genug Stoff für eine eigenständige Studie abgäbe ${ }^{34}$. Im folgenden wird es lediglich um eine relativ knappe Darstellung gehen, wobei vor allem zwei Aspekte im Vordergrund stehen: 1. Worin lag der tiefere parlamentarismusgeschichtliche Gehalt des Machtkampfes zwischen Staatspräsident und Linkskartell? 2. Inwieweit waren der Konflikt um

30 LT, 13. 5. 1924, S. 1, "Les élections d'hier“.

31 Vgl. auch Botschaftsbericht-Paris (Hoesch), Nr. 320, 6. 6. 1924, S. 3: „[...] der von der Linkspresse in täglichen Schmähungsartikeln und unflätigen Karikaturen angegriffene Präsident"; PA AA Berlin, R 70715.

32 Dies gilt nicht zuletzt auch für Bernard, L'affaire Millerand, die bislang detaillierteste Studie. Auszunehmen ist lediglich Farrar, Principled Pragmatist.

33 Bonnefous, Histoire 4, S. 10.

34 Grundlegend neben Bernard, L'affaire Millerand, sind Bonnefous, Histoire 4, S. 7-21; Berstein, Histoire 1, S, 390-397; Farrar, Principled Pragmatist, S. 361-371. 
den Staatspräsidenten und der zähe Prozeß einer linken Regierungsbildung von einem neuartigen Primat der Parteipolitik bestimmt?

Die Kampagne gegen Millerand begann am 12. Mai, einen Tag nach den Wahlen. Das Startsignal gab die linksliberale Tageszeitung Le Quotidien, die seit ihrer Gründung 1923 als wichtigste publizistische Triebkraft des Cartel des Gauches gewirkt und inzwischen eine Auflage von über 300000 erreicht hatte ${ }^{35}$. Ein Kommentar des Chefredakteurs Pierre Bertrand trug als Titel die Aufforderung „Présidents, allez-vous-en!“ und forderte den umgehenden Rücktritt des Président du conseil und des Staatspräsidenten ${ }^{36}$. Obwohl keineswegs auszuschließen gewesen wäre, daß die noch amtierende Regierung Poincaré dank der eventuellen Unterstützung jener parlamentarischen Kräfte, die dann unter der Fahne der Gauche radicale zur Linksallianz wechselten, auch in der neuen Kammer eine Mehrheit gefunden hätte ${ }^{37}$, zielte der Appell zum Rücktritt des Ministerpräsidenten eigentlich auf eine Selbstverständlichkeit. Angesichts des Wahlergebnisses konnte von Poincaré, der sein unbedingt legalistisches Verfassungsverständnis erst Ende März nach seiner überraschenden Abstimmungsniederlage bewiesen hatte ${ }^{38}$, kaum etwas anderes erwartet werden. Ganz anders verhielt es sich mit der an Millerand gerichteten Rücktrittsforderung, die als Reaktion auf eine Kammerwahl ein absolutes Novum darstellte.

Zur Demission eines Staatspräsidenten war es bislang in der Geschichte der Dritten Republik viermal gekommen ${ }^{39}$ : Der konservative Marschall Mac Mahon, der sich im großen Konflikt von 1877 trotz seines weitgehenden Machtverlustes noch im Amt behauptet hatte, trat Anfang 1879 vor allem aufgrund seiner politischen Isolierung zurück. Sein Nachfolger Jules Grévy, eine der republikanischen Symbolfiguren der frühen Dritten Republik, wurde 1887 infolge des „scandale des décorations" durch eine "grève des ministres“, eine Verweigerung der parlamentarischen Regierungsbildung, zum Rücktritt gezwungen ${ }^{40}$. Jean Casimir-Périer gab 1895 nach nur halbjähriger Amtszeit auf, weil er sich nicht in den verengten politischen Spielraum des Staatspräsidenten fügen wollte, aber auch weil Teile der sozialistischen Bewegung und insbesondere der damals noch linksradikale Alexandre Millerand den Bankier mit scharfen Tönen als Kapitalisten verteufelten. Paul Deschanel schließlich mußte 1920 wegen einer psychischen Erkrankung demissionieren.

Vom verfassungspolitischen Gehalt lag die nun von Teilen der Linkspresse unterstützte und „mit größter Heftigkeit“ geführte¹ Kampagne auf einer Ebene mit den Rücktritten von Mac Mahon und Casimir-Périer. In beiden Fällen war allerdings der Rücktritt weitgehend freiwillig erfolgt. Zwar hatte 1877 die von Gam-

35 Zur Auflage vgl. Bellanger (Hrsg.), Histoire générale de la presse française 3, S. 570.

6Q LQ, 12. 5. 1924, S. 1, „Présidents, allez-vous-en!“

37 Dies betont nachdrücklich Bernard, L'affaire Millerand. Vgl. dann die Entwicklung im Juli 1926.

$38 \mathrm{Vgl}$. oben S. 410.

39 Vgl. zum Überblick: Derfler, President and Parliament; Mayeur, Vie politique.

40 Vgl. ebd., S. 125. Daniel Wilson, der Schwiegersohn Grévys, hatte dank seiner Nähe zum Präsidenten einen schwungvollen Handel mit staatlichen Auszeichnungen betrieben.

41 Botschaftsbericht-Paris (Hoesch), Tel. Nr. 277, 14. 5. 1924; PA AA Berlin, R 70715. - An führender Stelle waren neben Le Quotidien auch die linksliberalen Blätter L'Euvre und L'Ere nouvelle sowie die sozialistische Parteizeitung Le Populaire beteiligt. 
betta ausgegebene Parole gegen Mac Mahon "Se soumettre ou se démettre“ gelautet. Nachdem Mac Mahon Ende 1877 eine weitgehende Unterwerfung vollzogen hatte, war auf republikanischer Seite von einer zu erzwingenden Demission nicht mehr ernsthaft die Rede gewesen. Millerand aber hatte nun nach den Forderungen der Kartellpresse keine Wahl mehr. Es ging nur noch darum, den Staatspräsidenten zu „verjagen“, „so wie er" - was weit übertrieben war - „Casimir-Périer verjagt hatte" 42 .

Das Sündenregister, für das Millerand nun die Quittung zahlen sollte, war lang und beschränkte sich keineswegs nur auf die berühmt-berüchtigte Rede von Evreux. Erinnert sei insbesondere an den „coup de Cannes“ im Januar 1922, an die Interventionen des Staatspräsidenten in die Wahlrechtsdiskussion Ende 1923 und an sein Verhalten Ende März 1924 nach dem Sturz der Regierung Poincaré II. Im Grunde ging es, wie schon mehrfach angesprochen wurde, vor allem um zwei eng miteinander verbundene Zielrichtungen des Millerandschen Amtsverständnisses, die nun politisch sanktioniert werden sollten: Zum einen die demonstrative Identifizierung mit der Politik des Bloc national, zum anderen das wiederholte Bestreben, aktiven Einfluß auf die Zusammensetzung und den Kurs der Kabinette zu gewinnen. Politische Parteinahme und der Versuch, die Autonomie des Parlaments in der regierungstragenden Funktion durch Einflußnahme des Präsidenten einzuschränken, hatten dabei nach und nach eine systemverändernde Qualität bekommen. Die sofortigen empörten Reaktionen des linksrepublikanischen Milieus verwundern daher nicht. Millerand selbst hatte im übrigen die jetzt über ihn hereinbrechenden Rücktrittsforderungen mit seiner oben zitierten Drohung vom 27. März geradezu provoziert ${ }^{43}$.

Daß sich die vehemente Pressekampagne, die das Interregnum bis zum Zusammentritt der neuen Kammer am 1. Juni füllte" ${ }^{44}$ tatsächlich zum Machtkonflikt zwischen dem siegreichen Linkskartell und Millerand entwickelte, war zunächst nicht unbedingt absehbar gewesen. Herriot, der weithin schon als künftiger Regierungschef gesehen wurde, gab sich zunächst sehr moderat. Am 22. Mai hatte er zusammen mit Paul Painléve, dem Ehrenvorsitzenden des Parti républicain-socialiste, sowie mit Poincaré und dem noch amtierenden Finanzminister FrançoisMarsal eine primär währungspolitisch motivierte Unterredung mit Millerand. Im Anschluß bedauerte der radikale Parteichef gegenüber der Presse die „campagne violente" gegen den Staatspräsidenten und kündigte an, einen eventuellen Auftrag zur Regierungsbildung annehmen zu wollen ${ }^{45}$.

Ohne hier auf die oftmals verwirrenden Einzelheiten der weiteren Entwicklung eingehen zu können, seien zwei wesentliche Faktoren herausgehoben. Zum einen zeichnete sich Ende Mai ab, daß die sozialistische Partei keine Regierung akzeptieren werde, die ihren Auftrag von Millerand erhielt ${ }^{46}$. Ausschlaggebend für diesen harten Kurs der SFIO war offenbar sowohl das Streben nach sicheren Rahmenbedingungen für eine von ihr unterstützte Regierung als auch die Furcht, bei

42 LQ, 28. 5. 1924, S. 1, „Nous chasserons Millerand comme il a chassé Casimir-Périer“.

43 Vgl. oben S. 411.

44 Farrar, Principled Pragmatist, S. 361.

45 Vgl. Bernard, L'affaire Millerand, mit Zitat aus dem Réveil du Nord.

46 Vgl. ebd. 
einem Verweilen Millerands im Amt bald selbst wieder ins politische Abseits zu rücken. Letzteres hatte sich bei der eben erwähnten Unterredung vom 22. Mai, zu der keine Sozialisten hinzugezogen worden waren, bereits angedeutet. Zum anderen zeitigte die seit zwei Wochen geführte Pressekampagne wohl auch deutliche Wirkungen innerhalb des Parti radical und des Parti républicain-socialiste. Berstein spricht in diesem Zusammenhang von einer "véritable dictature morale“ des Quotidien47.

Als sich die Abgeordneten der Kartellfraktionen zur Wiederaufnahme der parlamentarischen Arbeit versammelten, war der Druck auf Millerand bereits stark gewachsen. So schlossen sich die neue Fraktion der Républicains-socialistes und das Exekutivbüro des Parti radical bereits am 30. Mai der sozialistischen Haltung an. In der radikalen Fraktion wurde unter dem Einfluß von Herriot zunächst noch eine etwas gemäßigtere Formel verabschiedet. Diese forderte zwar auch klar die Demission Millerands, erhob den zentralen Vorwurf einer „politique personelle" und bezeichnete ein Verweilen im Amt als „Verletzung des republikanischen Gewissens“, schloß aber eine Regierungsbildung unter seiner Ägide nicht völlig aus ${ }^{48}$. Eine identische Position nahm dann am 1. Juni eine gemeinsam von Herriot, Blum und Painlevé, dem führenden Vertreter der républicains-socialistes, geleitete Versammlung aller Kartellabgeordneten ein.

An dieser Stelle ist ein kurzer Blick auf den Stand der Regierungsbildung sinnvoll. Nach den Kammerwahlen war, begünstigt durch die über zweiwöchige Frist bis zum Zusammentritt der neuen Kammer, eine relativ lange Phase des scheinbaren Abwartens eingetreten. Sicherlich wurden dabei nicht nur in der Presse, sondern auch hinter den Kulissen der politischen Szenerie verschiedene Möglichkeiten diskutiert und vielleicht auch schon erste Verhandlungen geführt. Die von Millerand offenbar zunächst favorisierte Vorstellung, Poincaré solle sich Anfang Juni mit seiner Regierung der Kammer stellen, war bereits am 13. Mai ausgeschieden, als der geschlagene Ministerpräsident für den 1. Juni seinen Rücktritt ankündigte ${ }^{49}$. Ebenso irreal war angesichts der Stimmungslage im Parti radical eine erneute Berufung Poincarés und damit eine Neuauflage des Bloc national 50 . Es blieben nun noch drei realistische Möglichkeiten, zu einer mehrheitsfähigen Regierung zu kommen. 1. Eine voll ausgeprägte Kartellregierung mit ministerieller Beteiligung der Sozialisten. 2. Eine linksbürgerliche Regierung ohne aktive Beteiligung, aber mit Unterstützung der Sozialisten. 3. Eine Regierung der Mitte vom

47 Berstein, Histoire 1, S. 391.

48 Es handelte sich um die sogenannte „motion Accambray“: „Le groupe des députés membres du parti républicain radical et radical-socialiste considérant que $\mathbf{M}$. Alexandre Millerand, président de la République, a, contrairement à l'esprit de la Constitution, soutenu une politique personnelle; considérant qu'il a pris ouvertement parti pour le Bloc national; considérant que la politique du Bloc national a été condamnée par le pays, estime que le maintien à l'Elysée de M. Millerand blesserait la conscience républicaine, serait la source de conflits incessants entre le Gouvernement et le chef de l'Etat et un danger constant pour le régime lui même." Zitiert nach Bonnefous, Histoire 4, S. 9. Das Urteil in Berstein, Histoire 1, S. 392, der Text enthalte "rien de définitif“ ist wohl zu milde, wie ebd. überhaupt die Rolle der Radicaux beim Sturz Millerands unterschätzt wird.

49 Trotzdem versuchte Millerand, Poincaré von dessen umgehend angekündigtem Rücktritt abzubringen. Offenbar hoffte der Staatspräsident, Poincaré werde auch in der neuen Kammer eine Mehrheit finden. Vgl. hierzu Persil, Millerand, S. 162.

50 Loucheur, Carnets secrets, S. 151, zum 30. 5. 1924 behauptet allerdings: „Il y a encore des ministres qui croient que Poincaré sera rappelé!“ 
Typus "concentration" unter Ausschluß der Sozialisten, aber unter Beteiligung der rechtsliberalen Kräfte im Umfeld der Alliance ${ }^{51}$. Angesichts des Linksrucks bei den Wahlen lag die breite Erwartung natürlich bei den beiden erstgenannten Optionen. In der liberal-konservativen Presse wurde hingegen bereits für die dritte Möglichkeit geworben ${ }^{52}$, und auch der deutsche Botschafter deutete in seinem Bericht an, daß er sich einen späteren Übergang zu diesem Modell vorstellen könne ${ }^{53}$.

Unabhängig vom Staatspräsidenten - und damit auch als Indiz für dessen faktischen Bedeutungsverlust - vollzogen sich Anfang Juni die entscheidenden Weichenstellungen für eine Regierungsbildung des Linkskartells. Die entscheidende Frage war, wie diese Regierung zusammengesetzt sein würde ${ }^{54}$. Daß die Sozialisten Ministerposten übernehmen würden, konnte nach der bisherigen Haltung der Partei und auch nach der extrem vorsichtigen Weise, in der die Wahlbündnisse geschlossen worden waren, kaum erwartet werden. Auch innerhalb des Parti radical wurde dies nur von den wenigsten angestrebt ${ }^{55}$. Der sozialistische Parteichef Blum, der in dem innerparteilichen Streit zwischen einer kleinen Gruppe von Koalitionsbefürwortern und den dominierenden Koalitionsgegnern einen mittleren Kurs verfolgte, zog sich auf die Position zurück, die SFIO könne als schwächerer Bündnispartner nicht das Wagnis einer Regierungsbeteiligung eingehen ${ }^{56}$.

Der kurze Verhandlungsprozeß, der schließlich zur sozialistischen Politik fester Unterstützung („soutien“) ohne eigenen Regierungseintritt führte, ist recht gut erforscht und kann hier knapp wiedergegeben werden. Ein erster Brief Herriots an seinen alten Duzfreund Blum - man kannte sich aus gemeinsamen Zeiten an der Ecole Normale - machte am 1. Juni ein äußerst vages Koalitionsangebot ${ }^{57}$. In einem kurzen Gespräch zwischen Vertretern beider Parteien am 2. Juni wurde diese Möglichkeit dann sehr schnell fallengelassen. In einem zweiten Brief umriß Herriot noch am selben Tag 58 ein stichpunktartiges Regierungsprogramm, für das er den „soutien“ der Sozialisten erbat. $\mathrm{Da}$ es sich hierbei um die einzige feststellbare „Koalitionsvereinbarung " handelte, seien die wesentlichen Punkte kurz aufgeführt: Rücknahme der parlamentarischen Ermächtigung, Wiederherstellung des Zündholzmonopols, Generalamnestie - hier ging es nicht zuletzt auch um die Fälle Caillaux und Malvy ${ }^{59}$-, Schließung der französischen Botschaft am Vatikan, Rücknahme des Dekrets vom Sommer 1923 zum obligatorischen Latein- und Griechischunterricht an Gymnasien, strikte Anwendung des Gesetzes zum Acht-

51 Nach Billard, Parti républicain-socialiste, S. 410, „la vieille recette briandienne par excellence“.

52 Vgl. z.B. LT, 14. 5. 1924, S. 1, „Causes et conséquences“.

53 Botschaftsbericht-Paris (Hoesch), Tel. Nr. 277, 14. 5. 1924, S. 3; PA AA Berlin, R 70715.

54 Zum folgenden vgl. v.a. Ziebura, Blum, S. 340-343; Berstein, Histoire 1, S. 390-397; Judt, Reconstruction, S. 180-185.

55 Vgl. Paul-Boncour, Entre deux guerres 2, S. 90 f., sowie überzeugend Ziebura, Blum, S. 342. Bei Berstein, Histoire 1, S. 394-396, wird die „Schuld“ dagegen weitgehend auf die SFIO geschoben. Das ebd. zu findende Urteil, daß die sozialistische Beteiligung „très clairement“ von den Radicaux gewünscht worden sei, ist vielleicht für die Basis, aber wohl nicht für die Parteispitze zutreffend.

56. Paul Boncour, Entre deux guerres 2, S. 91.

57 Umgehend veröffentlicht in Le Populaire; Zitat nach LP, 3. 6. 1924, S. 3, „Une lettre de M. Herriot"; ebd. auch Antwort. Vgl. zum Briefwechsel auch Herriot, Jadis 2, S. $135 \mathrm{f}$. Teilweise übersetzt bei Ziebura, Blum, S. 342.

58 Fälschlicherweise auf den 1.6. datiert in Bonnefous, Histoire 4, S. 20.

59 Vgl. oben S. 43 mit Anm. 66. 
stundentag, Koalitionsrecht der Beamten, Wiederaufnahme der diplomatischen Beziehungen mit der Sowjetunion, Stärkung des Völkerbundes, Räumung der Ruhr nach deutscher Erfüllung des Dawes-Plans ${ }^{60}$. Daß es sich dabei - sieht man vom außenpolitischen Feld ab - weniger um ein Regierungsprogramm handelte als um eine Ansammlung symbolträchtiger Einzelmaßnahmen, ist offenkundig.

Der Brief vom 2. Juni wurde dem nach Paris einberufenen außerordentlichen Parteitag der SFIO präsentiert und fand dort, nachdem zunächst ein Regierungseintritt abgelehnt worden war, breite Billigung. Der Parteitag verabschiedete darauf eine "motion", die eine Strategie des „appui“ festlegte und in diesem Sinne von der eigenen Fraktion strikte Disziplin einforderte ${ }^{61}$. Blum richtete nun seinerseits einen Brief an Herriot, in dem er zum einen auf die Gefahr verwies, den nach dem 11. Mai von der Masse der Nation gezeigten "ardent espoir" zu enttäuschen, zum anderen aber das Koalitionsangebot "dans les circonstances actuelles" ablehnte.

Neben der Frage, in welcher Form die sozialistische Fraktion in die Regierungskooperation integriert werden sollte, muß Ende Mai/Anfang Juni auch über die Einbindung der Gauche radicale verhandelt worden sein ${ }^{62}$. Wie ein Hinweis in den Aufzeichnungen Loucheurs über einen Besuch Painlevés zeigt, könnte dies zunächst in Gesprächen über die Wahl zum Kammerpräsidenten und über die Frage des Staatspräsidenten geschehen sein ${ }^{63}$. Vermutlich wurden der neuen Fraktion in traditioneller Manier der Regierungsbildung Kabinettsposten sowie ein Anteil an den neu zu vergebenden Führungspositionen in den Ausschüssen in Aussicht gestellt ${ }^{64}$.

Millerands Position verschlechterte sich nun rapide. Am 1. Juni, dem ersten Tag der neuen Legislaturperiode, demissionierte wie angekündigt das Kabinett Poincaré III. Raymond Poincaré selbst trat nun für über zwei Jahre wieder zurück in die Reihe der einfachen Senatoren ${ }^{65}$. Am 3. Juni schloß sich die starke Senatsfraktion der Gauche démocratique radicale et radicale-socialiste, in der sich neben Radicaux traditionell auch zahlreiche Modérés befanden, der von den Kartellfraktionen der Abgeordnetenkammer eingenommenen Haltung an. Falls Millerand

60 Teilweise Wiedergabe in Bonnefous, Histoire 4, S. 20; ausführlicher Berstein, Histoire 1, S. 395.

61 Text in LP, 3. 6. 1924, S. 3, „Le motion“.

62 In der Literatur wird diese - angesichts der engen Mehrheitsverhältnisse äußerst wichtige - Frage völlig ausgeblendet, was wohl auch an einem entsprechenden Quellenmangel liegt.

63 Loucheur, Carnets secrets, S. 151, 29. 5. 1924: „Visite de Painlevé à Louveciennes avec Heilbronner - Henry [de Jouvenel] - Bergery / Il me parle: présidence de la Chambre, puis Présidence de la République - sur ce point, je fais beaucoup de réserves." Ob mit dem zweiten Punkt bereits die geplante Wahl Painlevés gemeint ist, muß offen bleiben.

64 Ein Mitbegründer der neuen Fraktion, Eugène Raynaldy, übernahm - nachdem er zunächst zu einem der Vizepräsidenten der Kammer gewählt worden war - im späteren Kabinett Herriot I das Handelsressort. Hinzu kam für die Gauche radicale cin Staatssekretärsposten. Zu Raynaldy vgl. LT, 2. 6. 1924, S. 4, "La gauche radicale“. In der Legislaturperiode 1919-24 hatte Raynaldy der Gauche républicaine démocratique angehört.

$65 \mathrm{Vgl}$. zur Zeit bis zur erneuten Ministerpräsidentschaft 1926 v.a. Roth, Poincaré, S. 465-481. Poincaré verhielt sich politisch zurückhaltend, insbesondere gegenüber Herriot, den er durchaus schätzte. Vgl. hierzu eine auch ebd., S. 472, angeführte Stelle aus einem erhaltenen Splitter der „Notes journalières“ Poincarés vom 23. 11. 1924. Poincaré gibt eine Unterhaltung zwischen Mme Waldeck-Rousseau und Herriot wieder: „Elle a dit a Herriot: ,M. Poincaré m'a affirmé que vous étiez un bon patriote - mais certainement madame, et M. P. et moi, nous nous estimons réciproquement." " BN Paris, Papiers Poincaré, 16055, Bl. 3R. 
tatsächlich, wie zeitgenössisch teilweise angenommen wurde ${ }^{66}$, an eine Kammerauflösung gedacht haben sollte, war diese Hoffnung nun nachhaltig erschütter ${ }^{67}$, denn für eine verfassungsmäßige „dissolution“ benötigte der Präsident nach dem Gesetz vom 25. Februar 1875 den „avis conforme“ des Senats.

Einen Tag später wurde Painlevé in einer erregten Sitzung gegen Maginot zum neuen Präsidenten der Abgeordnetenkammer gewählt ${ }^{68}$. Das traditionell in geheimer Abstimmung ${ }^{69}$ erzielte Ergebnis von 296 zu 209 war ein klares Indiz für die neuen Stärkeverhältnisse und markierte gleichzeitig - ähnlich wie die folgenden Wahlen der Vizepräsidenten - eine für derartige Voten ungewöhnliche Polarisierung ${ }^{70}$. Die Antrittsrede Painlevés verstärkte diesen Eindruck noch. Ungeschickterweise bezeichnete sich der neue Kammerpräsident zunächst offen als Vertreter einer Partei, was seine Zusicherung einer überparteilichen Amtsführung schon vorab diskreditierte. Die weiteren Ausführungen ließen dann an parteigebundener Deutlichkeit nichts zu wünschen übrig71. Auf ein euphorisches Lob des Wahlergebnisses folgte eine klare Parteinahme im Fall Milllerand. Jeder habe sich, so Painlevé, dem Verdikt des allgemeinen Wahlrechts zu beugen ${ }^{72}$. Der höchste Repräsentant der Abgeordnetenkammer konfrontierte so den nominell „unverantwortlichen" Staatspräsidenten mit dem Ergebnis der Kammerwahlen als Quittung für dessen eigene Parteinahme.

Der Kampf des Kartells gegen Millerand hatte inzwischen eine Eigendynamik bekommen, die auch von Herriot kaum noch zu steuern war. Der radikale Parteichef, in vielem eher ein Politiker des traditionellen deliberativen Parlamentarismus $^{73}$, bildete nun gleichsam die Speerspitze einer unerbittlichen und im wesentlichen von Parteiräson bestimmten Konfrontationspolitik. Als Millerand am 5. Juni ${ }^{74}$ Herriot mit der Regierungsbildung beauftragen wollte, lehnte dieser ab eine Haltung, die ihm von manchem politischen Gegner nicht zugetraut worden war ${ }^{75}$. Bezeichnend für die Situation erscheinen die Informationen, die der deut-

66 So etwa Botschaftsbericht-Paris (Hoesch), Tel. Nr. 309, 31. 5. 1924, S. 2, zum Konfrontationskurs Millerands im Falle eines Ministerstreiks und einer dann eingesetzten Minderheitsregierung: „In diesem Falle denkt wohl Millerand gar an Versuch, sich von Senat Ermächtigung zur Auflösung Kammer geben und Neuwahlen unter Parole für oder gegen Beseitigung Präsidenten stattfinden zu lassen. "PA AA Berlin, R 70715. Ohne klare Aussage bleibt Farrar, Principled Pragmatist. Bonnefous, Histoire 4, S. 11, glaubt nicht, daß Millerand ernsthaft an Derartiges gedacht hat.

67 Bernard, L'affaire Millerand.

68 JO, Débats, Chambre 1924, S. 2252 (keine namentliche Abstimmung). LT, 6. 5. 1924, S. 3, „L'élection du bureau“, spricht von einer „atmosphère de fièvre et de passion“.

69 1925, bei der Wahl Herriots, erfolgte dann eine Änderung. Vgl. unten S. 457.

70 Vgl. in LT, 6. 5. 1924, S. 3, „L'élection du bureau“, alle Ergebnisse seit 1914.

71 JO, Débats, Chambre 1924, S. 2253 f.: „C'est l'élu d'un parti que vous avez élevé à cette haute fonction, un élu qui, au cours de ces dernières années, fut l'un des plus engagés dans la mêlée politique.“ Zum Wahlergebnis meinte Painlevé : „[...] c’est un immense espoir, un espoir de paix et de justice“; ebd., S. 2253. Vgl. auch Loucheur, Carnets secrets, S. 152, 4. 6. 1924, zur Rede: „Election de Painlevé - son discours - Effet très médiocre. Heureusement que la gauche radicale a voté pour lui. Il n'aurait pas eu la majorité absolue."

72 JO, Débats, Chambre 1924, S. 2253: „Le suffrage universel est notre maître à tous: quand il a fait entendre sa voix, chacun doit s'incliner devant son verdict.“

$73 \mathrm{Vgl}$. auch seinen geradezu fundamentalistischen Kampf gegen die décrets-lois.

74 Falsche Datierung auf den 6.6. bei Berstein, Histoire 1, S. 392. Vgl. z. B. den Bericht in LT, 7.6. 1924 , S. 3, "La crise politique“.

75 Vgl. Loucheur, Carnets secrets, S. 151, 30. 5. 1924, zu einer Unterhaltung nach der letzten Sitzung 
sche Botschafter „zuverlässig“ über das „penible“76 Gespräch Herriots mit Millerand am 5. Juni erhalten hatte. Herriot, „, bekanntlich eine etwas weiche, vorsichtige und konziliante Natur“, sei „an seine schwere Aufgabe, die Präsidentschaftskrise zum formellen Abbruch zu bringen, mit wenig Enthusiasmus herangegangen“. Millerand habe ihn dann auch massiv bestürmt, ein Mandat zur Kabinettsbildung anzunehmen. Es sei Herriot sehr schwer gefallen, „auf seiner Ablehnung zu beharren“, und der radikale Parteichef habe „ein Gefühl des Mitleids mit dem um seine Position kämpfenden Präsidenten nicht unterdrücken können“. Daher habe er dem Präsidenten beim Abschied erklärt, „dass er für seine Person bedaure, zu dieser Stellungnahme sich gezwungen zu sehen“. Erst eine schroffe Reaktion Millerands habe Herriot „von seiner Gefangenheit befreit und ihn in Zorn versetzt, der es ihm erleichtert hat, in seinem Widerstandswillen neu gestärkt zu seinen Parteifreunden zurückzukehren"77. Die Waffe der "grève des ministres“ war nun drohend gegen den Staatspräsidenten gerichtet.

Als Finale folgte ein kurzer, aber heftiger Abwehrkampf des Staatspräsidenten, der offenbar erst jetzt den Ernst seiner Lage erkannt hatte. Vergeblich versuchte Millerand zunächst, einen anderen radikalen Politiker als Herriot zum Versuch einer linken Regierungsbildung zu bewegen ${ }^{78}$. Dabei scheint er vor allem gehofft zu haben, ein Mitglied der Senatsfraktion der Gauche démocratique für sich zu gewinnen, um so - wie der deutsche Botschafter erkannte - eine „Bresche in Senatslinke und möglichst auch Radikalsozialisten der Kammer zu schlagen“"79.

Nach dem Scheitern dieser Taktik ging der Staatspräsident zur Gegenoffensive über. Millerand wandte sich an den bereits zurückgetretenen Poincaré, um vor beiden Kammern eine präsidentielle Botschaft verlesen zu lassen und so eine parlamentarische Debatte über die in der Verfassung fixierten präsidentiellen Rechte einzuleiten. Nachdem Poincaré abgelehnt hatte, beauftragte der Staatspräsident am 7. Juni seinen alten Vertrauten François-Marsal, den bisherigen Finanzminister, mit der Bildung einer gegen die parlamentarischen Mehrheitsverhältnisse gerichteten Minderheitsregierung.

Bereits einen Tag später war das neue Kabinett, dem überwiegend Minister der letzten Regierung Poincaré angehörten, zusammengestellt. Die Kabinettsliste ${ }^{80}$ war allerdings weitgehend unerheblich, denn diese „Kampfregierung“, die eine klare Mißachtung des Prinzips der parlamentarischen Regierungsbildung darstellte und über deren sofortigen Sturz kein Zweifel bestehen konnte, hatte nur

des Kabinetts Poincaré: „Poincaré et Maginot sont persuadés que Herriot se défilera, que jamais il n'osera dire au Président de la République qu'il doit démissionner, etc... Je leur dis le contraire."

76 So Herriot, Jadis 2, S. 136: „[...] un entretien qui m'avait été pénible mais ne me permettait pas d'hésiter sur mon devoir." Der hier gegebene Bericht bestätigt andeutungsweise die Informationen des deutschen Botschafters. Ebd. auch Zitate aus den anschließenden Pressekommuniqués Millerands und Herriots.

77 Botschaftsbericht-Paris (Hoesch), Nr. A 2315, 7. 6. 1924; PA AA Berlin, R 70715.

78 Umfangreiche Konsultationen fanden u.a. mit Franklin-Bouillon und Charles Chaumet statt. Théodor Steeg, ein alter Freund Millerands und 1924 Gouverneur von Algerien, war extra nach Paris geeilt, erkannte aber dort die Aussichtslosigkeit einer Regierungsbildung. Vgl. Bonnefous, Histoire 4, S. 12 f.; Farrar, Principled Pragmatist, S. 367. Vgl. hierzu und zum folgenden auch Persil, Millerand, S. 162-165.

79 Botschaftsbericht-Paris (Hoesch), Tel. Nr. 320, 6. 6. 1924, S. 2. Hier ist die Rede von den Senatoren Henry Berenger, Millies-Lacroix und Chaumet. PA AA Berlin, R 70715.

$80 \mathrm{Vgl}$. Bonnefous, Histoire 4, S. 385. 
einen Zweck: Ihre Präsentation vor Abgeordnetenkammer und Senat sollte die von Millerand gesuchte Verfassungsdebatte ermöglichen und den Konfliktfall auf eine grundsätzlichere Ebene heben. Dies wiederum, so die keineswegs unbegründete Aussicht, würde auf dem rechten Flügel der Kartellmehrheit für Verunsicherung und vielleicht auch für "Absplitterungen“ in einer entsprechenden Abstimmung sorgen ${ }^{81}$. Relativ gut standen die Chancen hierfür zweifellos im Senat, wo die Mehrheitsverhältnisse knapper und die Formierung einer Kartellmehrheit infolge der diffusen Fraktion der Gauche démocratique weniger konkret war. Gelang es Millerand, durch gegensätzliche Abstimmungsergebnisse in einer Verfassungsfrage gleichsam einen Keil zwischen Abgeordnetenkammer und Senat zu treiben, konnte vielleicht auch das Thema einer Kammerauflösung wieder aktuell werden.

Erneut bewies sich aber nun die Dynamik der linken Lagerbildung. „In taktisch außerordentlich geschickter Regie und unter Wahrung einer bemerkenswerten Disziplin" 82 konnte die neue Mehrheit am 10. Juni bei der Vorstellung des Kabinetts François-Marsal jede inhaltliche Diskussion vertagen ${ }^{83}$. Nachdem sich zunächst eine knappe Senatsmehrheit gegen eine Diskussion über die präsidentielle Botschaft ausgesprochen hatte, verweigerte sich die linke Kammermehrheit in demonstrativer Geschlossenheit. Die Vorsitzenden der vier zur Regierungskooperation entschlossenen Fraktionen (Radicaux, Sozialisten, Républicains-socialistes und Gauche radicale) - Herriot, Blum, Maurice Viollette und Eugène Raynaldy brachten eine Erklärung ein, worin jeder Kontakt zu einem Ministerium abgelehnt wurde, dessen Zusammensetzung eine "Negation“ der parlamentarischen Rechte sei ${ }^{84}$. Bevor sich François-Marsal einem Vertrauensvotum stellen konnte, fand diese Erklärung eine knappe Mehrheit von 327 zu 317 Stimmen ${ }^{85}$. Der geschlagene Regierungschef verließ daraufhin, während in der Mitte und auf der Rechten Rufe nach Auflösung der Kammer ertönten, den Plenarsaal und begab sich in den Elyséepalast. Die eingereichte Demission scheiterte jedoch zunächst am Staatspräsidenten.

Dieser leitete jetzt, als Schlußakt seines Konflikts mit der neuen Kammermehrheit, den eigenen Rücktritt ein ${ }^{86}$. Die letzte Waffe war ihm aus der Hand geschlagen worden, jedes weitere Verweilen im Amt hätte zu einer schweren inneren Krise geführt, an deren Ende möglicherweise eine Verfassungsrevision zu Lasten der noch bestehenden präsidentiellen Rechte gestanden hätte ${ }^{87}$. Millerand verlas am folgenden Tag im Kabinett ein kurzes Rücktrittsschreiben und übermittelte es den Präsidenten von Abgeordnetenkammer ${ }^{88}$ und Senat. Eine umfangreiche öffentliche Erklärung rekapitulierte und rechtfertigte zudem seine Politik seit 1920.

81 Vgl. Botschaftsbericht-Paris (Hoesch), Tel. Nr. 329, 11. 6. 1924, S. 1; PA AA Berlin, R 70715.

82 So ebd.

83 Mit 154 zu 144 Stimmen; JO, Débats, Sénat 1924, S. 896 f., 905 f. (Liste der namentlichen Abstimmung); Kammersitzung JO, Débats, Chambre 1924, S. 2285-2299.

${ }_{84}$ Ebd., S. 2298.

85 Ebd., S. 2299 f. (Liste der namentlichen Abstimmung).

86 Vgl. Bonnefous, Histoire 4, S. 16; Bernard, L'affaire Millerand; Farrar, Principled Pragmatist, S. 369-371.

87 Farrar, ebd., S. 369, sieht in einer derartigen Befürchtung das entscheidende Motiv für den Rücktritt.

88 JO, Débats, Chambre 1924, S. 2301. 
Der gescheiterte Staatspräsident stellte dabei die erzwungene Demission als fatalen Präzedenzfall dar: „Précédent redoutable qui fait de la Présidence de la République l'enjeu des luttes électorales, qui introduit par un détour le plébiscite dans nos mœurs politiques et qui arrache de la Constitution le seul élément de stabilité qu'elle renfermât." 89 In diversen Interviews bekräftigte Millerand die aus seiner Sicht zur Bewahrung eines Gleichgewichts der Verfassungsorgane notwendige Verfassungsänderung zugunsten des Präsidenten der Republik ${ }^{90}$.

Was Millerand freilich bei all dieser Kritik ausblendete, war der entscheidende Umstand, daß er selbst das Amt des Staatspräsidenten in die aktive Innenpolitik und auch in den Wahlkampf verstrickt und es somit als Element unparteiischer Stabilität entwertet hatte. Seine Gegner hatten dann nur konsequent reagiert und nach dem für sie siegreichen Wahlgang die Person des Staatspräsidenten für untragbar erklärt. Letztlich kam hier bei Millerand ein Grundwiderspruch zum Ausdruck, der sein ganzes Verfassungsverständnis durchzog: auf der einen Seite der Wille zur Stärkung eines autonomen Präsidentenamtes, auf der anderen der Versuch, in der Regierungspolitik eine politisch aktive Rolle zu spielen. Diese Haltung war tief verankert in einem weitverbreiteten dualistischen Verfassungsverständnis, das von einem Gegenüber und einer wünschbaren Machtbalance zwischen Parlament und Regierung ausging und die im parlamentarischen System geradezu zwangsläufige Verbindung von Regierung und parlamentarischem Regierungslager nicht wahrhaben wollte bzw. als Fehlentwicklung verteufelte. Wenn sich ein Staatspräsident für eine bestimmte Regierungspolitik engagierte, dann das war die Konsequenz aus der modernen Gewaltenverschränkung - nahm er auch Partei für das parlamentarische Regierungslager und mußte sich folglich die Feindschaft der Opposition zuziehen. Letztlich scheiterte Millerand so an den Aporien eines immer noch vom konstitutionellen System geprägten Parlamentarismusverständnisses.

Der Rücktritt Millerands konfrontierte das Cartel des Gauches mit der Notwendigkeit einer Neuwahl des Staatspräsidenten durch die beiden zur Assemblée nationale vereinigten Kammern'1. Die seit dem 11. Mai die innenpolitische Szene beherrschende Lagerbildung war dabei weiterhin bestimmend. Die Kräfte des Linkskartells brachen mit der Tradition einer Vorbesprechung zur Kandidatenaufstellung, die alle Fraktionen von Abgeordnetenkammer und Senat einbezog, und beriefen am 12. Juni eine separate Sitzung ein. Gaston Doumergue, der dem rechten Flügel der Radicaux zugehörende Präsident des Senats, zog darauf die von ihm angekündigte Kandidatur zurück, ohne freilich dem Drängen der linken Parteiführer nachzugeben und ein späteres Antreten in der Nationalversammlung auszuschließen. Die Spitzen des Linkskartells favorisierten offenbar schon seit längerem ${ }^{92}$ Painlevé, den frisch gekürten Präsidenten der Abgeordnetenkammer.

89 Zitiert nach Bonnefous, Histoire 4, S. 16.

90 Farrar, Principled Pragmatist, S. 370 f.

91 Vgl. zum folgenden v.a. Bonnefous, Histoire 4, S. 18. Wenig ergiebig ist Rives, Gaston Doumergue. Überblick zum politischen Lebenslauf von Doumergue in Dictionnaire des parlementaires français 4, S. 1476-1481. Auffallend ist, daß das Thema Präsidentenwahl in Herriot, Jadis 2, S. 136, äußerst lakonisch nur mit wenigen Worten behandelt wird: „Il [Millerand] était remplacé par M. Gaston Doumergue."

92 Darauf deutet Loucheur, Carnets secrets, S. 151, zum 29. 5. 1924 (Zitat Anm. 63). Vgl. auch ebd., 
Bei einer Probeabstimmung der vereinten Linkskräfte schlug Painlevé zwar den formell hier gar nicht angetretenen Doumergue mit 306 zu 149 Stimmen. Der hohe Stimmenanteil des letzteren war aber bereits ein aufsehenerregendes Indiz für den Ausgang der tatsächlichen Wahl93. Denn die Mitte-rechts-Kräfte ließen sich die unverhoffte Chance zu einer Blamage des Linkskartells nicht entgehen, verzichteten auf einen eigenen Kandidaten und unterstützten Doumergue. Dieser setzte sich am 13. Juni in der traditionsgemäß in Versailles tagenden Assemblée nationale bereits im ersten Wahlgang mit 515 zu 309 Stimmen gegen Painlevé durch. Der liberal-konservative Temps feierte am nächsten Tag den Sieg des „esprit national“ über den „esprit de parti“94.

Als Doumergue - mit 60 Jahren noch im besten politischen Alter - in einer kurzen Erklärung die Wahl annahm, machte er sofort deutlich, von welchem Amtsverständnis er sich geleitet sah: „Nul plus que moi ne demeurera au-dessus des partis pour être, entre eux, l'arbitre impartial.."95 Mit diesem Neutralitätsbekenntnis nahm der neue Präsident nicht nur eine Gegenposition zu seinem Amtsvorgänger Millerand ein, sondern auch zu dem in der Assemblée nationale unterlegenen Kontrahenten. Angesichts Painlevés führender Funktion bei den Républicains-socialistes und in der Ligue républicaine, angesichts seiner seit den Wahlen exponierten Rolle im "Triumvirat“ mit Blum und Herriot ${ }^{96}$, vor allem aber nach seiner erwähnten Antrittsrede als Kammerpräsident ${ }^{97}$ konnte kaum Zweifel darüber bestehen, daß er das Amt des Staatspräsidenten in einem politisch aktiven und damit auch parteiischen Sinne interpretiert hätte. Mit Painlevé als Staatspräsidenten hätte die Dritte Republik möglicherweise ein linkes Gegenstück zu Millerand erhalten.

Es kann daher nicht verwundern, daß in Teilen des eher zur Mitte hin orientierten Kartellflügels große Skepsis gegen Painlevé und gegen eine Einbeziehung des Staatspräsidenten in die parlamentarische Blockbildung bestand. In der Tat widersprach dies der seit Grévy geltenden präsidentiellen Tradition. Es widersprach aber auch der Logik eines konsequenten parlamentarischen Systems. Ein aktiver und womöglich auf die Regierungsgeschäfte Einfluß nehmender Präsident Painlevé hätte ebenso wie Millerand die alleinige Verantwortlichkeit der Regierung vor dem Parlament in Frage gestellt und somit die Autonomie der regierungstragenden parlamentarischen Funktion bedroht ${ }^{98}$. Indem die führenden Politiker des Kartells die Präsidentenwahl der Logik eines parteipolitischen Konflikts unterwarfen, liefen sie paradoxerweise nun selbst Gefahr, auf jene Revitalisierung des

S. 152, 11. 6. 1924: "Séances de groupes - Candidature de Painlevé commence à être combattue.“ Ebd. zu Doumergue: „[...] il est évidemment candidat le cas échéant“. Nach Berstein, Histoire 1, S. 391, wurde Doumergue durch Le Quotidien frühzeitig "designiert“.

93 Vgl. auch Bericht in LT, 14. 6. 1924, S. 1, "L'élection du président de la République“. Angeblich kamen von prominenten Angehörigen des Kartells Rufe „C'est une honte! une véritable trahison!“

94 LT, 15. 6. 1924, S. 1, „Le nouveau président de la République“.

95 Zitiert nach Bonnefous, Histoire 4, S. 18.

96 Vgl. Botschaftsbericht-Paris (Hoesch), Tel. Nr. 320, 6. 6. 1924, S. 2, der von gewissen Widerständen am rechten Flügel der Radicaux gegen die ,von dem Kampfradikalismus lärmend unterstützte Triumvirat-Diktatur H.[erriot] - Painlevé - Blum" sprach. PA AA Berlin, R 70715.

97 Auf den Gegensatz macht auch Bonnefous, Histoire 4, S. 18, aufmerksam.

98 Widerspruch des Cartel des Gauches klar expliziert in LT, 13.6. 1924, S. 1, „L'élection présidentielle“. 
Präsidentenamtes hinzuarbeiten, die Millerand eben zum Verhängnis geworden war. Daß dieses Argument für die Niederlage Painlevés eine Rolle gespielt hat, läßt sich nicht nachweisen. Implizit war es aber Bestandteil der "republikanischen" Tradition, keine allzu dominante Persönlichkeit in das Amt des Staatspräsidenten zu wählen. Clemenceaus berühmtes, 1887 anläßlich der Wahl Sadi Carnots entstandenes Diktum "Je vote pour le plus bête" hatte diese Haltung in pointierter Form zum Ausdruck gebracht ${ }^{99}$.

Das Scheitern Painlevés und die Präsidentenwahl von Doumergue bildeten den ersten großen Mißerfolg des Linkskartells. Der politische Schaden resultierte weniger aus der Person Doumergues, der kurzfristig sicher keine Gefahr für eine Umsetzung linker Regierungspolitik bedeutete, sondern er lag auf einer symbolischen Ebene: Die Grenzen der politischen Durchsetzungskraft des Linkskartells waren ebenso aufgezeigt wie die Möglichkeiten einer Mehrheitsbildung im Mitterechts-Spektrum. Der wochenlange Konflikt der Kartellparteien mit dem Staatspräsidenten endete damit für erstere in einem Pyrrhussieg.

Nach der Wahl Doumergues erfolgte in raschen Schritten die innenpolitische Beilegung der Krise. Am Abend des 13. Juni empfing der neue Staatspräsident den noch amtierenden Ministerpräsidenten François-Marsal und nahm dessen Demission an. Am Vormittag des nächsten Tages beauftragte er Herriot mit der Bildung einer neuen Regierung ${ }^{100}$. Einen Tag später lag die Ministerliste vor ${ }^{101}$. Der neue Regierungschef übernahm, wie schon sein Vorgänger, das Außenministerium. Im Kabinett saßen mit Camille Chautemps (Inneres), Jacques-Louis Dumesnil (Marine), Henri Queuille ${ }^{102}$ (Landwirtschaft), Justin Godart (Arbeit und Hygiene), Edouard Daladier (Kolonien) ${ }^{103}$, Victor Dalbiez (befreite Gebiete) sowie den beiden Staatssekretären Pierre Robert (Post) und Léon Meyer (Handelsmarine) neun Abgeordnete der radikalen Kammerfraktion sowie mit René Renoult (Justiz), Etienne Clémentel (Finanzen), François-Albert (Erziehung) und Victor Peytral (öffentliche Arbeiten) vier radikale Mitglieder der Senatsfraktion der Gauche démocratique. Hinzu kamen mit Edouard Bovier-Lapierre (Pensionen) und Vincent de Moro-Giafferri (Staatssekretär für Enseignement technique) zwei Abgeordnete der Républicains-socialistes, mit Eugène Raynaldy (Handel) und André LaurentEynac (Staatssekretär für Luftfahrt) zwei Abgeordnete der Gauche radicale und mit General Charles Nollet (Krieg), dem ehemaligen Vorsitzenden der interalliierten Militärkommission in Deutschland, ein Nichtparlamentarier. Es handelte sich demnach um eine nahezu vollständig aus Mitgliedern der beiden linksbürgerlichen Kartellparteien sowie der Gauche radicale zusammengesetzte Regierungsmannschaft, die eine politische Homogenität aufwies wie keines der Kabinette in der Legislaturperiode des Bloc national und die zudem das in der Dritten Repu-

\footnotetext{
${ }^{9}$ Clemenceau wurde dann bekanntlich 1920 selbst zum Opfer dieser Tradition.

100 Bonnefous, Histoire 4, S. 18.

101 Teilweise fehlerhafte Angaben ebd., S. 20 f.

102 Vgl. zur Ministertätigkeit 1924-28: de Tarr, Henri Queuille, S. 151-175. Queuille war ein enger politischer Freund von Herriot.

103 Dies war der Beginn der ministeriellen Karriere von Daladier, der „dans le sillage d'Herriot“ innerhalb des Parti radical aufgestiegen und 1924 auf der Kartelliste des Departements Vaucluse in die Abgeordnetenkammer gewählt worden war. Vgl. du Réau, Edouard Daladier, S. 53-58. Zur ministeriellen Tätigkeit in den Regierungen Herriot I, Painlevé III und Herriot II vgl. ebd., S. 59-65.
} 
blik übliche Muster ministerieller Stabilität in der Instabilität sprengte. Über Kabinettserfahrung verfügten einschließlich Herriot lediglich drei Minister ${ }^{104}$. Fünf weitere waren immerhin schon einmal Staatssekretär gewesen; davon hatte mit Laurent-Eynac, dem ehemaligen Républicain de Gauche ${ }^{105}$, nur einer auch einer Bloc-national-Regierung angehört.

Der parlamentarische Machtwechsel vollzog sich einige Tage später mit ähnlicher Konsequenz auch bei der Besetzung der Führungsposten in den Ausschüssen, nachdem deren Zusammensetzung den neuen Mehrheitsverhältnissen in der Kammer angepaßt worden war ${ }^{106}$. Erneut ist hier eine gewisse parteipolitische Dynamik zu beobachten, welche die traditionellen Gepflogenheiten sprengte. So einigten sich die Kartellkräfte schon vor den eigentlichen Wahlen der Vorsitzenden und Berichterstatter auf ihre Kandidaten. Anders als auf der ministeriellen Ebene ließen sich hier die Sozialisten voll mit in die politische Verantwortung nehmen, was wenig spektakulär, aber doch höchst bedeutsam war. Sieht man im Vorsitz der für den französischen Parlamentarismus so wichtigen Grandes Commissions auch eine Art Regierungsamt ${ }^{107}$, dann muß hier sogar die Auffassung modifiziert werden, daß sich die SFIO nur auf eine Politik des „soutien“ beschränkt habe. Bei der Wahl der Ausschußvorsitzenden setzten sich dann in 19 von 20 Fällen die linken Bewerber durch. Lediglich in der Armeekommission kam ein Mitglied der neuen parlamentarischen Opposition an die Spitze, indem der ehemalige Kriegsminister Maginot (Républicains de Gauche) gegen den Sozialisten PaulBoncour erfolgreich war. Sieben Vorsitzende waren fortan Radicaux ${ }^{108}$, sechs Sozialisten, zwei Républicains-socialistes, und drei gehörten der Gauche radicale an. Vincent Auriol konnte für die SFIO den besonders bedeutsamen und prestigeträchtigen Vorsitz des Finanzausschusses erobern ${ }^{109}$; der wichtige Posten des ständigen Berichterstatters dieser Kommission fiel an Maurice Viollette, den Fraktionsvorsitzenden der Républicains-socialistes 110.

Die Präsentation der neuen Regierung vor der Abgeordnetenkammer erfolgte vom 17. bis zum 19. Juni. Die neue parlamentarische Konstellation wurde hier mit einer gewissen Symbolkraft demonstriert. Nach einer kurzen Botschaft des neugewählten Staatspräsidenten bildete eine relativ konkrete Programmrede Herriots den eigentlichen Auftakt ${ }^{111}$. Deutlich zeigte sich hier das Bemühen, angesichts der "tâches redoutables qu'imposent les temps nouveaux"112 eine solide inhaltliche Basis für die künftige parlamentarische Unterstützung zu schaffen. Ähnlich wie in dem Brief an Blum vom 2. Juni skizzierte Herriot eine Liste vorgesehener Maß-

${ }^{10+}$ Renoult, Clémentel und Herriot. Nach Dictionnaire des ministres.

105 Von Bonnefous, Histoire 4, S. 21, fälschlicherweise immer als solcher bezeichnet, ebenso in Teilen der neueren Literatur, z. B. Delporte, III' République 3, S. 104.

106 Vgl. zum folgenden Bonnefous, Histoire 4, S. 25, sowie die Berichterstattung in Le Temps. In der Regierungszeit des Bloc national hatten bis zuletzt auch mehrere Radicaux als Ausschußvorsitzende agiert.

107 In diesem Sinne v.a. Schlesinger, Legislative Governing, S. 33-66.

108 An erster Stelle ist hier Franklin-Bouillon als Vorsitzender im Auswärtigen Ausschuß zu nennen.

${ }_{109}$ Ghebali, Vincent Auriol, S. 66, geht nur flüchtig auf Auriols Zeit als Vorsitzender des Finanzausschusses ein.

110 In Néré, Problème, S. 34, fälschlicherweise als Mitglied der Gauche radicale bezeichnet.

111 JO, Débats, Chambre 1924, S. 2305-2307. Vgl. auch Herriot, Jadis 2, S. 137 f.

112 JO, Débats, Chambre 1924, S. 2307. 
nahmen, die jetzt in eine etwas breitere politische Argumentation gestellt wurden. Als wichtigste Punkte sind hervorzuheben: Schließung der Botschaft am Vatikan und konsequente Anwendung des Gesetzes über die Kongregationen, Amnestie und Re-Integration der 1920 anläßlich des Generalstreiks entlassenen Eisenbahner, sofortige Aufhebung der noch gültigen parlamentarischen Ermächtigung113, Freigabe der gewerkschaftlichen Organisation für Beamte, Rückkehr zum „scrutin d'arrondissement", Übertragung der laizistischen Gesetzgebung auf ElsaßLothringen, Festhalten am Achtstundentag und Realisierung von Sozialversicherungen ${ }^{14}$, finanzielle Bestandsaufnahme, Mobilisierung der bereits verfügbaren Steuermittel und Sparpolitik, Verkürzung des Wehrdienstes, Zulassung des deutschen Eintritts in den Völkerbund nach Regelung der Reparationsfrage sowie Räumung der Ruhr nach Institutionalisierung einer internationalen Überwachung.

Insgesamt handelte es sich um ein breites und durchaus eindrucksvolles Programm; bezeichnend ist der ironische Zwischenruf eines oppositionellen Abgeordneten: "Que de choses en trois mois!" "115 Allerdings war es stark auf einzelne demonstrative Akte fixiert und gewann dadurch, trotz der von Herriot vermittelten Aufbruchsstimmung, einen etwas statischen Charakter. Zu diesen Ankündigungen mit Symbolwert gehörten insbesondere auch die angedeuteten laizistischen Maßnahmen, die - ähnlich wie bereits im Wahlkampf - besonders geeignet erschienen, eine traditionelle linke Gemeinsamkeit herzustellen. Während hiermit bereits die wesentlichen kirchenpolitischen Konfliktfelder benannt waren, auf denen das Cartel des Gauches in der Folgezeit zu streiten hatte, blieb das später so entscheidende finanzpolitische Thema einer Kapitalsteuer ${ }^{116}$ zunächst noch ausgespart.

Anders als in Deutschland war es im französischen Parlamentarismus traditionell nicht üblich, daß nach einer Regierungserklärung grundsätzliche Fraktionserklärungen abgegeben wurden, die entweder der Regierung Unterstützung versprachen oder aber eine oppositionelle Position markierten. Vielmehr schlossen sich in der Regel konkrete Interpellationen, meist mit oppositioneller Absicht, zu einzelnen Fragen an. Daß im Anschluß an die Rede Herriots dennoch von drei Fraktionen allgemeine Positionsbestimmungen vorgenommen wurden, spiegelt zum einen die relativ fortgeschrittene parteipolitische Verfestigung auf der politischen Linken, zum anderen aber auch einen besonderen Erklärungsbedarf. Für die erstarkte kommunistische Fraktion, die auch in Zwischenrufen und sogar in einem handgreiflichen Zwischenfall117 auf sich aufmerksam machte, trat am 17. Juni Marcel Cachin vor das Plenum und kündigte der neuen Linksregierung

113 Ebd., S. 2306: „Pour rétablir les garanties dues à tous, nous supprimerons sans délai les décretslois. (Vifs applaudissements à gauche et à l'extrême gauche.)“

114 Es blieb hier bei sehr allgemeinen Absichtserklärungen.

115 JO, Débats, Chambre 1924, S. 2306, Zwischenruf von Ferdinand Bougère (fraktionslos).

116 Angemerkt sei, daß diese auf unspektakuläre Weise in Deutschland bereits 1920 eingeführt worden war. Vgl. Huber, Verfassungsgeschichte 7, S. 13.

117 Nachdem der Kommunist Jean Garchery von einer "trahison socialiste“ gesprochen hatte, kam es zu einem heftigen Handgemenge zwischen Sozialisten und Kommunisten, begleitet von Rufen nach Auflösung der Kammer seitens der parlamentarischen Rechten und dem kommunistischen Gesang der Internationale; JO, Débats, Chambre 1924, S. 2353. Vgl. auch Bericht in LT, 21.6. 1924 , S. 4, „Séance de nuit. Violents incidents“. 
gegenüber einen unerbittlichen Oppositionskurs an ${ }^{118}$. Gegen Ende der Debatte ergriff dann am 19. Paul Faure für die SFIO das Wort und gab, ohne sich auf inhaltliche Fragen einzulassen, der neuen Regierung ein pauschales und auf manchen Parlamentarier sehr ungewöhnlich wirkendes Unterstützungsversprechen, band dieses allerdings an das vorliegende Programm und betonte ansonsten die weiter bestehende Unabhängigkeit seiner Partei ${ }^{119}$. Für die Gauche radicale ergriff schließlich noch Maurice Marchais kurz das Wort, äußerte im Namen seiner Fraktion allgemeine Anerkennung für die Regierungserklärung, gab aber gewisse „Reserven“ zu bestimmten Punkten - insbesondere zur geplanten Aufhebung der Botschaft beim Vatikan - zu Protokoll. Die Unterstützung für die Regierung begründete Marchais primär außenpolitisch ${ }^{120}$. Von vornherein war damit die parlamentarische Basis für ein umfassendes linkes Reformprojekt in Frage gestellt.

Die weiteren Interpellationen, die Herriot in Abgrenzung zu seinem Vorgänger sofort und ohne inhaltliche Einschränkung zuließ ${ }^{121}$, wurden fast durchweg von Abgeordneten des Mitte-rechts-Spektrums vorgetragen. Bezeichnend für ein Parlamentarismusverständnis, das dem Lagerkonzept des Linkskartells geradezu entgegengesetzt war, ist die einleitende Äußerung von Louis Rollin (Républicains de Gauche), der unmittelbar nach Cachin zu Wort kam und daher zunächst Wert auf die grundsätzliche Feststellung legte, nicht „dans un esprit d'opposition a priori et systématique“ zu sprechen, sondern nur das Recht der parlamentarischen Kontrolle wahrzunehmen. Hier zeigte sich ein ganz traditionelles parlamentarisches Denken, in dem Opposition ad-hoc in Ausübung der Kontrollfunktion entstand und in dem eine geschlossene Opposition nicht vorgesehen war.

Im Laufe der Interpellationen kam es dank des Insistierens von Maurice Bokanowski (Gauche républicaine démocratique) zu einer gewissen Präzisierung der finanzpolitischen Ankündigungen Herriots. Der neue Ministerpräsident legte

118 JO, Débats, Chambre 1924, S. 2307-2311.

119 Ebd., S. 2328-2329. Vgl. v.a. S. 2329 mit bezeichnenden Zwischenrufen der Abgeordneten Bouteille, Lambert, Gérard (jeweils Union républicaine démocratique) und Héraud (Gauche républicaine démocratique):

„M. Paul Faure. [...] Nous déclarons donc, sans vouloir entrer aujourd'hui dans la discussion d'aucune des questions posées dans sa déclaration ... par le ministère .../ M. Bouteille. C'est prudent!/ M. Marcel Héraud. Ecoutez la seconde déclaration ministérielle! [...]/ M. Paul Faure. Pas encore! ... que nous faisons confiance à ses intentions et que nous sommes résolus à lui prêter une aide franche et loyale, pour l'accomplissement de sa tache./ M. Join Lambert. La confiance dans la nuit!/ M. le baron François Gérard. Pour combien de temps?/ M. Paul Faure. Jusqu’à la fin./ M. Join Lambert. C'est un engagement! [...]/ M. Paul Faure. Nous n'avons demandé ou contracté aucun engagement. Nous n'attendons du Gouvernement nouveau qu'une satisfaction: Qu'il reste lui-même. Nous ne lui demandons pas de réaliser notre programme, mais le sien./ [...] En agissants ainsi, nous n'entendons aliéner aucune parcelle de notre indépendance de parti; nous demeurons libres vis-à-vis du Gouvernement, comme il est libre vis-à-vis de nous. Nous n'avons renoncé à aucune de nos doctrines."

$120 \mathrm{JO}$, Débats, Chambre 1924, S. 2352: „Plus spécialement, nous tenons à différer l'expression de notre sentiment sur la suppression de l'ambassade auprès du Vatican jusqu'au jour où la discussion de cette question devant le Parlement permettra à tous de prendre leurs responsabilités./ Appelés aujourd'hui à nous prononcer, sur l'ensemble de la politique du cabinet, nous estimons qu'au moment où le Gouvernement s'apprête à défendre devant l'étranger la thèse du droit et de la sécurité du pays, notre devoir est de le soutenir sincèrement et de lui faire confiance pour qu'il obtienne pour la France et le monde la justice et la paix."

121 Herriot verzichtete ausdrücklich auf einen terminlichen Vorschlag: „Le Gouvernement est aux ordres de la Chambre.“ Ebd., S. 2307. 
sich in seiner Antwort zunächst nachdrücklich auf eine „application sévère“ der bislang nur von einer kleinen Minderheit tatsächlich bezahlten Einkommenssteuer fest, um so steuerliche Ressourcen zu mobilisieren. Bokanowskis drängende Frage nach der in Teilen des Linkskartells bereits diskutierten Kapitalsteuer beantwortete Herriot mit einem: „[...] dans les conditions présentes, non!“ 122

Am Ende der Sitzung vom 19. Juni stellte Herriot die Vertrauensfrage anläßlich eines von den Abgeordneten Pinard, Ducos, Blum und Viollette - und somit von Vertretern der drei Kartellparteien ${ }^{123}$ - eingebrachten „orde du jour“124. Dieser sicherte der neuen Regierung mit 313 zu 234 Stimmen bei 24 Enthaltungen die uneingeschränkte Billigung zu. Wie die folgende Übersicht zeigt, formierten sich dabei die Blöcke des Regierungslagers und der Opposition - mit einer bemerkenswerten Ausnahme - in einer für den französischen Parlamentarismus atypischen Geschlossenheit:

Tab. 14: Votum der Abgeordnetenkammer am 19. 6. 1924: Investitur Regierung Herriot I 125

\begin{tabular}{lrrrrrrr}
\hline Fraktion & Abg. & ja & nein & $\begin{array}{l}\text { keine } \\
\text { Teil- } \\
\text { nahme }\end{array}$ & beurl. & $\begin{array}{l}\text { Kohä- } \\
\text { renz }\end{array}$ \\
\hline Communistes & 26 & - & 26 & - & - & $100 \%$ \\
Socialistes (SFIO) & 104 & 104 & - & - & - & $100 \%$ \\
Républicains-socialistes 126 & 44 & 42 & - & 1 & 1 & $98 \%$ \\
Radicaux et radicaux-socialistes & 139 & 137 & - & 1 & 1 & $99 \%$ \\
Gauche radicale & 42 & 28 & 4 & 10 & - & $67 \%$ \\
Démocrates & 14 & - & 14 & - & - & $100 \%$ \\
Gauche républicaine démocratique & 43 & - & 36 & 4 & 3 & $90 \%$ \\
Républicains de Gauche & 38 & - & 31 & 4 & 3 & $89 \%$ \\
Union républicaine démocratique & 103 & - & 102 & - & 1 & $100 \%$ \\
"Aucun Groupe“ & 28 & 2 & 21 & 4 & 1 & - \\
\hline Gesamt & 581 & 313 & 234 & 24 & 10 & - \\
\hline
\end{tabular}

Seitens des Regierungslagers ist die geradezu sensationelle Disziplin von Radicaux und Républicains-socialistes hervorzuheben. Die noch vor kurzem herrschende parlamentarische Zersplitterung schien hier für einen Augenblick vergessen. Die absolute Kohärenz bei den Sozialisten war hingegen keineswegs außergewöhnlich. Eine klare Schwachstelle bildete die Gauche radicale, in der es nicht nur eine größere Gruppe von Enthaltungen, sondern sogar vier Gegenstimmen gab. Sei-

122 JO, Débats, Chambre 1924, S. 2340.

123 Pinard und Ducos waren Abgeordnete des Parti radical. Auffallend ist, daß sich kein Abgeordneter der Gauche radicale beteiligt hat.

124 „La Chambre, résolue a poursuivre la politique républicaine affirmée pour le pays et confiante dans le gouvernement, passe a l'ordre de jour." Nach LT, 18. 6. 1924, S. 6, „Le débat sur la politique générale“.

125 Liste der namentlichen Abstimmung in JO, Débats, Chambre 1924, S. 2365 f.; Aufstellung nach Fraktionen aus LT, 22. 6. 1924, S. 2, "Ministère et majorité“.

126 Der volle Name lautet ab 1924: Républicains-socialistes et socialistes français. Wie auch zeitgenössisch üblich, ist im folgenden weiterhin von Républicains-socialistes die Rede. 
tens der Mitte-rechts-Opposition fällt - wie tendenziell bereits in der Ära des Bloc national - die Einmütigkeit der konservativen Fraktion (Union républicaine démocratique) auf. Daß auch die Kommunisten geschlossen gegen die Regierung stimmten, kann in keiner Weise überraschen, auch wenn auf der Rechten, wo die kommunistische "Gefahr" wieder an Bedeutung gewann, wohl teilweise etwas anderes erwartet worden war ${ }^{127}$.

Konnte sich das Cartel des Gauches alles in allem durch den Auftakt in der Abgeordnetenkammer bestätigt sehen, so erlitt es noch am selben Tag im Senat einen - nach der Wahl des Staatspräsidenten - zweiten empfindlichen Dämpfer. Bei der Bestimmung des Senatspräsidenten kam es zu einer Kampfabstimmung zwischen Jean-Baptiste Bienvenu-Martin, dem Kandidaten des Kartells, und dem rechtsliberalen Justin de Selves. Letzterer setzte sich, möglicherweise beeinflußt durch die kulturpolitisch polarisierende Regierungserklärung, mit 151 zu 134 Stimmen durch ${ }^{128}$. Dies war ein deutliches Indiz dafür, daß die Mehrheit des Senats keineswegs bereit war, auf einen konsequenten Linkskurs einzuschwenken.

Das Bemühen der neuen Regierung um eine symbolkräftige Politik führte parallel zur Präsentation in der Abgeordnetenkammer auch zur Vorlage der ersten beiden Gesetzesvorhaben. Finanzminister Clémentel brachte, wie von Herriot bereits in der Regierungserklärung angekündigt, gleich am 17. Juni eine Vorlage ein, welche die „innovation dangereuse et inutile“ der parlamentarischen Ermächtigung wieder aufheben sollte - noch bis Ende Juli galt ja formal die Frist von vier Monaten, die das Gesetz vom 22. März 1924 festgelegt hatte ${ }^{129}$. Bezeichnend für die Langwierigkeit der regulären parlamentarischen Verfahren erscheint der geradezu absurde Umstand, daß die Ermächtigungsklausel dann im März 1925, als die Gültigkeit schon längst abgelaufen war, in Form eines Gesetzes aufgehoben wurde ${ }^{130}$. Mit dem Verzicht auf das Mittel der décrets-lois war im übrigen auch die von der "Commission Louis Marin " ausgearbeitete Verwaltungsreform ${ }^{131}$ vorläufig wieder von der politischen Tagesordnung verschwunden.

Das zweite legislative Projekt der ersten Tage betraf die angekündigte Generalamnestie für Verurteilungen aus der Kriegszeit, ausgenommen Befehlsverweigerung und Verrat, sowie die Wiedereinstellung der 1920 entlassenen Eisenbahner ${ }^{132}$. Zweifellos ging es dabei auch, wie von Herriot vor der Kammer dargestellt, um ein Signal der inneren Aussöhnung. Noch wichtiger aber war die angestrebte faktische Rehabilitierung von Caillaux und Malvy ${ }^{133}$. Der Parti radical wollte zu-

127 So rief der Abgeordnete Bret (Union républicaine démocratique), der annahm, daß die Kommunisten für die Regierung gestimmt hätten, bei Bekanntgabe des Abstimmungsergebnisses: „C'cst l'Internationale qui triomphe!“ JO, Débats, Chambre 1924, S. 2353.

128 JO, Débats, Sénat 1924, S. 920. Die Regierungserklärung war wie üblich von einem Regierungsmitglied verlesen worden. Vgl. zur Wahl auch Bonnefous, Histoire 4, S. 24 (mit falschem Datum).

129 Zitiert nach LT, 19. 6. 1924, S. 2. Die Vorlage wurde an die Commission des crédits verwiesen. Vgl. JO, Débats, Chambre, 1924, 17.6. 1924, S. 2354.

130 Art. 40 innerhalb des Kreditgesetzes vom 10.3. 1925 unter „Dispositions spéciales“: „L'article $1^{\mathrm{cr}}$ de la loi du 22 mars 1924 est abrogé. Les décrets pris en exécution de cet article ne sont pas sanctionnés." Bulletin des lois de la République Française. Nouvelle Série, Année 1925, Lois et décrets d'intérêt général, Partie principale (1re séction), Bd. 17, Bulletin Nr. 385-408, Nr. 25715, S. 610669. Vgl. auch Rusu, Décrets-lois, S. 160.

$131 \mathrm{Vgl}$. oben S. 391 f. mit Anm. 227.

132 Hierzu Bonnefous, Histoire 4, S. 33-39.

133 Zur Amnestic von Caillaux vgl. Allain, Caillaux [2], S. $312 \mathrm{f}$. 
nächst seine eigene jüngste Vergangenheit von dem Makel der nationalen Unzuverlässigkeit befreien, bevor er selbst wieder die französische Politik gestaltete. Vom 9. bis zum 31. Juli wurde der gesamte Themenkomplex ausführlich und teilweise in äußerst erregter Stimmung in der Abgeordnetenkammer verhandelt, wobei sich die Regierungsmehrheit insgesamt als stabil erwies. Der Einzelbeschluß über die Amnestie von Caillaux fiel etwas knapper aus (309:207) als jener zu Malvy (338:149) ${ }^{134}$. Das Gesamtpaket einschließlich der Eisenbahnervorlage passierte die Kammer schließlich am 14. Juli mit 325 zu 185 Stimmen ${ }^{135}$.

Hatte das Kartell damit in der Abgeordnetenkammer in einer wichtigen und mit großer öffentlicher Anteilnahme verfolgten Frage Handlungsfähigkeit bewiesen, so geriet das Amnestievorhaben bei seiner Behandlung im Senat stark ins Stocken. Innerhalb der zweiten Kammer gab es zu verschiedenen Aspekten Vorbehalte und wohl auch eine grundsätzliche Skepsis gegenüber der forschen Gangart des Linkskartells. Die Beratung wurde daher Mitte Juli auf den Beginn der nächsten Parlamentssession, Ende 1924, verschoben. Erneut hatte sich damit erwiesen, daß die neue Regierung im Senat nur über eine sehr unsichere Basis verfügte.

$\mathrm{Zu}$ den beiden dargestellten Gesetzgebungsprojekten der ersten Tage kam noch ein dritter symbolträchtiger Kammerbeschluß. Eine klare Mehrheit von $323 \mathrm{zu}$ 116 sprach sich am 31. Juli für die Überführung der sterblichen Überreste von Jaurès in das Panthéon aus ${ }^{136}$. Neben der allgemeinen Bedeutung als Zeichen des linken Wiedererstarkens lag in dieser postumen Ehrung für den Vorkämpfer einer sozialistisch-bürgerlichen Kooperation auch eine konkrete politische Geste137, mit der das Linkskartell gleichsam eine höhere republikanische Weihe erhielt.

Gab es, wie oben geschildert, in den ersten Wochen nach dem Wahlerfolg des Cartel des Gauches durchaus schon drohende Vorzeichen der kommenden Probleme, so blieb die Lage auf dem finanzpolitischen Feld, auf dem sich dann die entscheidenden Schwierigkeiten entwickeln sollten, noch ruhig. Der Wahlsieg der Linken und die Bildung der Kartellregierung hatten auf den Kurs des Franc zunächst keinerlei negativen Einfluß. Das seit März 1924 eingependelte neue Verhältnis zu Dollar und Pfund blieb von dem Regierungswechsel nach einer kurzen Schwächephase zunächst unberührt und konnte sich auch in den folgenden Monaten stabil behaupten. Dazu trug vermutlich auch bei, daß mit Clémentel ein als gemäßigt und finanzpolitisch erfahren geltender Radikaler zum Finanzminister berufen und daß die Frage einer Kapitalsteuer von der Regierung zunächst kategorisch ausgeklammert wurde. Günstig für die Behauptung des Franc war aber auch das Wohlwollen, das die großen englischen und amerikanischen Banken Herriot wegen seiner versöhnlichen und auf alliierte Kooperation zielenden außenpolitischen Programmatik entgegenbrachten.

${ }_{134}$ Zweite Sitzung vom 12.7.; Liste der namentlichen Abstimmung in JO, Débats, Chambre 1924, S. $2704 \mathrm{f}$. und S. $2706 \mathrm{f}$.

135 Liste der namentlichen Abstimmung ebd., S. 2769.

136 Kurze Debatte ebd., S. 2897-2900; Liste der namentlichen Abstimmung cbd., S. 2919 f.

137 In diesem Sinne Paul-Boncour, Entre deux guerres 2, S. 95. 


\section{Erosion des Kartells und vergebliche Suche nach einer tragfäbigen Regierungsmebrbeit}

Mit der Bildung einer kohärenten Kartellregierung hatte die Linke dem Poincaréschen Konzept einer zur Mitte hin orientierten und auf eine präzise Bestimmung des Regierungslagers verzichtenden Politik ein neuartiges Modell entgegengesetzt. Gleichzeitig hatte man mit der erzwungenen Demission Millerands den Bemühungen um eine Wiederbelebung präsidentieller Verfassungselemente eine unerbittliche Sanktion folgen lassen. Auf diese beiden parlamentarismusgeschichtlichen Weichenstellungen folgte nun eine gut zweijährige Phase, in der nicht nur das Projekt einer Linksregierung langsam scheiterte, sondern auch der Versuch, $\mathrm{zu}$ einer modernen, parteiengestützten Praktizierung der regierungstragenden Funktion zu gelangen. Seit dem Sturz der ersten Regierung Herriot im April 1925 war dieser Prozeß des Scheiterns mit der Rückkehr einer extremen Instabilität der Kabinette (Painlevé II und III, Briand VII-X und Herriot II) und einer Welle der Parlamentarismuskritik in der politischen Öffentlichkeit verbunden. Ab Mitte 1925 wurde dabei der Typus der Kartellmehrheit in der Abgeordnetenkammer teilweise von Mehrheiten der "concentration“ in der politischen Mitte abgelöst, und ab Ende 1925 entsprach auch die Regierungszusammensetzung ansatzweise einer Kooperation der Mitte.

Das folgende Kapitel soll diese bewegte Periode in den wesentlichen parlamentarismusgeschichtlichen Zusammenhängen verfolgen, ohne sich in den weiten Konfliktfeldern und in den zahllosen innenpolitischen Windungen zu verlieren. In einem ersten Abschnitt werden zunächst die großen Themen skizziert, die zur Desintegration der linken Kammermehrheit beigetragen haben (I). Anschließend sollen die wesentlichen Etappen des Auflösungsprozesses und des allmählichen „Rückflusses“ der parlamentarischen Mehrheiten und der Regierungsbildungen zur politischen Mitte in ihrer Chronologie nachgezeichnet werden (II). In einem dritten Schritt wird dann versucht, die schweren Störungen der regierungstragenden Funktion, die sich seit 1924 in der Abgeordnetenkammer entwickelt haben und die auch erhebliche Auswirkungen auf die legislative Leistungsfähigkeit hatten, in ihren Symptomen und Ursachen systematisch zu analysieren (III). Abschließend ist der Frage nachzugehen, in welcher Weise sich seit dem Regierungsantritt des Cartel des Gauches die parlamentarische Alternativfunktion gestaltet hat (IV).

I. Die großen Themen, die zwischen Regierungsantritt und endgültigem Scheitern des Linkskartells die politische Szenerie Frankreichs beherrschten und die gleichsam den „Treibstoff“ der parlamentarischen Prozesse darstellten ${ }^{138}$, waren teilweise schon mit der Regierungserklärung Herriots vorgegeben, teilweise resultierten sie aber auch aus unerwarteten politischen und ökonomischen Entwicklungen.

1. Die bereits erwähnten Amnestiepläne der Regierung beschäftigten den mit erheblicher öffentlicher Anteilnahme verbundenen Gesetzgebungsprozeß bis Ja-

${ }_{138}$ Grundlegend zur politischen Ereignisgeschichte v.a. Bonnefous, Histoire 4, S. 40-159; Berstein, Histoire 1, S. 390-434; Mayeur, Vie politique, S. 279-284; zur ökonomischen Problematik auch Maier, Recasting Bourgeois Europe, S. 494-507. 
nuar 1925. Nach der raschen Verabschiedung in der Abgeordnetenkammer gelang es einer weitaus weniger engagierten Senatsmehrheit, die parlamentarische Verhandlung mittels zweimaliger Vertagung in die Länge zu ziehen. Letztlich konnten sich aber die Regierungspläne - mit gewissen Abstrichen insbesondere in der Frage der obligatorischen Wiedereinstellung der Eisenbahner - weitgehend durchsetzen. Für Malvy und Caillaux bedeutete dies eine moralische Rehabilitierung. Wenige Wochen später meldete sich Caillaux, der frühere Vorsitzende des Parti radical, auf einem Bankett der Ligue des droits de l'homme mit einer programmatischen Rede wieder in der innenpolitischen Szenerie zurück ${ }^{139}$.

2. Ein kaum zu überschätzender Stellenwert kam der gesamten religions- und kulturpolitischen Thematik $\mathrm{zu}^{140}$. Die drei wesentlichen Aspekte - laizistische Gesetzgebung in Elsaß-Lothringen, Umgang mit den Kongregationen und Aufhebung der Botschaft beim Vatikan - wurden ebenfalls bereits angesprochen. Für die Kräfte des Linkskartells handelte es sich dabei um tief in der Tradition des französischen Laizismus verankerte und insofern um identitäts- und kohärenzstiftende Grundfragen mit einigem Symbolwert. Dahinter stand weniger das Bemühen um einen neuen Schub laizistischer Politik, als vielmehr der Versuch, die religionspolitische Öffnung der Bloc-national-Ära wieder einzuschränken und an die Prinzipien der Zeit vor 1914 anzuknüpfen.

Die Durchsetzung der geplanten Maßnahmen mit Hilfe von Kartellmehrheiten in der Abgeordnetenkammer verlief zunächst weitgehend erfolgreich, wobei im einzelnen diverse Kompromisse eingegangen wurden ${ }^{141}$. Bemerkenswert im Hinblick auf die Stabilität des Linksbündnisses sind zum einen die damit verbundenen Spannungen innerhalb des Regierungsspektrums, insbesondere zwischen Teilen des Parti radical und der in diesen Fragen von Anfang sehr reservierten Gauche radicale, zum anderen die heftigen Widerstände aus dem katholischen Milieu. Diese Reaktionen leisteten einen wichtigen Beitrag zur Formierung einer breiten rechtsliberal bis konservativen öffentlichen Bewegung gegen das Cartel des Gauches. Auch jene bürgerlichen Kräfte der Mitte, die dem Kartell mit zum Wahlerfolg verholfen hatten, wurden teilweise davon erfaßt ${ }^{142}$. Protestbewegung, Widerstände im Senat und der Sturz der Regierung Herriot im April 1925 waren letztlich dafür verantwortlich, daß die genannten Gesetzesprojekte auf der Strecke blieben ${ }^{143}$. Die laizistischen Vorhaben blieben somit weitgehend erfolglos, hatten der Kartellregierung aber ungemein viel Gegenwind eingebracht.

3. Das außenpolitische Themenfeld besaß auch in den beiden Jahren nach den Kammerwahlen von 1924 erhebliche Bedeutung für die parlamentarische Ent-

139 Rede am 19. 2. 1925; vgl. Berstein, Histoire 1, S. 411. Allgemein zum "Comeback“ von Caillaux auch Binion, Defaeted Leaders, S. 90-94.

140 Vgl. hierzu Bonnefous, Histoire 4, S. 40-46; Mayeur, Vie politique, S. 280f., mit illustrierenden Quellen auch Rémond, L’anticléricalisme, S. 252-260. Ebd. wird von einem „été de la Saint-Martin pour l'anticléricalisme" gesprochen. Die Bedeutung dieses Themenkomplexes zeigt sich auch in der ausführlichen Darstellung bei Herriot, Jadis 2, S. 226-233.

141 So wurde Anfang Februar 1925 die Botschaft beim Vatikan formell aufgegeben, allerdings sollte in Rom weiterhin ein Chargé de mission für die Angelegenheiten Elsaß-Lothringens residieren. Vgl. Bonnefous, Histoire 4, S. 60-62.

$142 \mathrm{Vgl}$. in diesem Sinne auch ebd., S. 46.

143 Von der Regierung Painlevé wurden diese nicht mehr verfolgt. 
wicklung ${ }^{144}$. Die Auflösung der reparations- und deutschlandpolitischen Verhärtung, die über die Billigung des Dawes-Plans zum Vertrag von Locarno, zur Räumung des Ruhrgebiets und zur deutschen Aufnahme in den Völkerbund führte, sowie die damit verbundene Beendigung der französischen Isolierung gegenüber den westlichen Kriegsalliierten waren zweifellos ein großer Erfolg der Kartellzeit. Die parlamentarische Durchsetzung ${ }^{145}$ fiel insofern relativ leicht, als die von 1922 bis 1924 verfolgte Politik in die Sackgasse geführt hatte und auch von der Mitte-rechts-Opposition kaum noch ernsthaft vertreten wurde. So erzielten die Locarnoverträge am 3. März 1926 in der Abgeordnetenkammer eine klare Billigung von $413 \mathrm{zu} 71$ Stimmen bei 65 Enthaltungen.

Trotz dieser Erfolgsgeschichte entfaltete auch die reparations- und deutschlandpolitische Thematik eine gewisse Erosionskraft auf das Linkskartell. Wie sich bereits in der Regierungserklärung angedeutet hatte, war Herriot in seiner Deutschlandpolitik und insbesondere in seiner Bereitschaft zur Räumung des Ruhrgebiets weitaus zögerlicher als die französischen Sozialisten. Zwar kam es zu keinem direkten parlamentarischen Konflikt der Bündnispartner, doch sorgte die Problematik zeitweise für erhebliche Verstimmungen und trug somit zu einer Entfremdung zwischen den Kartellparteien bei. Noch brisantere Wirkungen hatte der im April 1925 ausgebrochene Kolonialkrieg in Marokko. Intern nahezu unumstritten war hingegen die am 28. Oktober 1924 vollzogene diplomatische Anerkennung der Sowjetunion, die freilich auf dem konservativen Flügel der politischen Öffentlichkeit für heftige Proteste sorgte ${ }^{146}$.

4. Die größte und entscheidende Sprengkraft aber besaß der finanz- und währungspolitische Themenkomplex ${ }^{147}$. Diese überaus komplizierte Materie, auf deren technische Details hier nur andeutungsweise eingegangen werden kann, läßt sich in drei, eng miteinander verflochtene Aspekte trennen:

a) Zum einen verschärfte sich das Problem der Haushaltslage. Hauptgrund hierfür war, daß die schon seit Kriegsende bestehende „dette flottante“ kurzfristiger Anleihen immer bedrohlichere Ausmaße annahm und die Masse der Kleinanleger immer weniger zu einer längerfristigen Umwandlung auslaufender Kriegsanleihen (Bons und Obligations de la défense nationale) bereit war. Dies wiederum hing mit einem Vertrauensschwund gegenüber den Kartellregierungen, aber auch mit einer Minderung der Anlagebereitschaft angesichts der andauernden Inflation zusammen. Statt dessen setzte ein Prozeß der Kapitalflucht ein. Ein weiteres Grundproblem für den Haushalt waren die an die Vereinigten Staaten zurückzuzahlenden Kriegsschulden, bei denen der französischen Außenpolitik zunächst

144 Vgl. zur französischen Reparations- und Ruhrpolitik bis August 1924 v.a. Bariéty, Relations, S. 369-732; Jeanesson, Poincaré, la France et la Ruhr; zur Folgezeit Hagspiel, Verständigung, S. 202-287.

${ }^{145}$ Liste der namentlichen Abstimmung in JO, Débats, Chambre 1926, S. 1150 f. Zur vorhergehenden Kammerdebatte (ab 25.2. 1926) ausführlich Ilić, Frankreich und Deutschland, S. 153-172; vgl. auch Bonnefous, Histoire 4, S. 120-122; Hagspiel, Verständigung, S. 266-272.

146 Vgl. Bonnefous, Histoire 4, S. 32 f., mit Hinweis auf einen Auftritt Millerands und dessen Ligue républicaine nationale im Dezember 1924.

${ }_{147}$ Vgl. hierzu allgemein ebd., S. 72-79; Sauvy, Histoire économique 1, S. 60-82; Jeanneney, Leçon, passim. Detailliert zum Konflikt mit der Banque de France ders., De Wendel, S. 179-318; Mouré, The Gold Standard Illusion, S. 76-100. Zahlreiche Hinweise auch in Schuker, End of French Predominance, S. 124-168. 
keine spürbare Erleichterung gelangi48. Infolge der Finanzknappheit reichte der gesetzlich vorgeschriebene Höchstrahmen für Haushaltsvorschüsse („avances“) der Banque de France nicht mehr aus und wurde mehrfach überschritten.

b) Ein zweites großes Problem lag im erneuten Anschwellen der Währungsund Inflationskrise. Nachdem im März 1924 für kurze Zeit sogar eine Trendumkehr erreicht worden war, konnte fast ein Jahr lang ein relativ stabiler Kurs des Franc gegenüber Dollar und Pfund gehalten werden. Allerdings setzte bereits 1924 wieder eine inflationäre Entwicklung ein, so daß sich der Index der Großhandelspreise im Dezember 1924 wieder dem Krisenwert vom Februar näherte. $\mathrm{Ab}$ Frühjahr $1925 \mathrm{kam}$ es dann zu einer Beschleunigung der Inflation und zu einem deutlichen Kursverfall des Franc. Im Herbst 1925 nahm diese Entwicklung dramatische Formen an, bis schließlich im Juli 1926 der Höhepunkt erreicht war. Der Dollar kostete jetzt im Monatsmittel mit 40,95 Franc über 40\% mehr als auf dem Höhepunkt der Krise von 1924 (28,7), der Index der Großhandelspreise lag etwa $60 \%$ über dem Spitzenwert vom März 1924149.

Tab. 15: Kurs des französischen Franc gegenüber dem Dollar von Mai 1924 bis Juli 1926 im Monatsmittel 150

\begin{tabular}{llllll}
\hline Jahr & Monat & $\begin{array}{l}\text { Dollarpreis } \\
\text { in Francs }\end{array}$ & Jahr & Monat & $\begin{array}{c}\text { Dollarpreis } \\
\text { in Francs }\end{array}$ \\
\hline 1924 & Mai & 17,35 & 1925 & Juli & 21,30 \\
& Juni & 19,10 & & August & 21,32 \\
& Juli & 19,57 & September & 21,22 \\
& August & 18,36 & Oktober & 22,54 \\
& September & 18,85 & & November & 25,32 \\
& Oktober & 19,11 & Dezember & 26,74 \\
& November & 18,96 & 1926 & Januar & 26,51 \\
& Dezember & 18,52 & & Februar & 27,23 \\
& Januar & 18,54 & & März & 27,95 \\
& Februar & 18,94 & April & 29,56 \\
& März & 19,28 & Mai & 31,92 \\
& April & 19,26 & Juni & 34,12 \\
Mai & 19,38 & Juli & 40,95 \\
& Juni & 20,98 & & \\
\hline
\end{tabular}

Politisch umstritten war insbesondere die Menge des Geldumlaufs, für deren Ausweitung es - ähnlich wie bei den „avances“ der Banque de France an die Staatskasse - enge gesetzliche Grenzen gab („plafonds“). In der zeitgenössischen Sprache Frankreichs, „qui prend ainsi l'effet pour la cause“, meinte „inflation“ meist die finanztechnische Erweiterung dieser Grenzen ${ }^{151}$, ein Akt, den die finanzpolitische Orthodoxie lange Zeit vermeiden wollte. Bereits während der Amtszeit

1*k Hierzu v.a. Artaud, La question des dettes interalliées 2, S. 699-727.

$149 \mathrm{Zu}$ den Zusammenhängen vgl. Néré, Problème, S. 29-32. Aus Perspektive des Regierungschefs: Herriot, Jadis 2, S. 199-226.

150 Zahlen nach Néré, Problème, S. 24, 31, 39, 73, 82, 100; Sauvy, Histoire économique 1, S. 445.

151 Néré, Problème, S. 39. 
Poincarés kam es hier jedoch zu Manipulationen, indem die Banque de France gefälschte Zweimonatsbilanzen vorlegte, um die Überschreitung der „plafonds“ zu verschleiern.

Die eigentliche Zuspitzung der Währungs- und Inflationskrise erfolgte im Herbst $1925 \mathrm{zu}$ einem Zeitpunkt, als das Linkskartell politisch schon weitgehend tot war. Es scheint daher fragwürdig, die Negativentwicklung des Franc allzu einseitig mit den Widerständen gegen sozialistische Einflüsse auf die Regierung und mit den Plänen einer Kapitalsteuer in Verbindung zu bringen ${ }^{152}$. Vielmehr gewannen offensichtlich auch die wachsenden Probleme parlamentarischer Mehrheitsbildung und die damit verbundene finanzpolitische Führungslosigkeit erheblichen Einfluß auf die Währungs- und Inflationskrise.

c) Zum großen finanzpolitischen Konfliktfeld wurde die Steuerpolitik. Herriot hatte, wie bereits erwähnt, im Juni 1924 mit Clémentel einen Finanzminister in sein Kabinett berufen, der die auf Anleihen und indirekte Steuern setzende Politik der Vorgängerregierungen im Prinzip fortführte. So wurde zum Beispiel die noch im Frühjahr von den Kartellparteien heftig bekämpfte pauschale Steuererhöhung des double décime beibehalten. Dieser Kurs erwies sich freilich als unzureichend für eine Haushaltskonsolidierung, und er erregte wachsenden Unmut bei den Sozialisten, aber auch bei großen Teilen der Radicaux und Républicainssocialistes. Ergänzend zur indirekten Steuerlast, welche die Masse der Verbraucher belastete, wollte man hier auch an der Schraube der einkommens- und vermögensabhängigen direkten Steuern drehen. Die Diskussion ging bald über die in der Regierungserklärung angekündigte konsequente Eintreibung der Einkommenssteuer hinaus. Zum Reizthema wurde die Frage einer Kapitalsteuer, die ab Frühjahr 1925 vor allem von der SFIO gefordert wurde ${ }^{153}$. Bereits die Diskussion dieses Mittels sorgte in den Reihen der Mitte-rechts-Opposition für heftigste Reaktionen, obgleich die Pläne keineswegs revolutionär waren und sich auf analoge Vorstellungen in Teilen des Parti radical und auf zahlreiche Vorbilder im Ausland stützen konnten. Aber allein die Aussicht auf einen Einstieg in eine derartige Besteuerung weckte alte Aversionen gegen eine drohende ,inquisition fiscale“, wie sie ja auch in dem jahrelangen Kampf um die Einkommenssteuer gepflegt worden waren ${ }^{154}$.

Gleichzeitig erwies sich das Thema als gefährlicher Spaltpilz. Während die Kapitalsteuer auf dem linken Flügel des Kartells und vorsichtiger auch bei Herriot Zustimmung fand, wurde sie auf dem rechten Flügel des Parti radical und in der Kammerfraktion der Gauche radicale abgelehnt. Auch nach dem Sturz der Regierung Herriot I spielte die Steuerfrage, insbesondere bei Gesprächen um eine zu erneuernde parlamentarische Kooperation mit den Sozialisten, immer wieder eine Rolle. Aus sozialistischer Sicht entwickelte sich die Kapitalsteuer mehr und mehr zur Bedingung für eine Fortsetzung der Kartellpolitik. Indem die Chancen auf eine Realisierung immer geringer wurden, stieg der Symbolwert des Vorhabens. Dabei drängt sich der Verdacht auf, daß es der SFIO angesichts der wachsenden

152 In diesem Sinne etwa Mayeur, Vie politique, S. 282.

153 Zur Vorgeschichte und zur Diskussion Jeanneney, Leçon, S. 100-107. Brief Blums an Herriot vom 25. 3. 1925, ausführliche Zitate in Herriot, Jadis 2, S. 215-218.

154 Vgl. zur Auseinandersetzung vor 1914 Allain, Caillaux [1], S. 227-269. 
Zentrifugalkräfte innerhalb des Kartells letztlich weniger um die finanzpolitische Weichenstellung ging, als gleichsam um ein Faustpfand für eine linke Regierungspolitik.

II. Wenn nun der Erosionsprozeß des Linkskartells und der einsetzende „Rückfluß" („reflux“) der parlamentarischen Mehrheiten in die politische Mitte chronologisch verfolgt werden, so ist keinerlei Vollständigkeit angestrebt ${ }^{155}$. Vielmehr geht es zum einen darum, besonders wichtige Stationen zu rekapitulieren, zum anderen soll aber auch die Komplexität einer Entwicklung verdeutlicht werden, die zuletzt an den Rand einer Systemkrise führte. Notwendigerweise wird sich der Blick dabei von der Abgeordnetenkammer aus mehrfach auch auf die Vorgänge im Senat zu richten haben.

Trotz aller Divergenzen innerhalb des Linkskartells war die Regierungszeit Herriots doch von relativ stabilen Regierungsmehrheiten in der Abgeordnetenkammer gekennzeichnet ${ }^{156}$. Dies zeigte sich etwa in der Vertrauensabstimmung nach der außenpolitischen Debatte Ende August 1924, als der Dawes-Plan eine klare Mehrheit fand (336 zu 206 Stimmen), beim entscheidenden Votum über die Wiedereingliederung der Eisenbahner im November 1924 (340 zu 136 Stimmen) und bei der Abstimmung über die Aufhebung der Botschaft am Vatikan am 2. Februar 1925 (314 zu 250 Stimmen).

Symptome für die Instabilität der Regierungskonstellation gab es zunächst vor allem im Senat ${ }^{157}$. Von den ersten Problemen im Sommer 1924 war ja bereits die Rede. Weitere Anzeichen dafür, daß sich der nominell von einer radikalen Mehrheit beherrschte Senat keineswegs einer Dominanz der Kartellmehrheit in der Abgeordnetenkammer fügen wollte, waren im August die - trotz der letztlichen Zustimmung - kritische Aufnahme der außenpolitischen Vereinbarungen von London ${ }^{158}$ oder die Probleme bei der Umsetzung der Amnestievorlage ${ }^{159}$. Strukturell war die Situation für die Regierung vor allem deswegen problematisch, weil sich die große linke Senatsfraktion der Gauche démocratique nicht einfach als Teil des Kartells begriff, sondern einen eigenständigen, mehr zur Mitte hin orientierten Kurs verfolgte. Hinzu kam, daß sich 1924-25 zeitweise eine als Union démocratique et radicale firmierende Gruppe vom rechten Flügel der Gauche démocratique abgespalten hatte ${ }^{160}$.

155 Eine detaillierte - und als „Steinbruch“ unverzichtbare - Darstellung findet sich lediglich bei Bonnefous, Histoire 4, S. 40-159. Angesichts der Schwächen dieser Arbeit stellt eine zuverlässige Ereignisgeschichte der Jahre 1924-26 ein Desiderat dar, dessen Realisierung zweifellos cine umfangreiche Monographie füllen würde. Jeanneney, Leçon, ist hierfür zu knapp, zu essayistisch und zu gegenwartsbezogen. - Grundsätzlich zum Phänomen des „reflux“ vgl. Delcros, Majorités de reflux.

156 Vgl. zum folgenden ebd., S. 34.

157 Vgl. ebd., S. $34 \mathrm{f}$.

158 Zum gesamten außenpolitischen Kontext Bariéty, Relations, S. 505-747. Ebd., S. 721 f., wird allerdings die milde Haltung Poincarés im Senat betont.

159 Vgl. Bonnefous, Histoire 4, S. 36-39.

160 Infolge der extrem schlechten Forschungslage zum Senat ist über diese Gruppierung so gut wie nichts bekannt. Nach Botschaftsbericht-Paris (Hoesch), Nr. 257, 11. 4. 1925, S. 3, umfaßte sie etwa 25 Senatoren. Ziel der Gruppe sei es gewesen, mehr Unabhängigkeit von der Regierung zu erlangen. PA AA Berlin, R 70716. - Ohne Angaben hierzu Bonnefous, Histoire 4, sowie Marichy, Deuxième Chambre. 
Ein Indiz für die Spannungen innerhalb des Regierungslagers bildeten auch die Diskussionen auf dem 22. ordentlichen Parteitag der SFIO vom 8. bis zum 12. Februar 1925 in Grenoble161. In Reaktion auf eine sehr national gefärbte und Deutschland gegenüber schroffe Rede Herriots vom 28. Januar in der Abgeordnetenkammer ${ }^{162}$ wurde hier eine explizite Drohung verabschiedet, der Regierung die Unterstützung zu entziehen.

Das Ende der Regierung Herriot I kam einerseits überraschend, andererseits war es aber auch das Ergebnis der finanzpolitischen Krise. Die diesbezüglichen Probleme hatten sich im Frühjahr 1925 in einem Maße zugespitzt, daß auch innerhalb des Kabinetts erhebliche Divergenzen auftraten. Diese konkretisierten sich vor allem im Gegensatz zwischen Herriot, der sich gegen eine Ausdehnung der "avances" der Banque de France aussprach und statt dessen immer mehr zu einer Kapitalsteuer tendierte, und Finanzminister Clémentel, der eine formelle Ausweitung der Vorschüsse und des Geldumlaufs in Aussicht stellte und von einer Kapitalsteuer nichts wissen wollte. Erheblich verschärft wurde die Situation noch dadurch, daß die Banque de France weitere Vorschüsse an die Staatskasse verweigerte und mit einer Offenlegung der bisherigen Manipulationen zur Ausdehnung des Geldumlaufs drohte ${ }^{163}$. Nach widersprüchlichen Aussagen von Regierungschef und Minister im Senat am 2. April reichte Clémentel seinen Rücktritt ein ${ }^{164}$. Nachfolger wurde einen Tag später Anatole de Monzie, der wie Clémentel Mitglied der Senatsfraktion der Gauche démocratique war.

De Monzie brachte umgehend eine Finanzvorlage ein, deren Kernstück eine zunächst freiwillige, im Falle einer Nichtzeichnung aber obligatorisch werdende einmalige Vermögensabgabe war ${ }^{165}$. Für den Augenblick hatte damit innerhalb der Regierung eine eher linke Finanzpolitik die Überhand gewonnen ${ }^{166}$. In der Debatte der Abgeordnetenkammer vom 9. April forderte dies die massive Kritik der Opposition heraus, die vor allem von Maurice Bokanowski, dem Finanzexperten der rechten Mitte, mit großem Nachdruck vorgetragen wurde. Zuvor hatte Herriot heftige Attacken gegen die Finanzpolitik der Regierung Poincaré gerichtet. Schon seit Anfang 1924 seien in verschleierter Form die zulässigen Vorschüsse der Banque de France an die Regierung überschritten worden. In der entscheidenden Vertrauensabstimmung konnte das Regierungslager eine Mehrheit von $290 \mathrm{zu} 246$ Stimmen bei 24 Enthaltungen auf sich vereinigen, bisher das knappste Kammervotum nach einer Vertrauensfrage der Kartellregierung ${ }^{167}$. Die Erosionserscheinungen auf dem rechten Flügel des Regierungslagers waren zwar

161 Vgl. AN Paris, F7 13076, v.a. Berichte des commissariat spécial. Vgl. zum Partcitag auch Ziebura, Blum, S. 349-351; Judt, Reconstruction, S. 189.

162 JO, Débats, Chambre 1925, S. 358-371.

163 Vgl. Jeanneney, Leçon, S. 108 f.; ders., De Wendel, S. 215-236, unter der bezeichnenden Überschrift „Herriot étranglé“.

${ }_{16+}$ Zum Konflikt Herriot-Clémentel ausführlich Jeanneney, Leçon, S. 109-112. Schilderung aus Sicht Herriots und Demissionsbrief in Herriot, Jadis 2, S. 220-223.

$165 \mathrm{Vgl}$. hierzu und zum folgenden v.a. Bonnefous, Histoire 4, S. $77 \mathrm{f}$.

166 Nach Jeanneney, Leçon, S. 108f., war Herriot zu diesem Zeitpunkt schon entschlossen, „nach links zu fallen" und hatte deshalb eine Konfrontationsstrategie gewählt.

167 JO, Débats, Chambre 1925, S. $2171 \mathrm{f}$. 
offensichtlich, von einer Ablösung der labilen Gauche radicale aus dem Linkskartell konnte aber insgesamt noch nicht die Rede sein ${ }^{168}$.

Der entscheidende Schlag gegen die Regierung Herriot wurde einen Tag später im Senat geführt ${ }^{169}$. François-Marsal widersprach zunächst für die Mitte-rechtsOpposition den von Herriot vorgebrachten Beschuldigungen. Erschwert wurde die Situation für den Regierungschef durch die Präsenz zweier anderer, hochsymbolischer Streitfragen. De Monzie hatte als Preis für seinen Eintritt in die Regierung eine erneute Prüfung der Botschaftsschließung beim Vatikan verlangt. Diese Angelegenheit sorgte nun offenbar hinter den Kulissen sowohl bei Befürwortern als auch bei Gegnern für erheblichen Wirbel170. Hinzu kam ein Konflikt des Senats mit Unterrichtsminister François-Albert, dessen Personalpolitik an der Rechtsfakultät der Sorbonne universitäre Proteste provozierte ${ }^{171}$. Bezeichnend für die enge Verknüpfung der politischen Themen im Kampf gegen das Linkskartell ist der von François-Marsal im Senat eingebrachte „ordre du jour": Das Finanzproblem, so wird hier explizit festgestellt, sei mit der allgemeinen Politik verbunden. Vertrauen können es daher für die Regierung nur dann geben, wenn diese inneren Frieden und nationale Einheit gewährleiste. Einen ähnlichen Appell zur Einheit und zur breiten Kooperation aller Parteien hatte am Vortag Bokanowski in der Abgeordnetenkammer an das Regierungslager gerichtet ${ }^{172}$. In der Vertrauensabstimmung des Senats setzten sich die Gegner des Kartells schließlich mit $156 \mathrm{zu} 132$ Stimmen durch, wobei sich die Gauche démocratique überwiegend der Stimme enthielt. Alle im Vorfeld der Finanzdebatte unternommenen Versuche der linken Kammerfraktionen, die Senatsfraktion der Gauche démocratique auf Kurs zu bringen, hatten sich damit als erfolglos erwiesen ${ }^{173}$. Herriot reichte nach dieser Abstimmungsniederlage sofort seine Demission ein.

Mit dem Sturz der ersten Regierung Herriot am 10. April 1925 war das Experiment eines linksbürgerlich-sozialistischen Regierungsbündnisses bereits weitgehend gescheitert ${ }^{174}$. Herriot war die unangefochtene Führungsfigur des Kartells gewesen, seiner Regierung hatte die sozialistische Stützungszusage gegolten. Die

168 Gemäß der Namensliste ebd. votierten 15 Abgeordnete der Gauche radicale für die Regierung, 8 dagegen, 12 enthielten sich und 3 waren beurlaubt. Führende Abgeordnete der Gauche radicale wie Loucheur, Eynac und Raynaldy haben für die Regierung gestimmt. Ebd. - Delporte, III République 3, S. 125, spricht zu pauschal von der "défiance de la gauche radicale“.

$169 \mathrm{Vgl}$. zum folgenden v.a. Bonnefous, Histoire 4, S. $78 \mathrm{f}$. Ohne nähere Informationen bzw. Deutungen bleibt Jeanneney, Leçon, S. 112.

170 Verstimmung herrschte offenbar v.a. in der Gauche démocratique, der de Monzie selbst angehörte. Vgl. LT, 6. 4. 1925, S. 1, „Le gouvernement et la situation“, S. 2, "Le Sénat“.

171 Vgl. auch die daran anschließende Generalkritik in Le Temps an der Kartellpolitik. In einer Zeit, in der gegenüber Deutschland nationale Einigkeit erforderlich wäre, zeige das Kartell „une volonté un peu trop tyrannique“. LT, 3. 4. 1925, S. 1, „Le malaise“.

172 Am Ende der Rede stand ein Appell zur breiten Union nationale: „[...] cette œuvre qui s'impose et qui devient inéluctable, ce n'est pas au nom d'un ou de plusieurs partis qu'elle pourra être accomplie dans les conditions les meilleurs pour la nation, c'est seulement dans l'union nationale de tous les partis sans distinction, et c'est à cette union que je fais appel“. JO, Débats, Chambre 1925, S. 2160.

173 Noch funktionierten in der Abgeordnetenkammer Mechanismen der Kooperation. So fand am 27. 3. 1925 eine Konferenz von Spitzenvertretern der vier Regierungsfraktionen statt, um die Taktik gegenüber dem Senat abzustimmen. Eine Delegation wurde beauftragt, mit der Gauche démocratique zu verhandeln. Vgl. LT, 29. 3. 1925, S. 3, „La Chambre. Le cartel et le vote du budget“.

$174 \mathrm{Vgl}$. in diesem Sinne auch Jeanneney, Leçon, S. 118. 
Anfangseuphorie war verflogen und die ehrgeizige Programmatik nur ansatzweise umgesetzt. Dennoch war die Idee eines Cartel des Gauches keineswegs tot, und es sollte noch über ein Jahr dauern, bis der letzte Versuch zu einer Wiederherstellung gescheitert war. Diese "quinze mois d'agonie“, wie sie Jeanneney rückblickend genannt hat ${ }^{175}$, bildeten eine Phase der fast permanenten Regierungskrise, in der sich sechs Kabinette in kurzem Rhythmus ablösten und in der Inflation und Währungsverfall ihrem Höhepunkt zusteuerten.

Nach dem Rücktritt Herriots wandte sich Staatspräsident Doumergue zunächst an Painlevé, den aktuellen Präsidenten der Abgeordnetenkammer und die nach Herriot zweite bürgerliche Führungsfigur des Linkskartells ${ }^{176}$. Painlevé, der bereits im Herbst 1917 für zwei Monate glückloser Premierminister gewesen war, lehnte das Angebot der Regierungsbildung jedoch sofort ab und schlug Aristide Briand vor, dessen Außenpolitik im zurückliegenden Jahr zu den wenigen $\mathrm{Er}$ folgsgeschichten des Linkskartells gehört hatte. Obgleich Briand eher als Vertreter einer republikanischen „concentration“ galt, suchte er eine Regierungsbildung im Sinne des Linkskartells in Angriff zu nehmen. Ebenso vergeblich wie 1924 Herriot wollte er dabei die Sozialisten zum Regierungseintritt bewegen ${ }^{177}$. Nach der öffentlichen Absage der SFIO gab Briand sein Mandat an den Staatspräsidenten zurück, der erneut Painlevé beauftragte. Dem führenden Républicain-socialiste, der auf weitere Gespräche mit den Sozialisten verzichtete - nicht zuletzt auch, weil er sich deren Unterstützung noch relativ sicher sein konnte ${ }^{178}-$, gelang nun recht schnell eine Kabinettsbildung, deren politischer Schwerpunkt im Vergleich zur Vorgängerregierung ein Stück weiter in der politischen Mitte lag. Ganz im Sinne einer klassischen „replâtrage" 179 reagierte Painlevé somit auf die Umstände des vorhergehenden Regierungssturzes, wobei er insbesondere die Zahl der von Senatoren der Gauche démocratique eingenommenen Ressorts von vier auf fünf erhöhte ${ }^{180}$. Deutlich gestärkt wurde auch die Position seiner eigenen Fraktion, die nun drei statt bisher nur einen Minister stellte ${ }^{181}$. Als den Républicains-socialistes nahestehend galt zudem der fraktionslose Pierre Laval (Travaux publics), der erstmals ein Ministeramt übernahm ${ }^{182}$.

Die spektakulärste Veränderung aber war zweifellos die Berufung des gerade erst amnestierten und in das politische Leben zurückgekehrten Joseph Caillaux

175 Ebd. Kapitelüberschrift.

176 Vgl. zum folgenden v.a. Bonnefous, Histoire 4, S. 79-99; Jeanneney, Leçon, S. 118-125. Vgl. auch den mit zeitlicher Nähe geschriebenen Bericht von Suarez, De Poincaré à Poincaré. Der Autor behandelt die Zeit von der Bildung des Kabinetts Painlevé II bis zum Sturz von Herriot II.

177 Nach Botschaftsbericht-Paris (Hoesch), Tel. Nr. 266, 17. 4. 1925, S. 1, hatte dabei auch „eine zeitlang Idee geherrscht, Brücken der Versöhnung zu den bisherige Regierungsmehrheit unmittelbar rechts anschließenden schwankenden Elementen zu schlagen und auf diese Weise auch Schaffung einer festen Regierungsmehrheit im Senat sicherzustellen". PA AA Berlin, R 70716.

178 So ebd., S. 2.

179 Der nur schwer zu übersetzende Begriff meint eine geringfügige Korrektur der Ministerliste als Anpassung an eine veränderte parlamentarische Konstellation.

180 Steeg Justiz, Schrameck Inneres, de Monzie Unterricht, Chaumet Handel und Industrie sowie Durand Landwirtschaft. Die Angaben bei Bonnefous, Histoire 4, S. 386 f., sind fehlerhaft, da mehrfach die Gauche démocratique mit der Gauche radicale verwechselt wird.

181 Neben Briand, der Außenminister blieb, Painlevé selbst (Présidence du conseil und Krieg) sowie Antériou (Pensions). Hinzu kamen noch zwei Staatssekretäre.

182 Laval war 1924 als Kandidat des Cartel des Gauches in die Kammer gewählt worden. Hierzu sowie zur ministeriellen Karriere bis Mitte 1926 vgl. Kupferman, Laval, S. 58-61. 
zum Finanzminister ${ }^{183}$. Diese Personalentscheidung des Mathematikers Painlevé stellte einen ebenso verwegenen wie folgenreichen Schachzug dar, der nur unter den Bedingungen einer weitgehend personalisierten Kabinettsbildung möglich war. Koalitionsstrategisch konnte Painlevé darauf hoffen, durch die Berufung von Caillaux kurzfristig einen gewissen Solidarisierungseffekt innerhalb des Linkskartells zu erzielen, dessen Amnestiepolitik sich nicht zuletzt auf diese Symbolfigur bezogen hatte. Finanzpolitisch galt die Hoffnung dem im Rufe eines "magicien" stehenden Fachmann, der vor dem Ersten Weltkrieg wesentlich an der Durchsetzung der Einkommenssteuer beteiligt war, der aber durchaus als Vertreter einer orthodoxen Finanzpolitik galt und daher geeignet schien, die in großen Teilen des Bürgertums verbreiteten Besorgnisse zu dämpfen. Gerade weil zeitgenössisch wenig Verständnis für die komplexen währungs- und finanztechnischen Vorgänge herrschte, so eine plausible These Nérés, erhoffte man sich vielfach von Caillaux eine Art Wunderkur ${ }^{184}$.

Die Taktik Painlevés schien zunächst durchaus aufzugehen. In der Vertrauensabstimmung nach der Investitur seiner Regierung in der Abgeordnetenkammer erhielt er am 21. April eine Mehrheit von 304 zu 217 Stimmen bei 41 Enthaltungen. Obwohl wesentliche Punkte der ursprünglichen Kartellprogrammatik fallen gelassen worden waren - so insbesondere auch die Aufhebung der Botschaft am Vatikan und die konsequente Umsetzung der laizistischen Gesetzgebung in ElsaßLothringen - und obwohl von einer Kapitalsteuer keine Rede mehr war, stimmte die sozialistische Fraktion geschlossen für das neue Kabinett. Blum begründete dies in der Kammer ausdrücklich mit dem Symbolwert der politischen Rehabilitierung von Caillaux ${ }^{185}$. Insgesamt handelte es sich immer noch um eine kohärente Kartellmehrheit, der eine weitgehend geschlossene Mitte-rechts-Opposition gegenüberstand. Im Vergleich zum ersten Vertrauensvotum für die Regierung Herriot $^{186}$ hatte sich die parlamentarische Blockbildung sogar noch leicht verstärkt.

$\mathrm{Da}$ es seitens des Linkskartells freilich mehr um eine Demonstration der Einigkeit ging als um einen wirklichen Beweis der Geschlossenheit und daß die Position des Kartells auch in der Abgeordnetenkammer bereits brüchig war, zeigte sich einen Tag später in der Abstimmung über die freigewordene Kammerpräsidentschaft. Der als Président $d u$ conseil gescheiterte Herriot erhielt, obwohl kein Gegenkandidat angetreten war, in namentlicher Abstimmung lediglich die magere Zahl von 266 Stimmen ${ }^{187}$.

${ }^{183}$ Vgl. Bonnefous, Histoire 4, S. 81 f.; Allain, Caillaux [2], S. 314-318, 333-356; Jeanneney, Leçon, S. $118 \mathrm{f}$.

184 Néré, Problème, S. 60-62. Vgl. zum Bild des "thaumaturge“ auch Allain, Caillaux [2], S. 314-318. Wenig ergiebig ist Caillaux, Mes mémoires 3, S. 215-218.

185 So lobte Blum, „d'avoir eu le courage faire vis-à-vis de M. Joseph Caillaux ce que M. Clemenceau, il y a quinze ans, a fait vis-à-vis du colonel Picquart“. Zur Opposition gewandt: „Et puisque vous avez mené cette campagne outrageante pour nous, je le répète, nous y prenons notre rang et nous la mènerons à notre place. Voyez-vous, messieurs, en même temps que votre intervention règle notre attitude dans ce débat, croyez-moi, elle règle aussi, plus peut-être que vous ne l'avez voulu, la situation politique." JO, Débats, Chambre 1925, S. 2238, gesamte Rede S. 2237 f.

186 Vgl. oben S. 445, Tab. 14.

187 JO, Débats, Chambre 1925, S. 2256f., 2267 f. (Liste der namentlichen Abstimmung). Vgl. auch LT, 24. 4. 1925, S. 3, „M. Herriot est élu Président.“ Ebd. Übersicht zu Ergebnissen seit 1914. Demnach war Herriots jetziges Ergebnis das klar schlechteste. 
Tab. 16: Votum der Abgeordnetenkammer am 21.4. 1925: Investitur Regierung Painlevé $I I^{188}$

\begin{tabular}{|c|c|c|c|c|c|c|}
\hline & Abg. & ja & nein & $\begin{array}{l}\text { keine } \\
\text { Teil- } \\
\text { nahme }\end{array}$ & beurl. & $\begin{array}{l}\text { Kohä- } \\
\text { renz }\end{array}$ \\
\hline Communistes & 26 & - & - & 26 & - & $100 \%$ \\
\hline Socialistes (SFIO) & 104 & 102 & - & 2 & - & $98 \%$ \\
\hline Républicains-socialistes & 42 & 39 & - & - & 3 & $100 \%$ \\
\hline Radicaux et radicaux-socialistes & 139 & 131 & - & 2 & 6 & $98 \%$ \\
\hline Gauche radicale & 41 & 27 & 7 & 3 & 4 & $73 \%$ \\
\hline Démocrates & 14 & - & 14 & - & - & $100 \%$ \\
\hline Gauche républicaine démocratique & 44 & - & 42 & 2 & - & $95 \%$ \\
\hline Républicains de Gauche & 36 & 2 & 30 & 2 & 2 & $88 \%$ \\
\hline Union républicaine démocratique & 104 & - & 103 & - & 1 & $100 \%$ \\
\hline "Aucun Groupe" & 28 & 3 & 21 & 4 & - & - \\
\hline Gesamt & 578 & 304 & 217 & 41 & 16 & - \\
\hline
\end{tabular}

Die sechs Monate des Kabinetts Painlevé II waren gekennzeichnet von offenen Auflösungsprozessen des im Prinzip immer noch bestehenden Linkskartells ${ }^{189}$. Verantwortlich hierfür waren zum einen die Gegensätze zwischen Sozialisten und linksbürgerlichen Kräften in der plötzlich akut werdenden Marokkofrage, zum anderen die quer durch Radicaux und Républicains-socialistes verlaufenden Divergenzen gegenüber den Plänen von Finanzminister Caillaux.

Nachdem Mitte Mai aufständische Kabylen französische Stellungen in Marokko angegriffen hatten, reagierte die Regierung zum Unwillen der SFIO mit harten und kostspieligen militärischen Gegenaktionen ${ }^{190}$. Die antikolonialistische Grundhaltung der Sozialisten geriet nun, auch unter dem Druck der eindeutigen kommunistischen Ablehnung der Marokkopolitik, in einen kaum auflösbaren Widerspruch zur Regierungsstützung. Als Ende Mai in der großen Kammerdebatte über Marokko eine überaus nationalistisch getönte und in einem breiten Spektrum heftig beklatschte Rede Painlevés für erhebliche sozialistische Verstimmung sorgte, konnte eine drohende Stimmenthaltung der SFIO bei einem "ordre du jour" gerade noch durch Verschieben des Votums und Neuformulierung des Textes vermieden werden ${ }^{191}$. In weiteren Vertrauensabstimmungen zur Marokkofrage im Juni brach der parlamentarische „soutien“ der Sozialisten dann weitgehend zusammen, während große Teile der Mitte-rechts-Opposition jeweils für die Regierung stimmten ${ }^{192}$. Zahlreiche regionale Föderationen der SFIO sprachen

${ }^{188}$ Liste der namentlichen Abstimmung in JO, Débats, Chambre 1925, S. 2355 f.; Aufstellung nach Fraktionen aus LT, 23. 4. 1925, S. 4, „Le scrutin".

189 Kurzer Überblick über die Entwicklung der Mehrheitsverhältnisse in zentralen Fragen vgl. auch Delcros, Majorités de reflux, S. $35 \mathrm{f}$.

190 Vgl. zum gesamten Themenkomplex Bonnefous, Histoire 4, S. 83-89; Ziebura, Blum, S. 352 f.; Judt, Reconstruction, S. $191 \mathrm{f}$.

191 JO, Débats, Chambre 1925, S. 2479-2484 (Rede Painlevés), S. 2503 (Vertagung der Debatte), S. 2521 (Vertrauensvotum am 29.5.).

192 Vgl. Bonnefous. Histoire 4, S. 84-86. 
sich jetzt gegen eine weitere Stützung der Regierung Painlevé aus. Am 18. Juni fand sich in einer gemeinsamen Sitzung der Fraktion und der Commission administrative permanente eine knappe Mehrheit für ein sofortiges Ende der Kartellpolitik, wobei unter den Mitgliedern der Fraktion die Gegner der weiteren $\mathrm{Zu}$ sammenarbeit noch in der Minderheit blieben ${ }^{193}$. Blum vermied zwar den offenen Bruch mit dem Kartell, fortan blieb die Fraktion in der Marokkofrage aber auf dem Kurs der Enthaltung ${ }^{194}$.

Zum Eklat innerhalb des Regierungslagers kam es anläßlich der weitgehend in den Bahnen der orthodoxen Finanzpolitik bleibenden und jede Form der Kapitalsteuer ausschließenden Pläne des neuen Finanzministers ${ }^{195}$. Die Gegensätze eskalierten, als die Abgeordnetenkammer Ende Juni über das immer noch nicht verabschiedete Budget für das laufende Jahr diskutierte. Die SFIO scheiterte hier mit einer eigenen Gesetzesvorlage für eine - sehr bescheidene - Kapitalsteuer mit 206 zu 319 Stimmen ${ }^{196}$, der Haushalt wurde nach Stellung der Vertrauensfrage bei sozialistischer Enthaltung und gleichzeitiger Unterstützung von Teilen der Modérés mit $320 \mathrm{zu} 34$ gebilligt $^{197}$. Noch deutlicher wurde die Verschiebung der Mehrheitsverhältnisse am 12. Juli, als in der Abgeordnetenkammer über eine nach den Beratungen im Senat notwendig gewordene Modifikation der Haushaltsvorlage

Tab. 17: Votum der Abgeordnetenkammer am 12. 7. 1925: Finanzgesetz Regierung Painlevé $I I 198$

\begin{tabular}{lrrrrrr}
\hline & Abg. & Ja & nein & $\begin{array}{l}\text { keine } \\
\text { Teil- } \\
\text { nahme }\end{array}$ & beurl. & $\begin{array}{l}\text { Kohä- } \\
\text { renz }\end{array}$ \\
\hline Communistes & & & & & & \\
Socialistes (SFIO) & 26 & - & 26 & - & - & $100 \%$ \\
Républicains-socialistes & 103 & - & 103 & - & - & $100 \%$ \\
Radicaux et radicaux-socialistes & 42 & 20 & 16 & 1 & 5 & $54 \%$ \\
Gauche radicale & 137 & 43 & 77 & 7 & 10 & $61 \%$ \\
Démocrates & 40 & 33 & - & 1 & 6 & $97 \%$ \\
Gauche républicaine démocratique & 14 & 14 & - & - & - & $100 \%$ \\
Républicains de Gauche & 44 & 41 & - & - & 3 & $100 \%$ \\
Union républicaine démocratique & 103 & 101 & 1 & - & 1 & $99 \%$ \\
"Aucun Groupe" & 21 & 10 & 2 & 9 & - & - \\
"Non inscrits" & 7 & - & 3 & - & 4 & - \\
\hline Gesamt & 574 & 295 & 228 & 18 & 33 & - \\
\hline
\end{tabular}

193 Judt, Reconstruction, S. 191 f.; Ziebura, Blum, S. 354 f., mit abweichenden Zahlen.

194 So wurde am 9. 7. 1925 ein Nachtragskredit mit 404 zu 28 Stimmen bei 121 Enthaltungen verabschiedet. JO, Débats, Chambre 1925, S. $3326 \mathrm{f}$.

195 Vgl. zum folgenden v.a. Bonnefous, Histoire 4, S. 89-92; Allain, Caillaux [2], S. 349-359; Berstein, Histoire 1, S. 413.

196 Liste der namentlichen Abstimmung in JO, Débats, Chambre 1925, S. $2961 \mathrm{f}$.

197 Liste der namentlichen Abstimmung am 26.6. 1925 ebd., S. $2965 \mathrm{f}$.

198 Liste der namentlichen Abstimmung ebd., S. 3475 (Abstimmung über das „amendement“ des sozialistischen Abgeordneten Bedouce); Aufstellung nach Fraktionen aus LT, 14. 7. 1925, S. 4, „Le vote de confiance“. - Die Bedeutung dieses Votums, das Teil eines wahren Abstimmungsmarathons war, wurde bereits in der zeitgenössischen Presse herausgehoben. Vgl. etwa LT, ebd. 
abgestimmt wurde. In der Frage, ob Kleinhändler von der Umsatzsteuer befreit werden sollten, kam es zu erbitterten Gegensätzen. Das Kabinett Painlevé, das erneut die Vertrauensfrage gestellt hatte, setzte sich zwar mit 295 zu 228 Stimmen durch, der größte Teil seiner parlamentarischen Basis (199 Stimmen) rekrutierte sich jetzt aber aus den Reihen der bisherigen Opposition, während der Großteil des Kartells, darunter auch die Mehrzahl der Radicaux, gegen die eigene Regierung votierte.

Daß die Regierung Painlevé II nach diesem die politischen Fronten verkehrenden Ergebnis weiter im Amt blieb, ist aus der Perspektive eines parteiengestützten Parlamentarismus, wie ihn das Linkskartell bislang ansatzweise realisiert hatte, kaum verständlich. Die folgenden Monate waren zunächst davon bestimmt, daß die SFIO weiter von der Regierung abrückte. Ein enttäuschter Auriol, bislang innerparteilich eine Stütze für die Politik des „soutien“, legte am 31. Juli 1925 sein Amt als Präsident der Commission des Finances nieder ${ }^{199}$. Die Sozialisten gaben damit die wichtigste Ausschußposition der Abgeordnetenkammer auf, die sie im Zuge der 1924 vereinbarten Regierungskooperation erobert hatten ${ }^{200}$. Mitte August verabschiedete ein außerordentlicher Parteitag der SFIO in Paris mit großer Mehrheit eine ambivalente Resolution, die sich faktisch von der Regierung distanzierte, allerdings für eine Politik der "vraies réformes“ eine fortgesetzte parlamentarische Stützung in Aussicht stellte201. Eine Wiederbelebung des Linkskartells war damit noch im Bereich des Möglichen.

Genau dies schien sich Mitte Oktober auf dem Parteitag des Parti radical in Nizza anzubahnen ${ }^{202}$. Herriot, der aktuelle, und Caillaux, der wieder in das politische Leben zurückgekehrte ehemalige Parteichef, lieferten sich hier einen Machtkampf, der sowohl um die politische Orientierung der Partei als auch um die führende Position in ihr ging. Herriots Treuebekenntnisse zum Linkskartell setzten sich dabei eindrucksvoll gegen die zur Mitte hin orientierte Position von Caillaux durch, was auch dadurch begünstigt wurde, daß sich dessen finanzpolitische Rezepte bislang als wenig erfolgreich erwiesen hatten ${ }^{203}$. Die mit großer Mehrheit verabschiedete Schlußresolution forderte eine Rückkehr zum Konzept der Kapitalsteuer und diskreditierte damit offen die Politik des Finanzministers. Die demonstrative Umarmung Herriots mit dem als Gast anwesenden Regierungschef Painlevé am Ende des Parteitags symbolisierte schließlich, daß sich die Regierung und ihre parlamentarische Basis wiedergefunden hatten und daß auch auf Kabinettsebene ein Kurswechsel zu erwarten war.

$\mathrm{Da}$ sich Caillaux einer isolierten Demission verweigerte und da die Regierung mit diesem Finanzminister vor dem sicheren Sturz stand, trat Painlevé am 26. Oktober mit dem gesamten Kabinett zurück. Der umgehend wieder mit der Regierungsbildung beauftragte Painlevé übernahm nun mit dem Schatzministerium persönlich einen Teil des bisherigen Finanzressorts. Budgetminister wurde der

199 Bonnefous, Histoire 4, S. 92. Ohne jeden Hinweis hierauf bleibt Ghebali, Auriol.

200 Nachfolger wurde Henry Simon (Parti radical).

201 Vgl. Judt, Reconstruction, S. 192; Ziebura, Blum, S. 357.

202 Vgl. Bonnefous, Histoire 4, S. 96-98; Berstein, Herriot, S. 139 f.; ders., Histoire 1, S. 414-419.

${ }^{203}$ So war insbesondere eine Ende Juni aufgelegte Anleihe ein Mißerfolg. Vgl. Allain, Caillaux [2], S. 337-339. 
radikale Abgeordnete Georges Bonnet, der damit das erste Amt einer langen Kabinettskarriere antrat ${ }^{204}$. Allein schon durch die Auswechslung von Caillaux lag der politische Schwerpunkt des neuen Kabinetts etwas weiter links, ansonsten wies es auf Ministerebene mit sechs Radicaux, drei Républicains-socialistes und einem Vertreter der Gauche radicale aus der Abgeordnetenkammer sowie vier Senatoren der Gauche démocratique eine ähnliche Mischung der politischen Kräfte auf wie die Vorgängerregierungen ${ }^{205}$.

Die Sozialisten blieben dem Kabinett Painlevé III trotz der auf eine Wiederherstellung der ursprünglichen Kartellkonzeption gerichteten Signale gegenüber gleichsam in Wartestellung und enthielten sich am 3. November beim obligatorischen Vertrauensvotum nach der ersten Präsentation in der Kammer der Stimme. Die Regierung kam daher lediglich auf $221 \mathrm{Ja}$-Stimmen und konnte ihren parlamentarischen Antritt nur überstehen, weil sich auch ein Teil der Modérés aus den Fraktionen der Gauche républicaine démocratique und der Républicains de Gauche enthielt bzw. sogar für die Regierung votierte und weil die Zahl der NeinStimmen somit nur bei 189 lag $^{206}$. Insgesamt markierte das Ergebnis eine extrem unsichere Basis der neuen Regierung, die in der Abgeordnetenkammer wohl kaum eine ernsthafte Überlebenschance hatte.

Die Konflikte um das sofort mit Amtsantritt ausgearbeitete neue Finanzpaket, das als Kernpunkte eine offizielle Ausweitung des Geldumlaufs sowie eine einmalige Kapitalabgabe enthielt, muten vor diesem Hintergrund und angesichts der zu erwartenden Gegnerschaft der Senatsmehrheit wie ein Schauspiel an, bei dem es weniger um die Durchsetzung einer bestimmten Finanzpolitik ging als vielmehr um eine verzweifelte Rekonstruktion des Linkskartells. Unter dem Druck der Sozialisten und mit Hilfe der Radicaux demontierte der Finanzausschuß der Kammer die Regierungsvorlage und ersetzte sie durch ein eigenes Projekt, in dem insbesondere die Kapitalabgabe verschärft wurde. Über ein Detail der Vorlage kam es zu einer mit der Vertrauensfrage verbundenen knappen Abstimmungsniederlage der Regierung mit 278 zu 275 Stimmen. Die nahezu geschlossene Rückkehr der SFIO in das Regierungslager war dabei durch die Abwendung der zuletzt als Mehrheitsbeschaffer eingesprungenen rechtsliberalen Mitte, aber auch des rechten Flügels der bisherigen Kartellkräfte konterkariert worden. Die Fraktion der Gauche radicale hatte überwiegend mit Nein gestimmt ${ }^{207}$, und auch etliche Radicaux hatten der Regierung die Gefolgschaft verweigert. Painlevé demissionierte umgehend und soll anschließend beim gemeinsamen Abendessen, so berichtet Bonnet in seinen Memoiren, freudig erleichtert gewesen $\operatorname{sein}^{208}$.

204 Bonnet brachte es bis 1940 auf 15 Kabinettsposten und verkörperte damit die berühmte ministerielle "stabilité dans l'instabilité". Vgl. Dictionnaire des ministres, S. 378-381. Vgl. generell auch die politischen Erinnerungen: Bonnet, Vingt ans.

${ }^{205}$ Zur Beurteilung auch Botschaftsbericht-Paris (Hoesch), Nr. 733, 29. 10. 1925; PA AA Berlin, R 70716

206 JO, Débats, Chambre 1925, S. 3579 f. Es gab insgesamt 162 Enthaltungen. Zum Stimmverhalten der Fraktionen vgl. LT, 5.11. 1925, S. 4, „Le scrutin“. Demnach stimmten 11 Abgeordnete von GRD und RG für die Regierung und 42 enthielten sich.

207 Betont auch von Bonnefous, Histoire 4, S. 101. Nach Bonnet, Vingt ans, S. 110, war Péret von der Gauche radicale sowie im Hintergrund Caillaux wesentlich an der Einfädelung der Niederlage beteiligt.

208 Bonnet, ebd., S. 111 f., berichtet zunächst über den Demissionsbesuch bei dem offensichtlich in be- 
Tab. 18: Votum der Abgeordnetenkammer am 22. 11. 1925: Sturz Regierung Painlevé III 209

\begin{tabular}{lrrrrrr}
\hline & Abg. & Ja & nein & $\begin{array}{l}\text { keine } \\
\text { Teil- } \\
\text { nahme }\end{array}$ & beurl. & $\begin{array}{l}\text { Kohä- } \\
\text { renz }\end{array}$ \\
\hline Communistes & & & & & & \\
Socialistes (SFIO) & 26 & - & 26 & - & - & $100 \%$ \\
Républicains-socialistes & 98 & 97 & - & - & 1 & $100 \%$ \\
Radicaux et radicaux-socialistes & 139 & 39 & 1 & - & 2 & $98 \%$ \\
Gauche radicale & 41 & 121 & 6 & 10 & 2 & $88 \%$ \\
Démocrates & 14 & - & 14 & - & - & $100 \%$ \\
Gauche républicaine démocratique & 44 & - & 44 & - & - & $100 \%$ \\
Républicains de Gauche & 37 & 1 & 36 & - & - & $97 \%$ \\
Union républicaine démocratique & 104 & - & 103 & 1 & - & $99 \%$ \\
"Aucun Groupe" & 28 & 4 & 24 & - & - & $86 \%$ \\
"Non inscrits" & 1 & - & - & 1 & - & - \\
\hline Gesamt & 574 & 275 & 278 & 16 & 5 & - \\
\hline
\end{tabular}

Mit dem Sturz der Regierung Painlevé III war die eingeleitete Rückkehr zu einer Kartellpolitik, noch bevor sie vor die kaum überwindbare Hürde des Senats gestellt wurde, bereits in der Abgeordnetenkammer gestoppt worden. Es erscheint daher nur konsequent, daß von nun an, obgleich die Idee eines Linkskartells noch nicht völlig untergegangen war, in erster Linie nach einer deutlich in die Mitte verschobenen Regierungsbildung gesucht wurde.

Wie auch schon nach den Wahlen von 1924 gelegentlich festgestellt wurde, gab es in der Abgeordnetenkammer auch eine theoretische Mehrheit der „concentration" im Sinne einer Kooperation von Radicaux, Républicains-socialistes, Gauche radicale, dem bisherigen linksbürgerlichen Flügel des Kartells, mit den Républicains de Gauche und der Gauche républicaine démocratique, den beiden rechtsliberalen Fraktionen im Umfeld der Alliance démocratique. Zusammengenommen verfügten diese Kräfte über eine Abgeordnetenzahl von etwa gut 300. Obgleich es in den zurückliegenden Monaten immer wieder auch zu Kammermehrheiten gekommen war, die weit in das bisher oppositionelle Lager übergegriffen hatten, erwies sich der Versuch einer längerfristigen Neugruppierung der Mehrheitsverhältnisse als äußerst zäher Prozeß. Zu groß war bei vielen Radicaux und Républicainssocialistes immer noch die Neigung zu einem Linkskartell210, zu eng aber auch bei Teilen der Rechtsliberalen die Verbundenheit mit dem einstigen Regierungs- und jetzigen Oppositionspartner der Union républicaine démocratique. Eine Einbe-

ster Laune befindlichen Doumergue („Au fond, il n'était pas fâché que cette mésaventure fût arrivée à son rival à la Présidence."), dann über das anschließßende Abendessen: „Nous allons dîner au ,Bœuf à la mode' avec mes collaborateurs et ceux de Painlevé. Le dîner fut extrêmement gai et cordial. Painlevé et moi, nous étions heureux d'être libérés de nos fonctions. Car il était évidemment impossible de réaliser un redressement financier dans de telles conditions."

209 Liste der namentlichen Abstimmung in JO, Débats, Chambre 1925, S. $3915 \mathrm{f}$. Aufstellung nach Fraktionen aus LT, 24. 11. 1925, S. 3, „Le scrutin“.

210 Vgl. auch Billard, Parti républicain-socialiste, S. 409, zu entsprechenden Bemühungen der Fraktion im Januar 1926. 
ziehung dieser großen konservativen und vielfach als „klerikal“ geltenden Fraktion in eine breite bürgerliche Formation der Union nationale, wie sie vereinzelt bereits im Gespräch war, aber stieß in weiten Teilen der Radicaux noch auf erbitterten Widerstand.

Doumergue wandte sich daher nach dem Sturz Painlevés zunächst wieder an Briand ${ }^{211}$. Dessen erster Ansatz zu einer Regierungsbildung zielte allerdings auf ein Spektrum von den Sozialisten bis zu den rechtsliberalen Mittelgruppen und erwies sich rasch als aussichtslos ${ }^{212}$. Nächster Kandidat war Paul Doumer aus der Senatsfraktion der Gauche démocratique, der sich um eine Kabinettsbildung der engeren concentration der Mitte bemühte, gegen die jedoch auf dem linken Flügel des Parti radical erhebliche Vorbehalte herrschten ${ }^{213}$. Der Staatspräsident gab darauf erneut Herriot die Gelegenheit, eine Kartellregierung zusammenzustellen, was allerdings schon im Vorfeld an immer strikteren programmatischen Forderungen und wohl auch an grundsätzlichen Bedenken der Sozialisten scheiterte ${ }^{214}$. Inzwischen war bereits die für französische Regierungsbildungen ungewöhnlich lange Zeit von einer Woche vergangen.

Erneut kam die Aufgabe nun auf den vom Staatspräsidenten offenbar stark bedrängten Briand zu. Dieser verzichtete jetzt auf jeden Kooperationsversuch mit den Sozialisten und betrieb eine zur linken Mitte hin orientierte Ministersuche. Am 28. November hatte Briand seine insgesamt achte Regierung gebildet ${ }^{215}$. Von der politischen Zusammensetzung unterschied sich das neue Kabinett, das vor allem Angehörige der drei linksbürgerlichen Kammerfraktionen sowie der Senatsfraktion der Gauche démocratique umfaßte, nicht wesentlich von den Vorgängerregierungen der Kartellzeit. Neu war mit Paul Jourdain (Pensionen) und dem ehemaligen Regierungschef Georges Leygues (Marine) freilich die Präsenz von zwei Abgeordneten der Républicains de Gauche. Bemerkenswert ist weiterhin die Stärke der Gauche radicale, die wesentlich zum Sturz Painlevés beigetragen hatte und nun de facto für ein Linksbündnis nicht mehr zur Verfügung stand. Die kleine Fraktion von etwa 40 Abgeordneten stellte im Kabinett Briand VIII immerhin zwei Minister (Loucheur im Finanzressort und Daniel-Vincent im Handelsministerium) sowie drei Staatssekretäre.

In der Regierungszusammensetzung war eine concentration der Mitte nur ansatzweise ausgeprägt. Deutlicher zeigte sich diese Tendenz in der ersten Vertrauensmehrheit, die das neue Kabinett - infolge der Reise Briands zur Unterzeich-

211 Nach Botschaftsbericht-Paris (Hoesch), Tel. Nr. 855, 23. 11. 1925, S. 4, „der gegebene Retter“; PA AA Berlin, R 70717 .

212 Vgl. v.a. Botschaftsbericht-Paris (Hoesch), Tel. Nr. 921, 29. 11. 1925; ebd. Vgl. auch LT, 25. 11. 1925, S. 2, „La crise ministérielle. A l'Elysée“; LT, 26. 11. 1925, S. 2, „La crise ministérielle. A l'Elysée".

${ }^{213}$ Vgl. LT, 26. 11. 1925, S. 2, „La crise ministérielle. A l'Elysée“; LT, 27. 11. 1925, S. 2, „La crise ministérielle. Le refus de M. Doumer“. - Hauptgrund war, daß Doumer 1918 im Haute-Cour für die Verurteilung von Malvy gestimmt hatte.

214 Vgl. Bonnefous, Histoire 4, S. 102; LT, 27. 11. 1925, S. 2, „La crise ministérielle. Les consultations de M. Herriot"; LT, 28. 11. 1925, S. 2, "A la Chambre“.

215 Zur Regierungsbildung im November 1925 vgl. v.a. Bonnefous, Histoire 4, S. 101-103. Sehr ergiebig ist der Botschaftsbericht-Paris (Hoesch), undatierter Anhang nach dem Bericht vom 29.11. 1925, S. 5f.; PA AA Berlin, R 70717. Allgemein zur Regierungszeit Briands 1925/26 vgl. auch Suarez, Briand 6, S. 151-187 (mit ausführlichen Zitaten aus den Kammerverhandlungen). 
nung der Locarno-Verträge in London etwas verzögert - am 3. Dezember erhielt. Die $257 \mathrm{Ja}$-Stimmen für das umgehend vorgelegte neue Finanzprojekt kamen im wesentlichen von Parti radical, Républicains-socialistes und Gauche radicale, die weitgehend geschlossen hinter Briand standen, sowie von etwa $40 \%$ der Abgeordneten von Républicains de Gauche und Gauche républicaine démocratique. Die Masse der Gegenstimmen stammte von den Sozialisten und Kommunisten auf der Linken und der Union républicaine démocratique auf der Rechten. Eine tragfähige parlamentarische Basis für die Regierung bedeutet dieses Ergebnis in keiner Weise, lag doch die erzielte weit unter der nominellen Kammermehrheit. Nur dank eines zwischen Ablehnung und Enthaltung geteilten Stimmverhaltens der bislang so geschlossenen sozialistischen Fraktion ${ }^{216}$ konnte das Kabinett Briand VIII seine erste Vorstellung in der Abgeordnetenkammer überstehen.

Tab. 19: Votum der Abgeordnetenkammer am 3. 12. 1925: Finanzvorlage/Investitur Regierung Briand VIII217

\begin{tabular}{lrrrrrr}
\hline & Abg. & ja & nein & $\begin{array}{l}\text { keine } \\
\text { Teil- } \\
\text { nahme }\end{array}$ & beurl. & $\begin{array}{l}\text { Kohä- } \\
\text { renz }\end{array}$ \\
\hline Communistes & 26 & - & 25 & 1 & - & $96 \%$ \\
Socialistes (SFIO) & 98 & 1 & 46 & 47 & 4 & $50 \%$ \\
Républicains-socialistes & 42 & 40 & 1 & - & 1 & $98 \%$ \\
Radicaux et radicaux-socialistes & 139 & 135 & - & 3 & 1 & $98 \%$ \\
Gauche radicale & 41 & 40 & - & - & 1 & $100 \%$ \\
Démocrates & 14 & - & 14 & - & - & $100 \%$ \\
Gauche républicaine démocratique & 44 & 16 & 16 & 12 & - & $36 \%$ \\
Républicains de Gauche & 37 & 17 & 7 & 12 & 1 & $47 \%$ \\
Union républicaine démocratique & 104 & 2 & 99 & 3 & - & $95 \%$ \\
"Aucun Groupe“ & 28 & 6 & 21 & 1 & - & - \\
"Non inscrits" & 1 & - & - & - & 1 & - \\
\hline Gesamt & 574 & 257 & 229 & 79 & 9 & - \\
\hline
\end{tabular}

Briand ging ohne Illusionen an sein "unmögliches Unternehmen“218. Die knapp achtmonatige Regierungszeit war gekennzeichnet von einer weiteren dramatischen Zuspitzung der Finanz-, Währungs- und Inflationskrise sowie von einer kaum noch nachvollziehbaren Verworrenheit der parlamentarischen Situation. In dieser kurzen Zeit stand Briand drei Kabinetten vor und verbrauchte vier Finanzminister ${ }^{219}$. Diverse finanzpolitische Projekte, die alle ohne das Reizthema einer

216 Zur innerparteilichen Situation vgl. Judt, Reconstruction, S. 186-196.

217 Liste der namentlichen Abstimmung in JO, Débats, Chambre 1925, S. 2355 f.; Aufstellung nach Fraktionen aus LT, 5. 12. 1925, S. 3f., "Les scrutins“.

218 So Briand gegenüber Hoesch am 16. 12. 1925 nach Botschaftsbericht-Paris (Hoesch), Tel. Nr. 987, 17. 12. 1925, S. 3; PA AA Berlin, R 70717. - Überblick zu parlamentarischer Konstellation in der Kammer in Delcros, Majorités de reflux, S. 37-40.

219 Loucheur war schon nach wenigen Wochen am 16.12. 1925 wegen Problemen mit der Finanzkommission des Senats zurückgetreten und wurde ersetzt durch Doumer, den Präsidenten dieser Kommission. Vgl. hierzu Bonnefous, Histoire 4, S. 104. Weitere Minister waren Péret (Briand IX) und Caillaux (Briand X). 
Kapitalabgabe auskamen, verfingen sich entweder schon im Entstehen in den parlamentarischen Instanzen oder aber sie erwiesen sich als weitgehend unwirksam.

Die erste Demission Briands erfolgte am 5. März 1926, als die Regierung in der Abstimmung über ein Detail der neuen Finanzvorlage, die vor allem auf eine Erhöhung der indirekten Steuern setzte und daher erhebliche linke Widerstände mobilisierte, mit $221 \mathrm{zu} 274$ in die Minderheit geriet ${ }^{220}$. Da eine alternative Mehrheit nicht zu erkennen war, wurde der bisherige Regierungschef wiederum mit der Kabinettsbildung beauftragt. Das politische Profil der neuen Regierung entsprach in etwa dem der alten, von 13 Ministern blieben $10 \mathrm{im} \mathrm{Amt.} \mathrm{Bei} \mathrm{der} \mathrm{Vertrauensab-}$ stimmung am 18. März erreichte das Kabinett Briand IX zwar die ungewohnt deutliche Mehrheit von 341 zu 165 Stimmen bei 48 Enthaltungen, was auch eine weitgehende Rekonstruktion der ursprünglichen Kartellmehrheit unter Einschluß der Sozialisten und der Gauche radicale bedeutete221. Dieses Ergebnis resultierte aber - ähnlich wie vor knapp einem Jahr bei der Berufung von Caillaux in das Kabinett Painlevé II - aus einer Personalentscheidung mit hohem „linkem“ Symbolwert: Malvy, der 1918 vom Haute-Cour verurteilte ehemalige Innenminister, übernahm unter heftigen Protesten der parlamentarischen Rechten erneut sein altes Ressort ${ }^{222}$. Infolge der um das Vertrauen der „possédants“ bemühten ${ }^{223}$ Politik des neuen Finanzministers Péret (Gauche radicale) ergab sich aber schon bald eine tiefe Kluft zur SFIO, während sich die Fraktion der Radicaux immer mehr zwischen Anhängern einer zur Mitte hin orientierten concentration républicaine und einer Wiederbelebung des Kartells gespalten zeigte.

Gleichermaßen Ausdruck der extrem labilen parlamentarischen Situation wie auch einer gewissen fachlichen Überforderung war die von Briand und Péret Ende Mai 1926 veranlaßte Berufung einer zwölfköpfigen Expertenkommission, die überwiegend aus Bankiers und Wirtschaftsprofessoren bestand und deren Ziel in einem „assainissement des finances“ lag224. In der Kammer wurde diese zeittypische Wendung an den tatsächlichen oder vermeintlichen Sachverstand - eine Entwicklung, die bis heute für den modernen Parlamentarismus charakteristisch ist vor allem auf der Linken kritisiert. Neben Fragen der personellen Besetzung ging es dabei auch um grundsätzliche Befürchtungen eines parlamentarischen Funktionsverlustes 225 .

Die Péretsche Finanzpolitik wurde überschattet durch einen neuen Schub im Verfall des Franc ${ }^{226}$. Als der Minister auf den Finanzmärkten unter Einsatz der

220 JO, Débats, Chambre 1926, S. 1298 f. (Liste der namentlichen Abstimmung); Billard, Parti républicain-socialiste, S. 409; Bonnefous, Histoire 4, S. 123 f. (Bonnefous und Billard mit falschem Datum 6.3.), zur Neubildung ebd., S. 125-128.

221 JO, Débats, Chambre 1926, S. 1355 f.; nach Fraktionen: LT, 20. 3. 1926, S. 3, „Le scrutin de la confinance".

222 Nach heftigen verbalen Attacken erlitt Malvy in der Kammer einen Zusammenbruch. JO, Débats, Chambre 1926, S. 1322-1334.

${ }^{223}$ So Péret bei der Ankündigung, ein Expertenkomitee berufen zu wollen. Nach Bonnefous, Histoire 4, S. 141.

224 Vgl. Namensliste in L'EEuvre, 1.6. 1926, S. 1, „Le Comité des experts est constitué“. Vgl. auch Bonnefous, Histoire 4, S. 142; Néré, Problème, S. 117-120; Jeanneney, De Wendel, S. 296-305.

${ }_{225}$ Vgl. JO, Débats, Chambre 1926, S. 2308, Interpellationen von Gaston Hulin (Radicaux).

226 Néré, Problème, S. 100-113. Néré gibt die Schuld einer von Péret betriebenen Politik des „laxisme“; ebd., S. 113. 
französischen Edelmetallreserven gegen diese Entwicklung intervenieren wollte, stieß er auf den erbitterten Widerstand der Banque de France und reichte schließlich seinen Rücktritt ein. Dies wiederum bewog auch den Regierungschef zum freiwilligen Rückzug. Am 15. Juni demissionierte das Kabinett Briand IX ${ }^{227}$.

Die nun folgenden Vorgänge bis zur Bildung des Kabinetts Briand X leiteten bereits die Wende vom Juli 1926 ein. Deshalb und auch wegen des fiebrigen und teilweise geradezu bizarren Charakters der Verhandlungen, die charakteristisch erscheinen für den jetzt akut krisenhaften Zustand des parlamentarischen Systems Frankreichs, seien diese Ereignisse etwas genauer betrachtet:

Der am 18. Juni erneut mit der Regierungsbildung beauftragte Briand sah nun offenbar keine andere Möglichkeit als eine breite Regierung der Union nationale, eine Lösung, die auch Péret in seinem Rücktrittsbrief als Bedingung für eine finanzielle Gesundung genannt hatte. Noch am selben Tag ging Briand zu Herriot und schlug ihm ein Kabinett vor, in dessen Zentrum eine Art Triumvirat unter Einschluß von Poincaré stehen sollte228. Der radikale Parteichef zeigte sich zwar zunächst aufgeschlossen, forderte allerdings Klarheit über das Regierungsprogramm, wobei er offenbar auch eine Beteiligung der Sozialisten in Betracht zog. Verhindert wurde dieser Ansatz freilich durch einen Beschluß der radikalen Kammerfraktion, die sich gegen eine Beteiligung Herriots an einer Regierung aussprach, die keinen radikalen Chef aufwies 229 . Briand gab darauf am 19. Juni den Auftrag zur Regierungsbildung wieder an Doumergue zurück.

Angesichts des radikalen Fraktionsbeschlusses war es konsequent, daß der Staatspräsident sich am folgenden Tag an Herriot wandte, der nach Gesprächen mit politischen Freunden den Auftrag akzeptierte230. In nächtlichen Verhandlungen - in der Presse verbreitete sich rasch der Begriff der "folle nuit“ 231 - versuchte Herriot eine diffuse „Union républicaine de gauche“ zu begründen, wie sie zuvor in einer Resolution der Senatsfraktion der Gauche démocratique gefordert worden war. Als Verbündete suchte er - nach der Absage des erfahrenen Maurice Bokanowski - zwei ausgewiesene Wirtschaftsfachleute aus den Reihen der Modérés zu gewinnen, den Républicain de Gauche François Piétri und den Direktor des konservativen Figaro, den Nichtparlamentarier Lucien Romier. Mit ihrer Hilfe wurde offenbar ad hoc ein gänzlich neues Finanzprojekt skizziert, das gleichermaßen Steuererleichterungen und Vermögensabgaben umfaßte. Im Laufe der Nacht und des frühen Morgens zog Herriot dann noch eine ganze Reihe weiterer Politiker hinzu, darunter insbesondere Auguste Champetier de Ribes, Vorsitzender der kleinen christdemokratischen Fraktion der Démocrates, die damit erstmals in das Spiel der Kabinettsbildungen einbezogen wurde. Die drei, von Herriot

${ }_{227} \mathrm{Zu}$ den Vorgängen v.a. Bonnefous, Histoire 4, S. 142 f.; Néré, Problème, S. 113-117, 120.

228 Vgl. das handschriftliche Gedächtnisprotokoll Herriots in AMAE Paris, Papiers Herriot, 12, Bl. 23-25, Zitat Bl. 23. Von Berstein, Histoire 1, nicht erwähnt.

229 Bonnefous, Histoire 4, S. 144.

230 Vgl. Bonnet, Vingt ans, S. 117-122; LT, 20. 6. 1926, S. 3, „La crise ministérielle“; LT, 27. 6. 1926, S. 2, "La crise ministérielle“, sowie den Bericht über Herriots anschließende Rechtfertigung vor der Fraktion (bei nur 30 Anwesenden!) in LT, 22. 6. 1926, S. 3, „M. Herriot devant le groupe radical socialiste".

${ }^{231}$ So LT, 22. 6. 1926, S. 3, „L'opinion de la presse“. Die in der Literatur meist als Beleg angeführte Überschrift bei Suarez, De Poincaré à Poincaré, S. 59, zitiert daher nur eine zeitgenössische Wendung. 
gleichsam als "Geiseln“ der rechten Mitte232 genommenen Verhandlungspartner sagten dem radikalen Parteichef aber schließlich ab, offenbar in realistischer Einschätzung der parlamentarischen Schwierigkeiten, auf die eine derartige Kabinettsbildung stoßen würde. Bezeichnend hierfür ist, daß die Kammerfraktion der Union républicaine démocratique bereits am Nachmittag einen "ordre du jour“ verabschiedet hatte, in dem sie sich strikt gegen eine Ministerpräsidentschaft Herriots wandte 233 .

Erneut mußte nun Briand in die Bresche springen. Während der gewiefte Taktiker nach außen zunächst den Eindruck erwecken wollte, lediglich eine Kombination der Concentration républicaine anzustreben, suchte er dann doch eine Lösung der Union nationale zu erreichen, wie sie auch in großen Teilen der Öffentlichkeit immer mehr gefordert wurde ${ }^{234}$. Briand führte zu diesem Zweck Gespräche mit den Vorsitzenden aller in der Kammer vertretenen Fraktionen, ausgenommen die Kommunisten. Kernstück einer breiten Kombination sollte die Berufung von Poincaré zum Finanzminister werden. Der ehemalige Staats- und Ministerpräsident zeigte sich auch bereit, ein Ministeramt zu übernehmen, machte aber Vorbehalte beim Finanzressort. Offenbar war Poincaré das Risiko zu groß, seine finanzpolitische Reputation in einer erneut scheiternden Regierung Briand zu gefährden ${ }^{235}$. Hinzu kamen die offen artikulierten Widerstände gegen Poincaré aus Teilen der radikalen Fraktion ${ }^{236}$. Eine Berufung Poincarés zum Justizminister scheiterte dann wohl an Widerständen verschiedener linksliberaler Ministerkandidaten ${ }^{237}$.

Letztlich lief die Kabinettsbildung dann doch wieder auf eine Dominanz von Radicaux und Républicains-socialistes hinaus, wobei der Schritt in Richtung einer concentration républicaine nun trotz der mißlungenen Einbeziehung Poincarés etwas deutlicher als bisher ausfiel238. Die spektakulärste Personalentscheidung war die erneute Rückkehr von Caillaux ins Finanzressort. Der umstrittene Politiker kam zum Zuge, nachdem auch der ehemalige Finanzminister Doumer (Senatsfraktion der Gauche démocratique) Briand eine Absage erteilt hatte239. Briand scheint mit dieser Entscheidung sehr gezögert zu haben ${ }^{240}$, doch brauchte er für sein Kabinett dringend einen führenden Vertreter des Parti radical. Trotz seiner Niederlage auf dem Parteitag im Herbst 1925 hatte sich Caillaux als innerparteili-

232 Bonnefous, Histoire 4, S. 145, spricht etwas allgemeiner von „,otages‘ à droite“.

${ }_{233}$ Text in LT, 20. 6. 1926, S. 3, „A la Chambre“.

${ }^{234}$ Detailliert zu den Verhandlungen Briands auch verschiedene Presseberichte, v.a. LT, 22. 6. 1926,

S. 3, „Les consultations de M. Briand“; L'CEvvre, 23. 6. 1926, S. If., „Les pourparlers de M. Briand n'ont pas encore abouti“. Zu den Erwartungen z.B. LT, 17. 6. 1926, S. 1, "Politique nouvelle“.

${ }^{235}$ Nach Bonnefous, Histoire 4, S. 146. Nach ebd. stellte Poincaré - ebenso dann Doumer - die Bedingung, daß die Kammer innerhalb von 48 Stunden sieben bis acht Milliarden Francs indirekte Steuern bewilligen müsse.

236 Vgl. L'Cuvre, 23. 6. 1926, S. 2, „Les pourparlers de M. Briand n'ont pas encore abouti“.

237 Botschaftsbericht-Paris (Hoesch), Tel. (Abschrift), 24. 6. 1926, S. 3: Die Linksparteien hätten Poincaré im Finanzministerium geduldet, nicht jedoch als Justizminister mit Einflußmöglichkeit auf die - religionspolitisch relevanten - elsaß-lothringischen Angelegenheiten. De Monzie, Lamoureux und dann auch Painlevé hätten erklärt, es sei für sie unmöglich, ein Kabinett BriandPoincaré-Doumer mit einem Justizminister Poincaré zu akzeptieren. PA AA Berlin, R 70717.

238 Dem Kabinett gehörten vier Mitglieder der Républicains de Gauche und erstmals auch ein Staatssekretär der Gauche républicaine démocratique. Vgl. auch Tab. 6 im Anhang.

${ }^{239}$ Zur Berufung und Tätigkeit von Caillaux Allain, Caillaux [2], S. 356-362.

${ }^{240} \mathrm{Vgl}$. L'Euvre, 23. 6. 1926, S. 1, „Les pourparlers de M. Briand n'ont pas encore abouti“. 
cher Konkurrent Herriots behauptet und galt als Repräsentant einer zur Mitte hin orientierten Politik. Als Preis für seinen Regierungseintritt erhielt der ehemalige radikale Parteichef zusammen mit dem Finanzressort den Rang des stellvertretenden Ministerpräsidenten (Vice-Président $d u$ conseil). Auch die Berufung mehrerer politischer Freunde von Caillaux markiert die herausgehobene Bedeutung, die dieser für das Schicksal des Kabinetts Briand X besaß241. Der neue Finanzminister gab sofort ein politisches Signal: Mit seiner ersten Amtshandlung ersetzte er den bisherigen Leiter der Banque de France, Georges Robineau, dessen starrer Währungspolitik Caillaux sein eigenes Scheitern als Finanzminister im Jahre $1925 \mathrm{zu}$ schrieb, durch Emile Moreau. Vizepräsident wurde der Wirtschaftsprofessor Charles Rist, bekanntermaßen Anhänger einer Abwertungspolitik ${ }^{242}$.

Das am 29. Juni nach einer vagen Antrittsrede Briands verabschiedete Vertrauensvotum von $292 \mathrm{zu} 130$ Stimmen bei 160 Enthaltungen ${ }^{243}$ spiegelt zum einen die relativ breite Basis des neuen Kabinetts, zum anderen aber auch die abwartende Haltung, die ein großer Teil der Abgeordneten einnahm. Nahezu geschlossen gegen die Regierung votierten nur die Sozialisten und Kommunisten, während sich die Fraktion der Union républicaine démocratique weitgehend enthielt. Entscheidend war nun, ob Caillaux, der sich finanzpolitisch zunächst noch bedeckt gab, den weiteren Währungsverfall würde stoppen können. In dieser Situation kam erneut jenes Instrument einer parlamentarischen Ermächtigung ins Spiel, mit dem Poincaré bereits 1924 für die Stabilisierung gekämpft hatte. Die heftigen Auseinandersetzungen um die von Caillaux geforderten finanzpolitischen pleins pouvoirs bildeten eine weitere wichtige Etappe in der Etablierung von décrets-lois in der politischen Praxis der Dritten Republik und sollen daher zusammen mit dem Sturz der Regierung Briand X innerhalb des folgenden Kapitels (II.4) gesondert betrachtet werden.

III. In einem dritten Schritt kann nun eine Bestandsaufnahme der seit Mitte 1924 verstärkt auftretenden parlamentarischen Probleme im Bereich der regierungstragenden Funktion erfolgen. Nach Skizzierung der Symptome folgt der Versuch einer Diagnose im Rahmen unseres funktionalen Parlamentarismusmodells ${ }^{244}$.

Zunächst ist zu betonen, daß es durchaus berechtigt erscheint, von schweren Funktionsstörungen zu sprechen, die sich von den traditionell im französischen Parlamentarismus üblichen Erscheinungen einer „normalen“ ministeriellen Instabilität abheben. Dies gilt zunächst für das Ausmaß: Von Mitte Juni 1924 bis Juni 1926 folgten einander nicht weniger als sechs Kabinette in einem immer schneller

241 Botschaftsbericht-Paris (Hoesch), Tel. (Abschrift), 24. 6. 1926, S. 4, nennt neben Laval, der bereits der Regierung Briand IX angehört hatte, Chapsal (Handelsressort), Piétri (Staatssekretär für Finanzen) und Duboin (Staatssekretär des Schatzamtes). PA AA Berlin, R 70717.

${ }^{242}$ Vgl. zu dem gesamten Vorgang Moreau, Souvenirs d'un gouverneur de la Banque de France, S. 1-7; Bonnefous, Histoire 4, S. 147; Néré, Problème, S. 123; Caillaux, Mémoires 3, S. 216, rühmt sich, „les écuries d'Augias à la Banque de France“ gereinigt zu haben. Ansonsten geht er in seinen Erinnerungen auf seine Zeiten als Finanzminister 1925 und 1926 nur extrem knapp ein.

${ }^{243}$ JO, Débats, Chambre 1926, S. 2619 f. Es ging um die Vertagung von Interpellationen. Briand übernahm demnach die Poincarésche Strategie. Falsches Datum 30.6. bei Bonnefous, Histoire 4, S. $147 \mathrm{f}$. Unter den Enthaltungen befand sich auch Herriot.

244 Die wesentlichen Literaturangaben zu den politischen Themen und Ereignissen finden sich bereits in den Abschnitten I und II. 
werdenden Rhythmus. Nimmt man in einer dieses Kapitel übergreifenden Perspektive noch die Regierung François-Marsal Anfang Juni 1924 sowie die später zu behandelnde zweite Regierung Herriot im Juli 1926 hinzu, dann kommt man für die Periode zwischen dem Wahlsieg des Cartel des Gauches und der Wende zur Union nationale auf acht Kabinettsbildungen. Im Schnitt ergibt dies eine Lebensdauer von gut drei Monaten. Auch für französische Verhältnisse ist dies ein ungewöhnlich niedriger Wert, der deutlich unter dem seit 1871 üblichen Mittel von gut neun Monaten Regierungsdauer liegt. Zudem waren seit $1914 \mathrm{im}$ Zeichen von Union sacrée und Bloc national nur drei von zwölf Regierungen direkt durch das Parlament abberufen worden ${ }^{245}$. Die Kabinette Clemenceau II und Poincaré II hatten sogar jeweils über zwei Jahre amtiert - länger als alle Nachfolgeregierungen bis Mitte 1926 zusammen.

Die neue Phase extremer Instabilität erschien aber nicht nur wegen des Kontrasts zu dem vorhergehenden Jahrzehnt als krisenhaft. Seitens der politischen Linken kam hinzu, daß das Cartel des Gauches zunächst als Parteienbündnis begründet worden war und damit zumindest implizit eine gewissen, für den französischen Parlamentarismus ungewöhnlichen Anspruch in sich trug. Daß gerade dieser koalitionsähnliche Neuansatz zu einem stärker disziplinierten System in einer geradezu chaotischen Instabilität endete, mußte besonders enttäuschend wirken ${ }^{246}$. Aber auch allgemein waren inzwischen in der politischen Öffentlichkeit Frankreichs die Erwartungen an das parlamentarische System im allgemeinen und an die Stabilität der Regierungen im besonderen gestiegen. Als deutlichste Indizien für die Krisenhaftigkeit der parlamentarischen Situation wurden der Kurs des Franc und die wachsenden Belastungen der "vie chère" wahrgenommen. Je länger die ungewohnte Währungs- und Inflationskrise andauerte, je mehr Ministerpräsidenten und Finanzminister sie verschliß und je mehr Finanzvorlagen in kaum mehr zu durchschauenden Konflikten scheiterten oder sich als finanzpolitisch wirkungslos erwiesen, desto mehr mußte aus den parlamentarischen Problemen eine tatsächliche „crise de régime“ werden ${ }^{247}$. Der französische Parlamentarismus drohte somit vor der Herausforderung einer neuartigen ökonomischen Krise zu versagen.

Das Problem lag freilich nicht allein in einer wachsenden Schwäche der parlamentarischen Regierungsstützung, die zur Instabilität und immer wieder zur Abberufung von Kabinetten führte. Vielmehr gab es nun auch Funktionsstörungen bei der Regierungsbildung. Die bisher für den französischen Parlamentarismus so charakteristische Abfolge von Sturz einer Regierung und schneller Neubildung kam damit ernsthaft ins Stocken. Fast jede Demission einer Regierung zog zwischen Mitte 1924 und Mitte 1926 eine Krise um die Neubildung nach sich. Der "Rückfluß“ der Kammermehrheiten und die Schwerpunktverlagerung in der Zusammensetzung der Kabinette hin zur politischen Mitte bildeten daher einen

${ }_{245}$ Am 13. 11. 1917 Painlevé I, am 12. 1. 1921 Leygues und am 26. 3. 1924 Poincaré II.

$246 \mathrm{Vgl}$. etwa die bitteren Schuldzuschreibungen in Herriot, Jadis 2, S. 199-226, gegen die „dictature de l'argent" (ebd., S. 199, Kapitelüberschrift) oder bei Paul-Boncour, Entre deux guerres 2, S. 120, gegenüber der - damals - eigenen sozialistischen Partei.

247 Nach Botschaftsbericht-Paris (Hoesch), Tel. Nr. 885, 23. 11. 1925, S. 3, wurde ,immer häufiger in öffentlicher Diskussion von einer, crise du régime“ gesprochen“. PA AA Berlin, R 70717. Vgl. auch unten S. 480-483 zur wachsenden rechten Parlamentarismuskritik. 
äußerst zähen Prozeß248. Das im Wahlergebnis von 1924 als mögliche Option durchaus angelegte Ziel einer concentration républicaine von linkem und rechtem Liberalismus wurde auch zum Schluß nur ansatzweise erreicht.

Worin lagen nun die tieferen Ursachen für diese Funktionsstörungen? Sinnvoll erscheint es, zunächst zwei Teilfragen zu unterscheiden: Warum scheiterten die Kartellregierungen und warum gelang keine Stabilisierung der regierungstragenden Funktion durch eine Verschiebung des Regierungsspektrums in die politische Mitte?

1. Die Frage nach dem Scheitern des Kartells war zeitgenössisch sofort ein wichtiges Thema, und sie steht in der Literatur absolut im Mittelpunkt. Die wichtigsten Erklärungsansätze seien daher im folgenden zunächst kurz rekapituliert.

a) Die bekannteste Antwort der Beteiligten zielt auf jene "mur d'argent“, die sich dem Linkskartell entgegengestellt hätte. Die Widerstände und der harte deflationistische Kurs der Banque de France lassen sich hier ebenso anführen wie die zunehmende Kapitalflucht, die mangelhafte Bereitschaft der Anleger, neue Anleihen zu zeichnen, oder die wirtschaftsdefaitistischen Kampagnen mancher Presseorgane249. In der Literatur findet sich dieser Ansatz heute freilich nur noch partiell250.

b) Gerade die mit der Linken sympathisierenden Autoren wie Jeanneney und Soulier suchen die Ursachen vielmehr primär im Verhalten des Kartells selbst ${ }^{251}$. Jeanneney, der eine Art Gebrauchsanweisung für künftige Linksregierungen verfaßt hat, wirft vor allem Herriot und seinem Finanzminister Clémentel vehement vor, in den ersten Wochen ihrer Regierungszeit keine schonungslose Offenlegung der finanzpolitischen Situation durchgeführt und keinen formellen Übergang zu einer Politik der inflationären Erhöhung der Geldmenge vollzogen zu haben ${ }^{252}$. Letzteres hätte schließlich zu einer offiziellen Abwertung des Franc führen müssen, wie sie dann später von Poincaré durchgesetzt wurde. Ein derartiger Überraschungscoup hätte die Widerstände der Banque de France gebrochen und das Kartell von seiner finanzpolitischen Dauerbelastung verschont. Statt dessen habe sich die Kartellregierung selbst in die Machenschaften der bisherigen Finanzpolitik verstrickt und sich so seitens der Banque de France erpreßbar gemacht. Es ist hier nicht der Ort, die finanzpolitische Validität dieser These, die in knapperer Form auch durch Soulier vertreten wird, zu überprüfen ${ }^{253}$. Aus allgemeinhistorischer Sicht ist ihr aber mit Berstein ein ahistorischer Grundansatz vorzuwerfen. Eine Abwertung war zu diesem Zeitpunkt angesichts der herrschenden, auf Geldwertstabilität und Wiederherstellung der alten Kurse fixierten „contraintes men-

${ }^{248}$ Vgl. zur allmählichen Verschiebung auch Tab. 6 im Anhang.

249 Vgl. Herriot, Jadis 2, S. 201-207.

250 So v.a. bei Wileman, What the Market will Bear.

251 Hier liegt eine gewisse Parallele zur SPD-kritischen Haltung von Winkler.

252 Jeanneney, Leçon, v.a. S. 36-42, unter Bcrufung auf einen Plan von Pierre de Moüy, Direktor des Schatzamtes. Vgl. auch Herriot, Jadis 2, S. 201-205. - Die Führung des dem Finanzministerium unterstellten Schatzamtes (Le Trésor) kämpfte schon seit Jahren gegen den deflationistischen Kurs der Banque de France. Vgl. Mouré, The Gold Standard Illusion, S. 65-67; Blancheton, Le Pape et l'Empereur, S. 220-231.

253 Soulié, Cartel des Gauches, S. $312 \mathrm{f}$. Ansatzweise findet sich eine derartige Kritik auch in anderen Arbeiten, so etwa bei Billard, Parti républicain-socialiste, S. $400 \mathrm{f}$., sowie jetzt auch in der währungsgeschichtlichen Studie von Mouré, The Gold Standard Illusion, S. 77. 
tales" weder für Herriot und seine Mitstreiter akzeptabel, noch parlamentarisch durchsetzbar ${ }^{254}$. Es bedurfte vielmehr erst der bitteren Erfahrungen der Jahre 1924 bis 1926, damit die Vorstellung einer Francabwertung allmählich an Breite gewinnen konnte. Und vermutlich war dieser Schritt dann durch eine Mitte-rechts-Regierung leichter zu vollziehen als durch eine gerade in finanzpolitischer Hinsicht argwöhnisch beäugte Linksregierung255.

c) Berstein selbst bietet einen differenzierteren Erklärungsansatz. Zum einen verweist er geradezu fatalistisch auf eine Unvereinbarkeit linker Finanzpolitik mit den dominierenden orthodoxen wirtschafts- und finanzpolitischen Mentalitäten ${ }^{256}$. Zum anderen sucht aber auch er nach spezifischen Schwachpunkten in der Politik der Kartellparteien. Im Vordergrund stehen dabei die mangelhaften Übereinstimmungen zwischen Radicaux und Sozialisten, das daraus resultierende Defizit an gemeinsamer Programmatik sowie - mit deutlicher Kritik an der SFIO die mangelnde Bereitschaft der Sozialisten zum Regierungseintritt.

d) In der Tradition zeitgenössischer Kritiker des Mitte-rechts-Spektrums stehen dagegen die Bewertungen Mayeurs, der dem Linkskartell im allgemeinen und Herriot im besonderen mehr oder minder deutlich Inkompetenz vorwirft. Gleichzeitig verweist auch Mayeur auf die innere Uneinigkeit der Kartellkräfte257.

Alles in allem dominieren - durchaus analog zu rückblickenden Bewertungen des Weimarer Parlamentarismus - in diesen Interpretationen doch sehr stark die Vorwürfe, während eine Betrachtung der strukturellen und funktionalen Zusammenhänge meist zu kurz kommt. In mehrfacher Hinsicht aber hatte es das Regierungsbündnis des Cartel des Gauches mit extrem ungünstigen Bedingungen zu tun.

a) Erinnert sei zunächst an die seit den Wahlen vom Mai 1924 in der Abgeordnetenkammer herrschenden Mehrheitsverhältnisse. Die im Wahlbündnis zusammengeschlossenen Kartellkräfte erreichten nominell lediglich 287 von (theoretisch) 581 Mandaten, und sie waren nun auf die neu formierte Fraktion der weit in der Mitte stehenden Gauche radicale (zunächst 42 Abgeordnete) angewiesen ${ }^{258}$. Aber auch die damit erreichte Zahl von 329 Mandaten bildete angesichts der individualistischen Traditionen des französischen Parlamentarismus eine sehr unsichere Basis.

Dennoch lagen die bei wichtigen Abstimmungen erreichten Kammermehrheiten der Regierung Herriot I fast immer mehr oder minder deutlich über 300, worin sich ein durchaus bemerkenswertes Streben nach Disziplin und nach stabiler Stützung der Regierung zeigt. Zweifellos trugen dazu auch die Bemühungen um eine informelle Verklammerung der vier regierungstragenden Fraktionen bei,

$254 \mathrm{Vgl}$. auch Herriot, Jadis 2, S. 205.

255 Vgl. auch Berstein, Herriot, S. 136.

256 Vgl. v.a. ebd., S. 138: „[...] la première c'est que les mentalités des Français sur les problèmes économiques et financiers demeurent imprégnées des vues orthodoxes qui sont celles de la droite, mais sont considérées comme universelles (intangibilité de la valeur de la monnaie, équilibre budgétaire, non-intervention de l'Etat dans l'économie) et que, pour les raisons qu'illustre le Cartel, la gauche se brise nécessairement contre elles (fuite des capitaux, refus de souscription aux bons du Trésor...)“.

${ }^{257}$ Vgl. Mayeur, Vie politique, S. 279-283, v.a. S. 280, 283.

258 Daß die Gauche radicale von Anfang an eine "Achillesferse“ gebildet hat, wird auch von Berstein, Histoire 1, S. 390 , betont. 
wie sie sich immer wieder in Treffen der Fraktionsspitzen (Délégation des Gauches) manifestierten ${ }^{259}$, wenngleich eine ähnlich intensive Verbindung von Kabinett und Regierungsmehrheit wie in den deutschen „Parteiführerbesprechungen“ wohl nicht erreicht wurde.

b) Nachdrücklich sei betont, daß die Regierung Herriot I nicht durch die Abgeordnetenkammer, sondern durch den Senat gestürzt wurde. Die Gleichberechtigung der zweiten Kammer im Hinblick auf die regierungstragende Funktion - ein in der französischen Literatur mit erstaunlicher Selbstverständlichkeit behandelter parlamentarismusgeschichtlicher Anachronismus - war im April 1925 entscheidend für die erste Unterbrechung des Kartellexperimentes, von der sich das Linksbündnis nicht mehr erholen konnte. Im Senat aber hatte sich ein den Kartellfraktionen der Abgeordnetenkammer analoges Regierungslager nie formiert. Von Anfang an achtete die überwiegend, aber eben nicht ausschließlich radikale Senatsfraktion der Gauche démocratique auf eine gewisse Distanz zur neuen Linksregierung und setzte dies beginnend mit der Wahl Doumergues zum Staatspräsidenten auch immer wieder demonstrativ in Szene. Von Anfang an wurde auch die durch die Kartellmehrheit der Abgeordnetenkammer inaugurierte Gesetzgebung durch den Senat verzögert oder gar blockiert. Hierbei spiegelten sich nicht nur die im Vergleich zur Abgeordnetenkammer konservativeren Grundüberzeugungen vieler Senatoren, sondern auch die gleich noch genauer anzusprechenden Kohärenzprobleme des Parti radical.

Der jederzeit wiederholbare Sturz einer Kartellregierung durch den Senat und die in traditioneller Manier der "replâtrage" stärker auf den Senat zugeschnittene Kabinettsbildung und Regierungspraxis Painlevés konnte nicht ohne Auswirkungen auf die Solidität des Kartells in der Abgeordnetenkammer bleiben. Die wachsende Distanz der SFIO zu den amtierenden Regierungen hing damit ebenso zusammen wie die immer striktere Verweigerung eines sozialistischen Kabinettseintritts. Auf dem Parteitag der SFIO im Januar 1926 bildete der drohende Sturz einer Linksregierung durch den Senat sogar ein Hauptargument der ,antiparticipationnistes" 260 . Es war daher durchaus konsequent, daß seitens der Sozialisten aber auch seitens linker Radicaux eine Kampagne gegen die parlamentarische Gleichstellung des Senats geführt wurde 261 . Le Quotidien machte im übrigen im Januar 1926 als Antwort auf die eben erwähnte sozialistische Argumentation den Vorschlag, ein etwaiges Linkskabinett solle vor dem Senat einfach keine Vertrauensfrage mehr stellen und es so zum Konflikt mit der zweiten Kammer kommen lassen ${ }^{262}$. Freilich waren derartige Vorstellungen insofern irreal, als die Institution

259 Vgl. z. B. Herriot, Jadis 2, S. 223. Zum Versuch, dem Cartel des Gauches eine institutionelle Klammer zu geben, gehörte auch die Schaffung einer Office de documentation du Cartel des Gauches; Polizeibericht hierzu in AN Paris, F7 13193.

260 Vgl. zu dem Parteitag, auf dem Blum seine berühmte Unterscheidung zwischen „conquête du pouvoir" und "exercice du pouvoir" postulierte, Ziebura, Blum, S. 361-368. Zur Argumentation mit dem Faktor „Senat“ vgl. auch Manifest der SFIO zur Frage der Regierungsbeteiligung in LP, 18. 3. 1926, S. 1, „Aux Travailleurs de France“.

261 Vgl. z. B. den Artikel von Alphonse Aulard zum 50. Jahrestag der Verfassung in LQ, 25. 5. 1925, S. 1 , "Notre constitution a aujourd'hui cinquante ans". Zur sozialistischen Verfassungsinitiative von 1926 gegen die legislativen Befugnis des Senats vgl. unten S. 513.

262 LQ, 11. 1. 1926, S. 1, "Le congrès socialiste": "Il n'y a que la dissolution pour le cas où la Chambres lui renvoie et maintient des lois qu'il ne veut pas voter./ Nous verrons s'il osera./ Rien n'em- 
des Senats - ganz im Gegensatz zu den Anfangsjahren der Republik - inzwischen gerade auch bei vielen Radicaux einen durch die Tradition gefestigten Platz im republikanischen Wertekanon hatte.

c) Auch in anderer Hinsicht trugen die Strukturen des französischen Parlamentarismus zur Erosion des linken Regierungslagers bei. In der Tätigkeit des Finanzausschusses der Kammer, der seine traditionelle Eigenständigkeit auch in der Zeit des Kartells demonstrierte, wird dies besonders deutlich ${ }^{263}$. Bereits unter der Regierung Herriot konnte von einer engen Kooperation zwischen Regierung und den Vertretern des Regierungslagers im Ausschuß keine Rede sein. Noch klarer zeigte sich dies bei den Vorgängen im November 1925. Der Ausschuß demontierte die Finanzvorlage der Regierung Painlevé III, ersetzte sie durch ein eigenes Projekt und leitete damit den Sturz der Regierung in der Abgeordnetenkammer ein. Der alte Dualismus zwischen Parlament und Regierung bestand in Form eines Gegensatzes zwischen Regierung bzw. Finanzministerium und Finanzausschuß der Kammer weiterhin fort und nahm angesichts der finanzpolitischen Konfusion zeitweise markante Züge an.

Generell boten die komplizierten Verfahrensweisen der im Hin und Her von Abgeordnetenkammer und Senat ausgeübten Gesetzgebung sowie die Praxis der individuellen Interpellationen, die nach Antritt der Regierung Herriot wieder von den Poincaréschen Restriktionen befreit worden waren, unendliche Gelegenheiten für Koordinationsprobleme innerhalb des Regierungslagers sowie für Fallstricke, die durch Oppositionspolitiker oder auch durch Abweichler aus den eigenen Reihen gelegt wurden. Die Komplexität des traditionellen deliberativen Parlamentarismus, der vom Ideal her auf die freie Diskussion unabhängiger Abgeordneter zugeschnitten war, entfaltete nun in der polarisierten Konfrontation zwischen dem Linkskartell und seinen Gegnern ihr destruktives Potential. Le Temps sprach in diesem Zusammenhang Mitte 1926 von den „partisans hypertrophiques" des parlamentarischen Systems, die nun zu seinen schlimmsten Gegnern geworden seien ${ }^{264}$.

Ohne Einfluß auf die Desintegration des Regierungslagers scheint dagegen in der Phase der eigentlichen Kartellregierungen (Herriot I bis Painlevé III) der Staatspräsident geblieben zu sein. Doumergue, 1924 von der Assemblée nationale als erklärter Gegner des Linksbündnisses gewählt, verhielt sich loyal gegenüber der Kartellmehrheit und beauftragte mit Herriot und dann mit Painlevé jeweils umgehend deren Repräsentanten mit der Regierungsbildung. Fundierte Hinweise

pêche donc les socialistes de mettre dans leurs conditions que la Chambre du suffrage universel ne sera pas une fois de plus humiliée et trahie par la Chambre du suffrage restreint."

${ }^{263} \mathrm{Vgl}$. auch die überaus scharfe Kritik in der zeitgenössischen rechtswissenschaftlichen Arbeit von Mauchant, La Commission des finances de la chambre des députés. Der Autor beklagt - ganz im Sinne der verbreiteten konservativen Parlamentarismuskritik - generell die Schwäche der Exekutive. Die Kritik an der Übermacht des Parlaments wird hier modifiziert zu einer Kritik an der Übermacht der Finanzkommission. Diese habe angesichts der Unfähigkeit der Kammer eine enorme Machtfülle gewonnen.

${ }^{264}$ LT, 18. 7. 1926, S. 1, „Gouvernement et parlement“: „Les pires ennemis du régime parlementaire ne sont pas ses adversaires déclarés. Ce sont ses adeptes dégénérés qui transforment leurs droits en licences, leur attributions en privilèges, leurs pouvoirs en abus. Ce sont ses partisans hypertrophiques qui rendent presque impossible le fonctionnement du pouvoir exécutif." Kontext dieses Artikels war der Streit um die von Caillaux vorgelegte Ermächtigungsvorlage. 
darauf, daß Doumergue bereits früh auf ein breites Regierungsbündnis von Poincaré bis Herriot hingearbeitet habe ${ }^{265}$, liegen nicht vor.

d) $\mathrm{Zu}$ einem grundsätzlichen Problem für das Linkskartell wurde sein „parteipolitisch“ polarisierender Grundansatz, der in dieser klaren Form im Gegensatz zur parlamentarischen Tradition Frankreichs stand. Das eigentlich Neue und für weite Bereiche des Mitte-rechts-Spektrums ein Skandalon war die Einbeziehung einer starken und geschlossenen sozialistischen Partei in das Regierungslager, die das neue Cartel des Gauches erheblich weiter nach links rückte als den alten Bloc des Gauches von 1902, in dem Radicaux und ein beachtlicher Teil der Modérés bestimmend gewesen waren und für den die zersplitterten und parlamentarisch schwachen Sozialisten nur bescheidene Unterstützung gewährt hatten. Das neue Kartell hatte zudem die enge Verbindung zwischen Radicaux und „linkem“ Flügel der Modérés weitgehend zerrissen, lediglich in der Einbindung der kleinen Gruppe der Gauche radicale blieb ein Rest dieser Brücke erhalten. Vor allem aber war mit der linken Blockbildung ein demonstrativer Gegenentwurf zu dem durch den Ersten Weltkrieg dominant gewordenen Paradigma der nationalen "Union“ errichtet worden. In der finanzpolitischen Krise sollte sich allerdings zeigen, wie stark die Wahrnehmung der politischen Realitäten noch immer durch die Kriegserfahrung geprägt war. Die bekannte Wendung vom „Verdun financier“ ist nur der intensivste Ausdruck dieser Stimmung.

Die Bildung einer parteiengestützten Regierung unter Einbeziehung der Sozialisten war aus liberal-konservativer Perspektive eine nicht zu verzeihende Grundsünde. Bezeichnend hierfür ist die grundsätzliche Kritik, die Mitte April 1924 in einer Analyse des Temps geäußert wurde 266 . Herriot, der 1919 am Zustandekommen des Bloc national und 1923/24 an der Bildung des Cartel des Gauches führend beteiligt war, wurde zunächst bescheinigt, eigentlich der geborene Schiedsrichter („arbitre“) für ein Regieren über den Parteien im Zeichen der „union“ zu sein. Statt dessen sei er ein festes Parteienbündnis eingegangen, die immer mehr von "okkulten“, weil nicht offen in der Regierung vertretenen sozialistischen Ideen beherrscht werde. Die „faute lointaine“ der Regierung Herriot sei es daher gewesen, nach den Wahlen vom 11. Mai 1924 eine „formation électorale“ zu einer „formation gouvernementale" gemacht zu haben ${ }^{267}$.

Dabei ging es nicht allein um die Ablehnung jedes sozialistischen Einflusses auf die französische Politik, sondern auch um eine tiefe Aversion gegen den Funktionsgewinn von Parteien. Deutlich wurde dies Anfang Januar 1926 in der bereits zu Beginn dieser Arbeit zitierten Betrachtung, die Le Temps zum 50. Jahrestag des Inkrafttretens der Verfassung der Dritten Republik anstellte. Die hier zum Ausdruck kommende düstere Parlamentarismuskritik bezog sich neben der Klage über die Kräfteverschwendung einer selbstzerstörerisch gewordenen parlamentarischen Praxis auch auf einen Strukturwandel des parlamentarischen Systems. Die Kammermehrheit habe in der zurückliegenden Zeit eine einseitige Politik betrieben und den Bezug zur gesamten Nation verloren, politische Entscheidungen hät-

265 Dies legt Bonnet, Vingt ans, S. 111-115, ohne nähere Erläuterung nahe.

266 LT, 12. 4. 1925, S. 1, „La chute du ministère“.

267 Ebd.: „[...] c'est d'avoir, au lendemain du scrutin du 11 mai 1924, voulu maintenir pour gouverner la France, une formation électorale en formation gouvernementale“. 
ten sich aus dem Parlament immer mehr in Parteiinstanzen verlagert ${ }^{268}$. Letztlich zielte derartige Kritik, die hier in der einflußreichsten liberal-konservativen Zeitung Frankreichs formuliert wurde, auf den parlamentarismusgeschichtlichen Modernisierungsansatz, der mit dem Cartel des Gauches als einer Parteienkooperation zwischen Parti radical und SFIO verbunden war ${ }^{269}$. Dieser Ansatz band, wie im parteiengestützten Parlamentarismus üblich, die regierungstragende Funktion des Parlaments an ein fest umgrenztes Regierungslager und verzichtete in der Regel auf eine freie, parteiunabhängige Mehrheitsbildung.

Die Neigung des Kartells zu einer ausgeprägten Symbolpolitik verstärkte dessen polarisierende Wirkung. Dies betraf nicht nur die umstrittene Kapitalsteuer, sondern gerade in der Regierungszeit Herriots auch andere Themen wie den Laizismus oder die Überführung der Asche von Jaurès in das Panthéon ${ }^{270}$. Hierbei zeigte sich zum einen das generelle Bemühen, „linke“ Politik zu demonstrieren. Zum anderen legte das Fehlen einer grundsätzlichen Koalitionsvereinbarung die Suche nach und das starre Festhalten an programmatischen Fixpunkten nahe. Den symbolkräftigen Vorhaben des Kartells kam somit auch eine Art kompensatorische Funktion zu. Freilich blieb angesichts zahlreicher Widerstände und innerer Widersprüche der integrative Effekt für das Regierungslager schon bald auf der Strecke, während den Gegenkräften provokative Angriffsflächen geboten wurden. Charakteristisch ist hier der oben zitierte „ordre du jour“, der am 10. April 1925 im Senat auf die Störung des inneren Friedens und der nationalen Einheit verwies und den Sturz der Regierung Herriot I auslöste271.

e) Die in der Literatur immer wieder als eine Hauptursache des Scheiterns genannten inneren Divergenzen des Linkskartells waren zweifellos ebenfalls von erheblicher Bedeutung. Drei Bruchlinien lassen sich dabei unterscheiden.

- Die Schwachstelle zwischen den ursprünglichen Kräften des Wahlbündnisses (Parti radical, Républicains-socialistes und SFIO) und der erst nach den Wahlen formierten Fraktion der Gauche radicale war von Anfang an zu erkennen. Der eigentliche Bruch erfolgte allerdings erst relativ spät. Als es am 9. April 1925 - einen Tag vor dem Sturz im Senat - in der Abgeordnetenkammer um das Schicksal der Regierung Herriot I ging, schlug sich nur eine Minderheit von acht Mitgliedern der Fraktion, das sind etwa 20\%, auf die Seite der Opposition. Insbesondere die führenden Abgeordneten der Gauche radicale hielten dem Linkskartell in dieser Situation noch die Treue. Beim Sturz der Regierung Painlevé III im November 1925 war dann aber eine Mehrheit der Fraktion mitbeteiligt, und fortan stand die Gauche radicale für eine Regierungsbildung im Sinne des Kartells nicht mehr zur

268 LT, 15. 1. 1926, S. 1, „Le cinquantenaire du Parlement“.

269 Wie beschrieben traten bei den Républicains-socialistes die parteipolitischen Bezüge weit weniger in den Vordergrund, bei der Gauche radicale fehlten sie ganz.

270 Dic Überführung ins Panthéon fand am 23. 11. 1924 statt. Die parallel dazu durchgeführte Großdemonstration der Kommunisten machte in bürgerlichen Kreisen einen tiefen Eindruck und kann als "Geburtsstunde“ des französischen Faschismus gelten. Vgl. Wirsching, Vom Weltkrieg zum Bürgerkrieg?, S. $284 \mathrm{f}$.

271 Vgl. oben S. 455. - Vgl. auch Botschaftsbericht-Paris (Hoesch), Tel. Nr. 257, 11. 4. 1925, S. 1f. Der Sturz der Regierung Herriot im Senat habe „allgemeine Ursachen“ und „akute Gründe“. Zu ersteren werden gezählt: „Auflehnung der französischen Bourgeoisie“ gegen die linke Regierung, insbesondere auf den Gebieten der Außen-, Finanz- und Kirchenpolitik; Gegnerschaft des Militärs, der Wirtschaft und der kirchlich gesinnten Bevölkerung. PA AA Berlin, R 70716. 
Verfügung. Alle Versuche zu einer Wiederbelebung des Linksbündnisses waren daher allein schon von den Mehrheitsverhältnissen in der Abgeordnetenkammer her zum Scheitern verurteilt.

- Die Spannungen zwischen den bürgerlichen, an der Kabinettsbildung beteiligten Kräften des Kartells und der die Regierung parlamentarisch stützenden SFIO erhielten trotz mancher öffentlicher Verstimmung ebenfalls erst relativ spät, d.h. nach dem Sturz von Herriot I, parlamentarische Relevanz. Ein erster Bruch in der Strategie des „soutien“ erfolgte angesichts der Marokkopolitik Painlevés im Juni 1925. Bis dahin hatte die SFIO, obgleich es schon bald zu heftigen parteiinternen Problemen kam ${ }^{272}$, dank ihrer ausgeprägten Fraktionsdisziplin die stabilste parlamentarische Stütze des Kartells dargestellt. Das spektakuläre "renversement“ der parlamentarischen Allianzen, mit dem die Regierung Painlevé am 12. Juli 1925 ihr Haushaltsgesetz gegen den Großteil des eigenen Regierungslagers und mit zahlreichen Stimmen aus der Opposition durch die Abgeordnetenkammer brachte, kann schwerlich den Sozialisten zur Last gelegt werden. Auch der größte Teil der Radicaux und sogar eine relativ starke Minderheit der Républicains-socialistes stimmte in dieser Situation gegen die Regierung Painlevé, die unter dem Einfluß von Finanzminister Caillaux wenig Rücksicht auf ihre parlamentarische Basis genommen hatte. Eine deutliche Entfernung der SFIO von den bisherigen Bündnispartnern erfolgte erst am 3. November 1925 in der ersten Vertrauensabstimmung für die Regierung Painlevé III, als sich die Fraktion der Stimme enthielt. Wenig später, bei der zum Sturz Painlevés führenden Abstimmung vom 22. November, waren die Sozialisten aber bereits wieder Bestandteil des jetzt in die Minderheit geratenen Regierungslagers.

$\mathrm{Ob}$ die Nichtbeteiligung der Sozialisten an den Kartellkabinetten tatsächlich destabilisierend auf den Zusammenhalt des Linksbündnisses gewirkt hat, wie in der Literatur meist ohne nähere Begründung nahegelegt wird273, erscheint daher fraglich. Möglicherweise, so läßt sich zugunsten dieser These argumentieren, wäre die symbolbeladene Verhärtung der SFIO in der Frage der Kapitalsteuer bei einer eigenen Präsenz im Kabinett vermieden worden. Andererseits ist das von Blum mehrfach gegenüber den Avancen des Parti radical gebrauchte Argument nicht von der Hand zu weisen, sozialistische Kabinettsmitglieder würden die Erwartungshaltung an der Parteibasis deutlich steigern. Die Sozialisten seien daher, so Blum, außerhalb des Kabinetts die verläßlicheren Bündnispartner274. Und daß eine personelle Regierungsbeteiligung der SFIO weniger Feindseligkeit und $\mathrm{Pa}$ nikmache seitens der rechtsliberalen und konservativen politischen Öffentlichkeit auf sich gezogen hätte als die vermeintlich „okkulten“ sozialistischen Einflüsse ${ }^{275}$, ist kaum anzunehmen. Vielleicht war der von Blum zwischen den konträren Positionen innerhalb seiner Partei gesteuerte Kurs des „soutien“ tatsächlich die beste

272 Dieser Themenprozeß bleibt hicr weitgehend ausgeklammert. Erinnert sci an die oben erwähnten Diskussionen auf dem Parteitag im Februar 1925 in Grenoble. Zur weiteren Entwicklung des Streites zwischen Anhängern einer Stützungsstrategie, Befürwortern eines Regierungseintritts und grundsätzlichen Gegnern einer Regierungskooperation mit bürgerlichen Parteien vgl. Judt, Reconstruction, S. 190-195; Ziebura, Blum, S. 354-357.

${ }^{273}$ V.a. bei Berstein, Histoire 1, passim.

${ }^{274}$ Ziebura, Blum, S. 340.

275 Vgl. oben S. 474 f. zur Kritik in Le Temps. 
Strategie, um einerseits den Zusammenhalt der Partei zu wahren und andererseits ein relatives Höchstmaß an Verläßlichkeit bei der parlamentarischen Unterstützung einer Kartellregierung zu erreichen.

- Erstaunlicherweise haben die Verwerfungen innerhalb des Parti radical bei der Analyse des Scheiterns des Linkskartells in der Literatur bislang kaum eine Rolle gespielt ${ }^{276}$. Auch diese Problematik zeigte sich in der Abgeordnetenkammer erst relativ spät bzw. nur schwach. Sieht man von dem eben erwähnten finanzpolitischen Debakel im Sommer 1925 ab, dann blieb die radikale Fraktion weitgehend eine Stütze der wechselnden Kabinette. Immerhin aber wurde die im November 1925 beim Sturz der Regierung Painlevé III von der Mehrheit der Gauche radicale vollzogene Absetzbewegung zur Mitte-rechts-Opposition auch von 16 Abgeordneten des Parti radical unterstützt. Angesichts des knappen Abstimmungsergebnisses (275:278) war dies durchaus ein relevanter Faktor. Die kleine Fraktion der Républicains-socialistes hingegen, dies sei nur kurz angemerkt, wahrte die seit Bildung der ersten Kartellregierung weitestgehend bewiesene Disziplin $^{277}$. Angesichts der starken ministeriellen Stellung der Républicains-socialistes während der Regierungszeit ihres Ehrenvorsitzenden Painlevé verwundert dieses Verhalten kaum ${ }^{278}$.

Das entscheidende Kohärenzproblem des Parti radical lag im Senat. Der extrem starke Gegenwind, der dem Linkskartell aus der französischen Wirtschaft und aus der liberal-konservativen Presse entgegenwehte, fand hier weitaus mehr Angriffsflächen als im Regierungslager der Abgeordnetenkammer. Zwar ist unklar, wieviele Senatoren der Gauche démocratique radicale et radicale-socialiste, wie die große Linksfraktion mit vollem Namen hieß, dem Parti radical angehörten. Daß es die Mehrzahl war, dürfte aber ebenso außer Zweifel stehen wie der Umstand, daß ein erheblicher Teil der radikalen Senatoren sich noch weniger in die Linie der Parteiführung fügte als die radikalen Deputierten in der Abgeordnetenkammer.

Kompliziert wurde die Lage innerhalb des Parti radical noch dadurch, daß zu den inhaltlichen Differenzen eine wachsende Konkurrenz zwischen Herriot, dem aktuellen, und Caillaux, dem früheren Parteivorsitzenden, hinzutrat. Letzterer hatte den Aufstieg Herriots schon lange argwöhnisch beäugt und positionierte sich nun im Gegensatz zu seiner ersten politischen Karriere vor dem Ersten Weltkrieg eher am sozialkonservativen rechten Parteiflügel. Passend dazu fand der gerade ernannte Finanzminister Mitte Juli 1925 in einer Nachwahl eine neue parlamentarische Heimat als Senator der Gauche démocratique 279 . Die vom Linkskartell betriebene Amnestie und politische Rehabilitierung von Caillaux führte so auf die Dauer zu einer fatalen Belastung der innerparteilichen Kohärenz und damit auch des Zusammenhalts im linken Regierungsbündnis. Der Parti radical wurde in der Person von Caillaux auf unerwartete Weise von der eigenen Vergangenheit eingeholt.

276 Gerade in Berstein, Histoire 1, und in ders., Herriot, wird die Bedeutung der internen Differenzen des Parti radical für die Auflösung des Linkskartells kaum thematisiert. Statt dessen wird hier die Verantwortung immer wieder einseitig bei den Sozialisten gesucht.

277 Vgl. die Ergebnisse in Tab. 14, 16 und 18 oben S. 445, 458 und 462.

${ }^{278}$ Zur Disziplin der Fraktion vgl. auch Billard, Parti républicain-socialiste, S. 396-400. Der Autor spricht von „le pilier le plus solide du Cartel“.

${ }^{279}$ Am 12. 7. 1925 bei einer Nachwahl zum Senat. 
2. Mit dem faktischen Ende des Linkskartells im November 1925 begann eine gut halbjährige Krisenphase, in der sich während der Amtszeiten der Kabinette Briand VIII-X die Probleme der regierungstragenden Funktion noch erheblich verstärkten. Der in der Literatur verbreitete Begriff des „reflux“ der parlamentarischen Mehrheitsverhältnisse entgegen der in den Wahlen von 1924 vorgegebenen Richtung ${ }^{280}$ hat in diesem Zusammenhang einen geradezu euphemistischen Beiklang. Während 1925 die entscheidenden Schwierigkeiten zunächst im Senat aufgetreten waren und erst danach auch auf die Abgeordnetenkammer übergriffen, herrschte nun in der Kammer das Problem einer "majorité introuvable“. Warum führte, so ist zu fragen, der seit Ende 1925 in verschiedenen Varianten unternommene Versuch, das Regierungsspektrum in die politische Mitte zu verschieben, bis zur großen Wende vom Sommer 1926 nicht zu einer Stabilisierung der Mehrheiten in der Abgeordnetenkammer? Und warum nahm die Regierungsbildung nun eine für französische Verhältnisse ungewohnt zähe Form an?

Eigentlich eröffnete gerade die Person des Ministerpräsidenten die Aussicht auf eine flexible Regierungsbildung und Regierungspraxis. Briand stand deutlich weiter in der Mitte als sein Fraktionskollege Painlevé, war bereits mehrfach und auch zu Zeiten des Bloc national Regierungschef gewesen, beherrschte meisterhaft die Spielregeln des traditionellen französischen Parlamentarismus und galt in schwierigen Verhandlungen - wie Clemenceau einmal boshaft bemerkt hat - als "monstre de souplesse" 281 . Grundsätzlich ist jedoch zu bedenken, daß sich im Vergleich zu den Verhältnissen vor dem Ersten Weltkrieg die parlamentarische Bastion der politischen Mitte starke Einbußen erlitten hatte. Die konservative Fédération républicaine hatte zwar die 1919 eroberte Dominanz in den Wahlen vom 11. Mai 1924 wieder verloren ${ }^{282}$, das Wachstum der sozialistischen und kommunistischen Linken (1924 in der Summe 130 Abgeordnete ${ }^{283}$ ) hatte aber dafür gesorgt, daß die Spielräume der liberalen Mitte eng blieben. Eine Regierungsbildung im Sinne einer concentration républicaine zwischen den Kräften des linken und des rechten Liberalismus, wie sie unmittelbar nach den Wahlen vereinzelt gefordert bzw. für möglich gehalten worden war, hätte 1925/26 zwar über eine knappe Kammermehrheit verfügt (über 300 Mandate für alle Fraktionen von den Républicainssocialistes bis zu den Républicains de Gauche), bei den notorischen Disziplinproblemen gerade in diesem Teil des politischen Spektrums wäre dies aber selbst in einer ökonomisch weniger krisenhaften Lage eine unsichere Basis gewesen.

Verhindert wurde eine Neukonstruktion des Regierungslagers im Sinne einer concentration vor allem durch die vorausgegangene Blockbildung auf der Linken und im Mitte-rechts-Spektrum. Die einst mit großen Hoffnungen verbundene Kartellidee besaß auch nach dem Sturz der Regierung Painlevé III noch eine gewisse Attraktivität ${ }^{284}$, und die Bereitschaft der rechtsliberalen Fraktionen zu einer

280 Vgl. v.a. Delcros, Majorités de reflux.

${ }^{281}$ Zur Äußerung Clemenceaus s. Art. „Briand“, in: Dictionnaire des ministres, S. 387-389, hier S. 388.

282 Aus 183 Mandaten für die Fraktion der Entente républicaine démocratique wurden 104 Mandate für die Union républicaine démocratique.

283 Im Vergleich dazu: 1906 verfügte die SFIO über 54 Mandate, 1910 über 75, 1914 über 104. Zahlen nach Mayeur, Vie politique, S. 213, 222, 230.

284 Dies gilt v.a. für die Basis des Parti radical. Vgl. Berstein, Histoire 1, S. 424. 
Kooperation der Mitte unter Ausschluß der konservativen Kräfte blieb sehr beschränkt. Letzteres zeigte sich vor allem in den Problemen der Kabinettsbildung. Briand fiel es sehr schwer, Kabinettsmitglieder rechts vom Parti radical zu gewinnen. Die Regierungen Briand VII-X besaßen daher jeweils einen radikalen Schwerpunkt und verfügten nur über einzelne „Brückenköpfe“ zur rechten Mitte. Die parlamentarische Basis blieb somit schwach. Hinzu kam, daß die informelle Kooperation zwischen der Regierung und den Fraktionen des Regierungslagers in der Abgeordnetenkammer, wie es sie unter den Regierungen Painlevés im Zeichen einer Délégation des Gauches noch gegeben hatte, nun offenbar zum Erliegen gekommen war. Selbst auf das engere Regierungslager von Radicaux und Républicains-socialistes war unter diesen Umständen wenig Verlaß285, so daß Briand es immer öfter nicht mehr wagte, das traditionelle Disziplinierungsmittel der Vertrauensfrage einzusetzen ${ }^{286}$. Ohne die partielle Tolerierung durch Teile der Sozialisten mittels Stimmenthaltung wäre selbst das außergewöhnliche parlamentarische Geschick Briands noch sehr viel früher am Ende gewesen.

Die einzige Möglichkeit, die rechtsliberalen Kräfte in das Regierungslager einzubeziehen, lag in einer Union-nationale-Strategie unter Einschluß der konservativen Union républicaine démocratique. Alle Versuche in diese Richtung stießen allerdings auf vehemente Widerstände innerhalb des Parti radical, zu stark waren hier - gerade nach den Ereignissen in der Anfangsphase des Kartells - die Vorbehalte gegen die als klerikal geltende parlamentarische Rechte. Die Möglichkeiten einer Regierungsbildung auf der Linken bzw. in der politischen Mitte mußten, wie die späteren Ereignisse zeigen sollten, erst vollständig diskreditiert sein, die Währungskrise mußte erst einen weiteren Höhepunkt erreicht haben, vor allem aber mußte Herriot, der Hauptstratege einer radikalen Kartellpolitik, selbst an der Spitze eines derartigen Kurswechsels stehen, damit er ohne Zerbrechen der Partei vollzogen werden konnte.

Die verfahrene parlamentarische Situation schien demnach seit Ende 1925 keinen praktikablen Ausweg zu besitzen, solange es nicht zum völligen Debakel der regierenden Radicaux und Républicains-socialistes gekommen war. In dieser Lage wuchs in der politischen Öffentlichkeit eine Welle des „esprit antiparlementaire" 287 , die in ihren Ursachen gleich noch näher zu betrachten sein wird.

Vielleicht wäre hier eine Kammerauflösung ein geeignetes Mittel gewesen, um für neue Mehrheitsverhältnisse und auch für neue politische Legitimation zu sorgen, nachdem das siegreiche Wahlbündnis von 1924 so offensichtlich Schiffbruch erlitten hatte. $\mathrm{Zu}$ einer ernsthaften Diskussion dieses Auswegs kam es allerdings nicht 288 . „Depuis Mac-Mahon“, so stellte Bonnet in diesem Zusammenhang in seinen Erinnerungen fest, "la dissolution apparaissait comme une manière d'attentat contre la République et comme un pas vers la dictature." $289 \mathrm{Zweifellos}$ hatte die

${ }^{285}$ Zur nachlassenden Disziplin der Républicains-socialistes in der Regierungszeit Briands vgl. auch Billard, Parti républicain-socialiste, S. 411.

286 Vgl. auch die scharfe Kritik von André Tardieu, Impressions d'un nouveau élu. Discours prononcé le 28 avril 1926 par M. André Tardieu au déjeuner de „L'Union du commerce et de l'industrie pour la défense sociale“; AAE Paris, Papiers Herriot, 12, Bl. 5-8, hier Bl. 7.

287 Vgl. oben S. 4, Anm. 16, Zitat aus Le Temps.

288 Dies gilt im übrigen auch für die Literatur.

289 Bonnet, Vingt ans, S. 115. Bonnet hielt nach dem Sturz der Regierung Painlevé III am 22. 11.1925 
Schlacht des Linkskartells gegen die präsidentiellen Ansprüche Millerands zu einer Auffrischung und Verstärkung des Tabus der Kammerauflösung geführt. Vermutlich wirkte, wie der deutsche Botschafter Anfang März in einem Bericht meinte ${ }^{290}$, aber auch das immer noch gültige Wahlrecht als Blockade für einen durchaus sinnvollen und systemimmanenten Einsatz des präsidentiellen Auflösungsrechtes, denn die Prämierung breiter Listenverbindungen stand inzwischen im Gegensatz zu den aktuellen parlamentarischen Realitäten: Das Linkskartell zerfiel, und im Mitte-rechts-Spektrum herrschte eine verworrene Lage. Unter diesen Umständen konnte keine der großen politischen Kräfte Interesse an baldigen Neuwahlen haben.

IV. In unserer Analyse der wesentlichen parlamentarismusgeschichtlichen Entwicklungen seit Regierungsantritt des Cartel des Gauches soll nun abschließend der Frage nachgegangen werden, in welcher Weise und in welchem Ausmaß während jener zwei Jahre die parlamentarische Alternativfunktion zur Geltung gekommen ist. Von verschiedenen Aspekten der Oppositionspolitik war in den vorstehenden Ausführungen ja bereits die Rede, eine funktionale Bewertung steht aber noch aus.

Die parlamentarische Opposition spielte in den Zeiten der Kartellregierungen eine lebhafte Rolle und nutzte auf intensive Weise alle Mechanismen der Kontrollfunktion und nicht selten auch der Obstruktion. Die Alternativfunktion wurde dabei auf traditionelle Weise ausgefüllt: Inhaltliche Ad-hoc-Alternativen ergaben sich im Rahmen der parlamentarischen Verhandlungsprozesse, von einer systematischen Konfrontation der Regierungspolitik mit oppositionellen Vorstellungen konnte aber keine Rede sein. Kurzfristige Alternativen der Regierungsbildung eröffneten sich - allerdings wie beschrieben nur in kleinen und mühsamen Schritten - nach Demission des vorhergehenden Kabinetts. Gemessen an den Maßstäben des deliberativen Parlamentarismus kann also von Störungen der Alternativfunktion in den Jahren 1924-26 keine Rede sein.

Dennoch wuchs in Teilen der politischen Öffentlichkeit eine grundsätzliche Unzufriedenheit mit dem parlamentarischen System. Dies äußerte sich nicht nur in einer parlamentarismuskritischen Rhetorik rechtsliberal-konservativer Kreise, wie sie oben am Beispiel von Le Temps vorgestellt wurde291. Auch der markante und in der Forschung vielbeachtete Aufschwung rechtslastiger bzw. rechtsextremer außerparlamentarischer Organisationen läßt sich in diesem Zusammenhang anführen ${ }^{292}$. Erinnert sei an die beiden bereits 1924 gegründeten Verbände, die in

eine Auflösung für sinnvoll. In der parlamentarischen Gerüchteküche der couloirs war Ende November 1925 von diesem Mittel ebenfalls die Rede. Vgl. Note Jean, 30.11. 1925; AN Paris, F7 12953, Bl. 935: „Il [die neue Regierung Briand IX] réclamera le rétablissement, aussi rapide que possible, du scrutin d'arrondissement, prélude d'une dissolution, si nous en croyons certains commentateurs."

290 Botschaftsbericht-Paris (Hoesch), Tel. Nr. 236, 6. 3. 1926, S. 3: „Lage wird noch besonders dadurch kompliziert, dass selbst Hilfsmittel der Auflösung Parlaments augenblicklich wenig praktisch [unterstrichen] ist, da niemand im Lande Lust hat, mit dem gegenwärtig unsinnigen Wahlrecht, dessen Abänderung in wenigen Tagen in Angriff genommen werden sollte, in Wahlkampf zu gehen." PA AA Berlin, R 70717. - Zu einer Wahlrechtsänderung kam es erst im Sommer 1927.

$291 \mathrm{Vgl}$, oben S. $474 \mathrm{f}$.

${ }^{292}$ Vgl. v.a. Soucy, French Fascism, S. 27-184; Douglas, From Fascism to Libertarian Communism, 
erster Linie bürgerliche Sammlungs- und Protestbewegungen gegen den Anfangselan des Linkskartells und gegen die vermeintlich wachsende kommunistische Gefahr darstellten: Vom ehemaligen Staatspräsidenten Millerand wurde zusammen mit führenden liberalen und konservativen Parlamentariern - darunter Pierre-Etienne Flandin, André Maginot und Louis Marin ${ }^{293}$ - die Ligue républicaine nationale ins Leben gerufen. General Edouard de Castelnau, in Zeiten des Bloc national Kammerabgeordneter der Entente républicaine démocratique, Vorsitzender des Armeeausschusses und Präsident der alten Ligue des Patriotes, gründete die Fédération nationale catholique. Beide Verbände erreichten bis 1925 eine hohe Mitgliederzahl (rund 300000 in der Ligue républicaine nationale und 1800000 in der Fédération nationale catholique ${ }^{294}$ ). Radikaler und in mancherlei Hinsicht geprägt von faschistischen Einflüssen waren die ebenfalls bereits Ende 1924 im Rahmen der Ligue des Patriotes gegründeten Jeunesses patriotes des Champagnerfabrikanten und Kammerabgeordneten Pierre Taittinger (Union républicaine démocratique) sowie der seit Anfang 1926 auf Initiative des MaurrasSchülers Georges Valois formierte paramilitärische Faiscean.

Diese „erste Welle“ ${ }^{295}$ rechtsextremer Mobilisierung in der französischen Zwischenkriegszeit, die in einer autochthonen bonapartistischen Tradition stand, aber auch ausländische Vorbilder nachahmte, kann insgesamt als Reaktion auf die Regierung des Linkskartells, auf die Währungs- und Inflationskrise und auf die verstärkte parlamentarische und öffentliche Präsenz der Kommunisten ${ }^{296}$ verstanden werden. In der Forschung wurde dies in vielfacher Hinsicht expliziert. Von Interesse für unsere Untersuchung ist aber vor allem die speziellere Frage, inwieweit sich hier auch ein Problem der parlamentarischen Alternativfunktion spiegelte.

Wie oben ausgeführt wurde, stellte die Bildung der ersten Kartellregierung auch einen Anlauf zu einer disziplinierten, kohärenten und damit auch moderneren Ausfüllung der regierungstragenden Funktion dar. Verbunden war dieser Anlauf mit hochfliegenden linken Erwartungen und Hoffnungen sowie einer ganzen Reihe hochsymbolischer Akte und Projekte. Die traditionelle Art und Weise, in der die Kräfte der Mitte-rechts-Opposition die parlamentarische Alternativfunktion wahrnahmen, gab hierzu sicher keine adäquate Antwort. Von einer dem Linkskartell analogen blockartigen Verfestigung der Opposition konnte keine Rede sein, klare inhaltliche Alternativen zur Regierungspolitik wurden nicht entwickelt - dies betrifft vor allem das Feld der Finanzpolitik, wo allgemeine Konfu-

S. 67-121; Wirsching, Vom Weltkrieg zum Bürgerkrieg?, S. 271-298. Überblick zur Entwicklung der Ligen in der Zwischenkriegszeit vgl. Defrasne, L'antiparlementarisme en France, S. 59-77.

${ }^{293}$ Flandin und Maginot gehörten der Gauche républicaine démocratique an, Marin der Union républicaine démocratique. Flandin, der im kurzlebigen Kabinett François-Marsal erstmals für wenige Tage ein Ministeramt innegehabt hatte, war sogar Fraktionsvorsitzender. Zur politischen Vorstellungswelt des späteren Vorsitzenden der Alliance démocratique und Ministerpräsidenten vgl. jetzt Mayaffre, Le poids des mots, v.a. S. 292-356. Zu Marin vgl. oben S. 96.

294 Zahlen nach Wirsching, Vom Weltkrieg zum Bürgerkrieg?, S. 280.

295 Vgl. den Untertitel „First Wave“ bei Soucy, French Fascism.

${ }^{296}$ Ein wichtiges Signal war die große kommunistische Demonstration bei Überführung der sterblichen Überreste ins Panthéon am 23.11. 1924. Wirsching, Vom Weltkrieg zum Bürgerkrieg?, S. 284 f. (Zitat S. 284), spricht vom „spektakulären Höhepunkt dieser als Bedrohung empfundenen kommunistischen Präsenz in den Straßen von Paris“. Zur kommunistischen Propaganda vgl. auch ders., Kleinbürger für den Klassenkampf? 
sion herrschte -, eine deutliche Alternative für einen Regierungswechsel bestand bis Mitte 1926 nicht.

Daran erinnert sei, daß führende Vertreter der konservativen Entente républicaine démocratique bereits in Zeiten des Bloc national vergeblich auf eine Festigung und eine klarere Positionierung des damals noch im Regierungslager befindlichen Mitte-rechts-Spektrums hingearbeitet haben ${ }^{297}$. Auch jetzt in der Opposition gelang dies nicht: Teile der rechtsliberalen Modérés zeigten sich partiell zur Kooperation mit den linksliberalen Kabinetten bereit. Zudem hatten die seit 1924 in der Union républicaine démocratique vertretenen konservativen Kräfte bei den Kammerwahlen stark an parlamentarischem Boden verloren ${ }^{298}$. Es überrascht daher nicht, daß es zwischen den außerparlamentarischen Ligen und der parlamentarischen Rechten personelle Verbindungen gab.

Das Wachstum der außerparlamentarischen Opposition erscheint demnach einerseits als Folge der Kartellpolitik und andererseits als Konsequenz aus dem Fehlen eines klar definierten parlamentarischen "Gegenblocks“ auf der Rechten. Die sowohl in den rechten Verbänden als auch in systemloyalen Kreisen grassierende Parlamentarismuskritik erwuchs zudem, wie bereits dargestellt, aus den neuartigen Ansätzen eines parteiengestützten Parlamentarismus sowie aus den offensichtlichen Störungen der regierungstragenden Funktion. Es verwundert daher nicht, daß die vor allem von Millerand mit seiner Ligue républicaine nationale propagierten Vorstellungen einer „réforme d'Etat“, die sich auf eine Machtbeschneidung des Parlaments und auf die im zurückliegenden Verfassungskampf gescheiterte Revitalisierung der präsidentiellen Position bezogen, an Resonanz gewannen 299 . Extreme Kräfte wie der Faisceau-Führer Georges Valois träumten sogar schon davon, daß ihnen Staatspräsident Doumergue angesichts der parlamentarischen Unfähigkeit bei einem weiteren Verfall des Franc an die Macht verhelfen werde ${ }^{300}$.

Eine andere Konsequenz aus der Krisenlage zog der energiegeladene André Tardieu, der in der Phase des Bloc national einer der profiliertesten jüngeren Parlamentarier gewesen war und der im April 1926 - nach seinem Scheitern am 11. Mai 1924 und anschließender „zweijähriger Verschollenheit“301 - dank einer Nachwahl wieder in die Kammer zurückkehrte. In einer „Impressions d'un nouvel élu" betitelten Rede vor einem Wirtschaftsverband zeichnete er aus Sicht seines Wahlkreises, des Territoire de Belfort, ein extrem kritisches Bild des aktuellen französischen Parlamentarismus und seiner für den Wähler immer unverständlicher werdenden Wirren und Debatten ${ }^{302}$. Als Antwort hierauf entwarf Tardieu

${ }^{297}$ Vgl. Kap. I.2 und I.4 (Zweiter Teil, B).

${ }^{298}$ Zum langsam beginnenden "dérive“ der Fédération nach rechts am regionalen Beispicl 1924-26 vgl. Bernard, La dérive des modérés, S. 315-317.

299 Vgl. v.a. Gicquel, Le problème de la réforme de l'Etat.

${ }_{300}$ Vgl. Douglas, From Fascism, S. 121-125. Valois ging dabei offenbar von dem Vorbild der faschistischen Machtübertragung durch den König in Italien aus.

301 Botschaftsbericht-Paris (Hoesch), Tel. Nr. 736, 23. 7. 1926, S. 4; PA AA Berlin, R 70717.

302 André Tardieu, Impressions d'un nouveau élu. Discours prononcé le 28 avril 1926 par M. André Tardieu au déjeuner de „L'Union du commerce et de l'industrie pour la défense sociale“; AAE Paris, Papiers Herriot, 12, Bl. 5-8, hier Bl. 6R, zur verwirrenden Instabilität: „Vous croyez, Messieurs, qu'on prend cela au sérieux dans nos provinces? Pas un instant. On trouve cette façon de faire intolérable. On l'impute d'abord aux députés. Nos discussions, par leur violence, par leur in- 
bereits die Grundlinien seiner späteren - vergeblichen - Bemühungen als Ministerpräsident (1929-30 und 1932): Überwindung der traditionellen politischen Fronten und Reformierung traditioneller parlamentarischer Verfahren durch eine energische Führung der Regierung, gestützt auf eine neuartige Mehrheit reformwilliger Parlamentarier ${ }^{303}$.

Alles in allem ergibt sich ein ambivalentes Urteil über die Ausübung der parlamentarischen Alternativfunktion in den zwei Jahren von Mitte 1924 bis Mitte 1926. Einerseits gab es in der Abgeordnetenkammer ständig fluktuierende Adhoc-Alternativen traditioneller Art. Andererseits fehlte es sowohl an klaren inhaltlichen Alternativen der Opposition als auch an einer deutlich unterscheidbaren Option für die Regierungsbildung. Infolge der Mehrheitsverhältnisse war eine grundlegende Alternative zu den Modellen einer Kartellregierung und auch zu den seit Briand IX praktizierten Mehrheitsbildungen der linken Mitte nicht zu erkennen. Nur die Möglichkeit einer Kammerauflösung und anschließender Neuwahlen hätte einer derartigen Alternative eine realistische Attraktivität gegeben.

Unter den gegebenen Bedingungen blieb nur die Hoffnung auf eine breite Kabinettsbildung der Union nationale von den Radicaux bis zur parlamentarischen Rechten. Mancher dachte sogar an eine Einbeziehung der Sozialisten, eine „union de Blum à Marin“304. Die jetzt etwas ausführlicher zu betrachtenden Ereignisse vom Juni und Juli 1926, die das dramatische Finale der im Mai 1924 begonnenen parlamentarismusgeschichtlichen Phase darstellten, sollten den Weg für eine derartige Lösung der Union nationale freimachen.

\section{Höhepunkt der Krise im Sommer 1926: Verweigerung einer Ermächtigung für die Regierung Briand $X$ und das endgültige Scheitern des Kartells}

Im Sommer 1926 erreichte die Krise in mehrfacher Hinsicht ihren Höhepunkt. Der Währungsverfall nahm nun dramatische Formen an. Hatte der Dollar im März noch knapp 28 Francs gekostet, so stieg sein Wert bis zum Juni auf 34 und Ende Juli auf fast 50 Francs $^{305}$. Gleichzeitig erfolgten die letzten verzweifelten Rettungsversuche einer von der linken Mitte, d.h. in erster Linie vom Parti radical dominierten Regierungsbildung - Versuche, die den offenen Bankrott des 1924 er-

cohérence, par leur rétrospectivité, par leur caractère nocturne, ennuient et irritent l'électeur. Il n'y comprend rien./ Comme disait M. Louis Dubois [offenbar der Vorredner von der gastgebenden Union du commerce et de l'industrie pour la défense sociale], c'est trop obscur pour qu'il puisse suivre. J'ajouterai que souvent c'est aussi obscur pour nous, les élus, que pour lui, l'électeur. (Rires et applaudissements.)"

${ }^{303}$ Zur Regierungspraxis von Tardieu, der letztlich auch auf ein am englischen Beispiel orientiertes Zweiparteiensystem zielte, vgl. v.a. Monnet, Refaire la république, S. $106 \mathrm{f}$. Zur weiteren, immer mehr an den rechten Rand des Systems drängenden Entwicklung: Roussellier, André Tardieu et la crise du constitutionnalisme libéral; Mayaffre, Le poids des mots, S. 607-739. Allgemein zu Tardieu auch Junot, André Tardieu.

$304 \mathrm{Vgl}$. als Beleg für die Verbreitung „dans la presse et dans les couloirs du Parlement“ : André Tardieu, Impressions d'un nouveau élu. Discours prononcé le 28 avril 1926 par M. André Tardieu au déjeuner de "L'Union du commerce et de l'industrie pour la défense sociale"; AAE Paris, Papiers Herriot, 12, BI. 5-8, hier Bl. 8R.

${ }_{305}$ Vgl. oben S. 451, Tab. 15. Extremwert war am 20. 7. 1926 die Noticrung von 49,22 Francs für einen Dollar. Vgl. LT, 21.7. 1926, S. 4, "Côte des changes“ (Börsennotierung 20.7.). Falscher Wert für den 20.7. bei Fohlen, Frankreich, S. 107, der das Monatsmittel mit 40,95 angibt. Vgl. Sauvy, Histoire économique 1, S. 445. 
folgten Neuansatzes markierten und gleichzeitig die Wende zur Union nationale unter Poincaré vorbereiteten. Und schließlich markiert der Konflikt um die von der Regierung Briand X geforderte legislative Ermächtigung einen Höhepunkt in den Auseinandersetzungen um das Mittel der décrets-lois während der Inflationskrise.

Seit Regierungsantritt des Cartel des Gauches und der sofortigen Vorlage eines Gesetzes zur Aufhebung der dem Parlament von Poincaré abgetrotzten Legislativermächtigung war dieses umstrittene Kriseninstrument kein Thema mehr gewesen. Inzwischen aber hatten die wachsenden Probleme der regierungstragenden Funktion und auch die hartnäckigen Kämpfe um immer neue Finanz- und Stabilisierungsprojekte ein derartiges $\mathrm{Maß}$ angenommen und die Krisenlösungskapazität der regulären Gesetzgebung derart diskreditiert, daß auch die Frage nach décrets-lois wieder in den Vordergrund trat. Bereits während der Bildung des Kabinetts Briand X war in politischen Kreisen davon die Rede ${ }^{306}$, und Briand selbst, der als Ministerpräsident während des Ersten Weltkriegs eine breite Ermächtigung hatte durchsetzen wollen und 1924 keineswegs zu den exponierten Kritikern Poincarés gehört hatte ${ }^{307}$, bestätigte am 23. Juni, daß seine Regierung im Bereich der Wirtschaft pleins pouvoirs anstrebe ${ }^{308}$.

Der 1924 noch sehr selten gebrauchte hypertrophe Begriff der pleins pouvoirs trat nun plötzlich in den Mittelpunkt der Diskussion. Vermutlich ging dies auf Caillaux zurück, der eine erneute Übernahme des Finanzressorts von einer weitreichenden Vollmacht abhängig gemacht hatte ${ }^{309}$. Hiefür gab es die naheliegenden sachlichen Gründe einer extrem labilen Mehrheit und eines unberechenbaren regulären Gesetzgebungsverfahrens. Möglicherweise spielten aber auch Motive eine Rolle, die in der Persönlichkeit von Caillaux lagen. Es sei daran erinnert, daß der damalige radikale Parteichef bereits während des Krieges für den Fall einer Berufung zum Ministerpräsidenten mit seinem berühmt gewordenen „plan Rubicon“ weitreichende Ermächtigungspläne gehegt hatte ${ }^{310}$. Ganz im Gegensatz zu Herriot war seine ideologische Verbundenheit mit den Traditionen des französischen Parlamentarismus wohl nur schwach ausgeprägt; Caillaux sah sich vielmehr als pragmatischen und handlungsstarken Finanzexperten. In den langen Jahren der politischen Kaltstellung, juristischen Verfolgung, patriotischen Diskreditierung, mühsamen Rehabilitierung und schließlich auch in der jüngsten Konfrontation mit Herriot hatte sein Selbst- und wohl auch Sendungsbewußtsein geradezu megalomanische Züge angenommen. Bezeichnend hierfür ist, daß er am 23. Juni in

306 Note Jean, 23. 6. 1926, „Au sujet de la formation d'un ministère Briand-Caillaux“; AN Paris, F7 12954/2, Bl. 740f.: [...] „Enfin, on prétend, dans certains milieux politiques, que M. Caillaux s'il obtient, comme il l'espère, les pleins pouvoirs, en matière financière, exercerait, à la première occasion, des poursuites judiciaires contre certains établissements de crédit, notamment contre la Direction de la ,Banque de Paris et des Pays Bas', en visant plus spécialement M. FINALY.“

$307 \mathrm{Vgl}$. oben S. 394 und 406.

${ }^{308} L^{\prime}$ Euvre, 24. 6. 1926, S. 2, "Comment s'est formé le dixième ministère Briand“, Untertitel: „Les pleins pouvoirs": „Et les pleins pouvoirs?/ - Cette formule, dont on a beaucoup parlé, répliqua M. Briand, ne s'appliquera qu'aux économies."

309 Ebd. Caillaux antwortete demnach auf die Frage, ob er Finanzminister werde, dies sei wahrscheinlich, „mais avec les conditions que j'ai toujours dites. J'estime qu'on ne peut prendre le portefeuille des finances sans avoir tout le pouvoir".

$310 \mathrm{Vgl}$. Text unten S. 491, Anm. 360. 
einem Presseinterview seine künftige Rolle als bevollmächtigter „Konsul“ neben Briand sah ${ }^{311}$.

Die Regierungserklärung Briands hatte am 29. Juni in finanzpolitischer Hinsicht kaum mehr als Allgemeinplätze geboten. Da Finanzminister Caillaux zunächst abwartete, bis das im Mai eingesetzte Expertenkomitee am 4. Juli sein Gutachten veröffentlichte, kam es erst am 6. Juli zu einer finanzpolitischen Grundsatzrede des neuen Ministers ${ }^{312}$. Die vorgesehenen und in wesentlichen Punkten dem Expertenplan folgenden Leitlinien eines „redressement financier“ brauchen hier im einzelnen nicht diskutiert zu werden. Besondere Bedeutung kam dem erneuten Versuch zu, durch Reduzierung der direkten Steuern Vertrauen der Anleger zurückzugewinnen und gleichzeitig durch Erhöhung indirekter Steuern neue Einnahmequellen zu erschließen. Das letztgenannte Vorhaben mußte Caillaux die scharfe Gegnerschaft der Sozialisten zuziehen ${ }^{313}$. Zukunftsweisend waren die Bereitschaft zu einer Abwertung des Franc und das Vorhaben, eine von der Regierung unabhängige Kasse zur Rückzahlung von Anleihen zu schaffen ${ }^{314}$. Eine Schlüsselstellung in den Plänen von Caillaux besaß schließlich die Gewinnung von großzügigen ausländischen Anleihen, was die Ratifizierung des im April 1926 in Washington vom damaligen Finanzminister Péret geschlossenen Schuldenabkommens mit den Vereinigten Staaten notwendig machte ${ }^{315}$. In einer leidenschaftlich vorgetragenen Rede ${ }^{316}$ forderte der Finanzminister auch die Erteilung einer parlamentarischen Ermächtigung. Die notwendigen Maßnahmen müßten mit einer Schnelligkeit getroffen werden, „que ne comporte pas le mécanisme parlementaire" 317 .

Im Vergleich zu den heftigen Kontroversen um das relativ bescheidene Ermächtigungsgesetz von 1924 fällt auf, daß sich nach den weitreichenden Ankündigungen von Caillaux die verfassungspolitische Erregung in Grenzen hielt. Zweifellos gab es in parlamentarischen Kreisen erhebliches Mißtrauen gegen die Person des neuen Finanzministers. In den couloirs der Kammer betrieben zudem, so Bonnet in seinen Memoiren, die Anhänger Herriots eine heftige Kampagne gegen

311 L'CEuvre, 24. 6. 1926, S. 2, „Comment s'est formé le dixième ministère Briand“: „Naturellement, je ne vois aucune difficulté à le [tout le pouvoir] partager avec mon ami Briand./ Et M. Caillaux ajouta en souriant:/ - Les deux consuls, quoi...".

312 JO, Débats, Chambre 1926 (2. Sitzung 6.7.), S. 2730-2736. Vgl. zum Kontext Bonnefous, Histoire 4, S. 149-151, allgemein zu den Plänen von Caillaux auch Néré, Problème, S. $123 \mathrm{f}$.

313 Sofort nach Bekanntwerden des Expertenplans setzte scharfe Kritik von links ein. So trat der Abgeordnete Renaudel auf einer SFIO-Veranstaltung in Paris am 5. 7. 1926 auf. Ein Polizeibericht vom 6.7. vermerkt hierzu: „M. Renaudel répondant à Montignon, s'étonne qu'un socialiste accepte le plan des Experts et fasse confiance au Ministre des Finances actuel. ,Dans leur plan, dit-il, les Experts se sont attachés à ne pas toucher à la richesse acquise et à tout demander aux classes laborieuses. Quant à faire confiance à M. Caillaux, nous ne le pouvons pas, en raison de son manque de stabilité politique; ne venons-nous pas de constater qu'en deux jours, il a changé plusieurs fois d'idée'."AN Paris, F7 13080.

314 Vgl. zur Realisierung unter Poincaré unten S. 512.

315 Vgl. hierzu Bonnefous, Histoire 4, S. $134 \mathrm{f}$.

316 Zur unfreiwilligen Komik, als sich ein erregter Finanzminister am Ende auf ein Verlaine-Gedicht über den Untergang des byzantinischen Reiches bezog (JO, Débats, Chambre 1926, hier S. 2736), vgl. Bonnet, Vingt ans, S. $115 \mathrm{f} .:$ „[...] la Chambre fut prise d'une sorte de fou rire qui détruisit l'effet excellent jusqu'alors obtenu“.

317 JO, Débats, Chambre 1926, S. 2734. Zur Begründung verwies der Minister u.a. auf die Gefahr langwieriger amendements. 
Caillaux, wobei offenbar auch die Erinnerung an den „plan Rubicon“ eine Rolle spielte ${ }^{318}$. Von Anfang stieß auch das aktuelle Vorhaben einer Ermächtigung auf Widerstände in der informellen parlamentarischen Diskussion ${ }^{319}$.

Im Plenum blieb die explizit verfassungspolitische Ablehnung zunächst jedoch schwach. Dies zeigte sich am 7. Juli in der Debatte, die auf die Rede von Caillaux folgte ${ }^{320}$. Zwar schlug dem Finanzminister breite Kritik entgegen, insbesondere von Marin und Blum im Namen der Union républicaine démocratique und der SFIO sowie von Tardieu, der seit seinem Wiedereinzug in die Kammer als fraktionsloser Einzelkämpfer auftrat ${ }^{321}$. Bei aller Unterschiedlichkeit der inhaltlichen Akzente fürchteten Marin, Blum und Tardieu die mit der Ermächtigung gegebene Erweiterung des politischen Spielraums von Caillaux. Am schärfsten war dabei Blum, der in einer dreistündigen Rede die finanzpolitischen Grundlinien der neuen Regierung scharf attackierte. Gemeinsam war den drei genannten Abgeordneten die Sorge, Caillaux könne eine Ratifizierung des Washingtoner Schuldenabkommens auf dem Verordnungsweg vollziehen. Auf die für Frankreich ungünstigen Bedingungen dieser Vereinbarung hatte zuvor auch Henry Franklin-Bouillon, Vorsitzender des Auswärtigen Ausschusses und eigentlich Parteifreund von Caillaux, hingewiesen ${ }^{322}$. Grundsätzliche Kritik am Mittel der Ermächtigung kam nur von Blum. Ein finanzpolitischer Blankoscheck widerspreche den Prinzipien des parlamentarischen Systems, die Sozialisten würden zwar für eine Beschleunigung des parlamentarischen Verfahrens eintreten, sie seien aber gegen eine „abdication" des Parlaments ${ }^{323}$. Was in dieser Plenardebatte im Vergleich zu den Diskussionen von 1924 aber fehlte, war der leidenschaftliche und von republikanischem Pathos getragene Widerspruch seitens der Radicaux und der Républicainssocialistes. Schwer zu entscheiden ist, ob hierfür mehr die Solidarität gegenüber der Regierung Briand entscheidend war oder ob in beiden Fraktionen die verfassungspolitische Sensibilität angesichts der enervierenden Krisen und der sich mehrenden ausländischen Vorbilder für Ermächtigungen ${ }^{324}$ bereits so weit geschwunden war.

Ohnehin war in der Abgeordnetenkammer unter dem Eindruck der Krise inzwischen eine gewisse Bereitschaft gewachsen, vereinfachend in traditionelle Verfahrensweisen der Deliberation einzugreifen. So wurden am 15. Juli die Vorschläge einer Reformkommission unter der Leitung des Abgeordneten und Staatsrechtlers Joseph Barthélemy (Gauche républicaine démocratique) gebil-

${ }^{318}$ Bonnet, Vingt ans, S. 116. Der Rubicon-Plan wird hier ausdrücklich erwähnt.

${ }^{319}$ Note Jean, 24. 6. 1926; AN Paris, F7 12954/1, Bl. 747 f. Die pleins pouvoirs werden hier - neben der Frage des Schuldenabkommens von Washington - zu den "deux points noirs“ der Pläne von Caillaux gezählt.

320 Vgl. Bonnefous, Histoire 4, S. 151-153 (Die entsprechenden Seiten im JO fehlen in der benutzten Ausgabe). Vgl. ähnlich in der Debatte vom 9. 7. 1926; JO, Débats, Chambre 1926, S. 2855-2747 (Marin), 2845-2850 (Blum), 2850-2854 (Tardieu).

321 Bis 1924 war Tardieu Mitglied der Républicains des gauches gewesen. Zum fraktionslosen Status vgl. Botschaftsbericht-Paris (Hoesch), Tel. Nr. 736, 23. 7. 1926, S. 4; PA AA Berlin, R 70717.

322 Nach Bonnefous, Histoire 4, S. 151. Franklin-Bouillon hatte bereits 1917 als "Clemencist“ Caillaux bekämpft.

323 Ebd.

${ }^{324}$ Vgl. auch die explizite Bezugnahme auf Deutschland, Österreich, Polen und die Tschechoslowakei von Caillaux am 6.7.1926 in seiner Kammerrede. JO, Débats, Chambre 1926, S. 2735. Zum aktuellen Bezug auf Belgien vgl. Anm. 339. 
ligt ${ }^{325}$, die eine „Rationalisierung " der in der Geschäftsordnung geregelten Plenardiskussion vorsah. Funktionsträger wie Ausschußvorsitzende und Fraktionsredner kamen fortan - bis zur Revision von 1932 - in den Vorzug längerer Redezeiten, einzelne Abgeordnete mußten sich mit kürzeren begnügen ${ }^{326}$. Dies bedeutete gleichermaßen einen Einschnitt in das klassische, vom individuellen Abgeordneten ausgehende Parlamentarismusverständnis wie eine weitere Aufwertung des Fraktionswesens. Am selben Tag brachte der Sozialist Pierre Renaudel einen Vorschlag ein, die Geschäftsordnung der Kammer um eine „procédure exceptionelle pour l'examen et le vote des projet de loi urgents touchant aux intérêts supérieurs de l'Etat" zu ergänzen ${ }^{327}$. Er sah vor, daß auf Antrag der Regierung bei wichtigen Gesetzesvorhaben auf einen Kammerbeschluß hin eine beschleunigte, auf drei Tage begrenzte Ausschußberatung festgesetzt werden konnte. Dieser Vorschlag, der an eine entsprechende Praxis während des Weltkriegs anknüpfte und bewußt als eine im Rahmen der parlamentarischen Verfahren bleibende Alternative zum geplanten Ermächtigungsprojekt der Regierung Briand-Caillaux gedacht war, wurde am 20. Juli von der Kammer angenommen 328 .

Was die geplante Ermächtigung für die Regierung Briand anbelangt, so gab es in den Reihen der Radicaux einen vehementen Gegner, der sich in der Öffentlichkeit noch zurückhielt. Herriot, Vorkämpfer gegen die décrets-lois-Politik Poincarés und immer noch führender parlamentarischer Repräsentant des Parti radical, blieb als Kammerpräsident vorerst außerhalb der parlamentarischen Diskussion. Intern signalisierte er freilich klar seine Ablehnung des Ermächtigungsprojektes. Vermutlich lag hier ein Grund dafür, daß Briand seinen Finanzminister dazu bewegen konnte, die bereits fertig ausgearbeitete Gesetzesvorlage zunächst zurückzustellen ${ }^{329}$.

Für einige Tage sah es nun so aus, als ob es eine mehrheitsfähige Lösung geben könne. Caillaux gelang es bei einem Besuch in London, zu einem Kompromiß in der französisch-britischen Schuldenfrage zu kommen ${ }^{330}$. Hoffnungen auf eine analoge Regelung mit den Vereinigten Staaten nahmen einer eventuellen Ermächtigung in einer zentralen Frage die Brisanz, und in den couloirs der Kammer wuchs nach einem Geheimdienstbericht die Bereitschaft zu einer von der Zielsetzung her beschränkten Ermächtigung 331 . Als die US-Regierung allerdings auf einer Ratifizierung des Washingtoner Schuldenabkommens beharrte, kam Caillaux auf seine ursprüngliche Vorlage zurück. Am Abend des 15. Juli wurde diese

325 JO, Débats, Chambre 1926, S. 2883-2899. Die Vorschläge wurden bis auf einen Punkt alle in offener Abstimmung schnell genehmigt.

326 Vgl. hierzu auch Roussellier, Gouvernement et parlement, S. 257.

327 JO, Débats, Chambre 1926, S. 2992.

328 Diskussion und Annahme ohne namentliche Abstimmung: JO, Débats, Chambre 1926, S. 29903005. Schon bald sollte dieses Instrument beschleunigter parlamentarischer Beratung die Durchsetzung einer Ermächtigung der Regierung Poincarés erleichtern.

329 Ebd., S. 2992 mit kurzer Diskussion. Vgl. hierzu Bonnefous, Histoire 4, S. 155, mit Text der Vorlage vom 9. 7. 1926.

330 Vgl. ebd., $154 \mathrm{f}$.

331 Vgl. Note Jean, 13. 7. 1926; AN Paris, F7 12954/1, Bl. 857: „La question des pleins pouvoirs, est toujours âprement controversée, cependant, on paraît admettre que si le Gouvernement doit en profiter pour un simple remaniement dans le mode de perception des impôts, il obtiendra à cet égard une majorité." Nach Bonnefous, Histoire 4, S. 156, ging es lediglich um die Hoffnung auf amerikanische Kredite. 
im Ministerrat gebilligt ${ }^{332}$, und bereits am folgenden Tag lag sie dem Finanzausschuß der Kammer zur Beratung vor.

Der Text der Vorlage lautete: Art. 1: „Le gouvernement est autorisé, jusqu'au 30 novembre 1926, à prendre, par décrets délibérés en Conseil des Ministres, toutes les mesures propres à réaliser le redressement financier et la stabilisation de la monnaie." Art. 2: „Ceux de ces décrets qui comportent des dispositions fiscales seront soumis à la ratification législative à l'ouverture de la session ordinaire de 1927, les mesures qu'ils auront prescrites restant définitivement acquises. “333

Die unterschiedliche Dimension im Vergleich zur Ermächtigung Poincarés im März 1924 ist evident. Ging es damals lediglich um eine Vollmacht im Hinblick auf „administrative Reformen und Vereinfachungen“"334, so betraf das Vorhaben jetzt „alle Maßnahmen, die geeignet sind, die finanzielle Gesundung und die Währungsstabilisierung zu verwirklichen". Zwar erreichte diese Formulierung nicht die Pauschalität der beiden großen deutschen Ermächtigungen vom Oktober und Dezember 1923335 und gab immerhin noch grob eine Zielrichtung an. Letztlich hätte aber auch diese Ermächtigung eine kaum zu begrenzende Breite an legislativen Maßnahmen ermöglicht. Der zeitgenössische Begriff der pleins pouvoirs erscheint daher durchaus angemessen. Auffallend ist auch, daß die in Art. 2 vorgesehene Ratifizierung durch das Parlament sich nur auf Verordnungen bezieht, die "dispositions fiscales" enthalten. Einer Ratifizierung des Washingtoner Schuldenabkommens auf dem Verordnungsweg hätten Abgeordnetenkammer und Senat daher nichts entgegensetzen können.

Im Finanzausschuß der Kammer fand am 16. Juli eine mehrstündige Anhörung des Finanzministers und zeitweise auch des Ministerpräsidenten mit anschließender Kommissionsberatung statt. Das vollständig erhaltene maschinenschriftliche Protokoll, das einen detaillierten und von rhetorischen Effekten weitgehend ungetrübten Einblick in die Ermächtigungsdiskussion bietet, umfaßt über 200 Seiten und kann hier nur in einigen wenigen zentralen Punkten referiert werden ${ }^{336}$. Das ihm persönlich entgegengebrachte Mißtrauen suchte Caillaux gleich zu Beginn unter Anspielung auf seinen mysteriösen Plan „Rubicon“ zu entkräften. Eine Gefährdung der Rechte des Parlaments habe er nie beabsichtigt, er sei ein „trop vieux parlementaire et trop attaché au régime parlementaire", um derartige Absichten hegen zu können ${ }^{337}$. In der weiteren Begründung der geforderten Ermächtigung stand vor allem der Verweis auf die außergewöhnliche Notlage im Mittelpunkt. "Il y a“, so führte der Finanzminister aus, „des circonstances dans la vie des peuples où il faut savoir suspendre, je ne dirai pas le jeu des institutions, mais certaines prérogatives pour parer au plus pressé. [...] Nous sommes dans une période où il est nécessaire d'user de moyens qui ne rentrent pas dans les méthodes parlementaires habituelles, mais auxquels les événements forcent à recourir." ${ }^{338} \mathrm{Als}$

332 Note Jean, 13. 7. 1926; AN Paris, F7 12954/1, Bl. 857

333 Abgedruckt bei Bonnefous, Histoire 4, S. 155.

334, „.... réformes et simplifications administratives“. Vgl. Text im Anhang unter 7.2.a.

$335 \mathrm{Vgl}$. Texte im Anhang unter 7.1.

336 AAN Paris, Procès-verbaux de la Commission des Finances, XIIIe Législature, 16. 7. 1926, Audition sténographiée. In der Forschung wurde diese Quelle bisher noch nicht beachtet.

337 Ebd., S. 3.

338 Ebd., S. 4. 
aktuelles Vorbild verwies der Minister auf Belgien, wo seit der Bewilligung von „pouvoirs étendus“ der Kurs des belgischen Franc stark steige ${ }^{339}$. Im Gegensatz zur Argumentation Poincarés 1924 unternahm Caillaux keinerlei Versuche, sein Projekt zu bagatellisieren und es in die Traditionslinie der engen Spezialermächtigungen während des Ersten Weltkriegs und zur Eingliederung Elsaß-Lothringens zu stellen. Angesichts der Reichweite der diskutierten Ermächtigung wäre dies wohl auch kaum überzeugend gewesen.

In der Befragung durch die Kommissionsmitglieder, von denen sich vor allem die Sozialisten Auriol, Blum und Renaudel sowie Caillaux' Parteikollege und was juristische Verfolgung und Amnestie angeht - Schicksalsgenosse Malvy kritisch hervortaten, wurde deutlich, daß es grundlegende Bedenken gegen das Instrument einer Ermächtigung offenbar nicht mehr gab. Die Diskussion bezog sich allein auf die Frage nach der legislativen Reichweite. Dabei kamen fortbestehende Befürchtungen hinsichtlich der Person von Caillaux zur Geltung, aber auch verfassungspolitische Bedenken gegenüber einem Ausufern der Verordnungspraxis. Es zeigte sich allerdings auch, daß bei Abgeordneten der rechten Mitte angesichts der parlamentarischen Lähmungserscheinungen eine schon fast fatalistische $\mathrm{Be}$ reitschaft bestand, sich auf ein tatkräftiges Verordnungsregime einzulassen. Bezeichnend ist hier die Aussage von Léon Baréty (Gauche républicaine démocratique): „Si vous demandez des pouvoirs, certains d'entre nous les donneront à la condition essentielle que vous les exerciez. Car nous sommes fatigués de demander des réformes et de ne pas les obtenir." 340

Nach heftigen internen Kontroversen, ob der Ausschuß in einer derartigen Verfassungsfrage überhaupt zuständig sei, beteiligte sich nur noch ein Teil der Mitglieder an einer Neufassung der Gesetzesvorlage ${ }^{341}$. Die Ermächtigung wurde schließlich explizit und verbindlich auf jenes in einem Annex beigefügte finanzpolitische Themenfeld beschränkt, das der Finanzminister selbst in seinem Exposé des motifs unverbindlich umrissen hatte ${ }^{342}$. Der Ausschuß hatte damit die Ermächtigung zwar im Prinzip gebilligt, allerdings eine bemerkenswerte materielle Begrenzung festgelegt ${ }^{343}$.

Caillaux wollte sich - zwar mit Rückendeckung, aber offenbar gegen die Auffassung von Briand ${ }^{344}$ - auf einen derartigen Kompromiß nicht einlassen und be-

339 Dem seit Mai 1926 regierenden Kabinett der Union nationale in Belgien wurden mit Wirkung vom 16. 7. 1926 weitgehende Vollmachten übertragen. Vgl. Tingstén, Pleins pouvoirs, S. 136-145.

340 AAN Paris, Procès-verbaux de la Commission des Finances, XIIIe Législature, 16. 7. 1926, Audition sténographiée, S. 65.

341 Der Großteil der rechtsliberalen Abgeordneten - tonangebend war hier Bokanowski - enthielt sich der Stimme, die Sozialisten waren aus Verärgerung darüber ausgezogen.

342 Der verabschiedete Text lautete: Article premier: „Le Gouvernement est autorisé jusqu'au 30 novembre 1926, par des décrets délibérés et approuvés en Conseil des Ministres, à réaliser les réformes financières et la stabilité monétaire en conformité des dispositions énumérées dans l'annexe ci-jointe." Article 2: „Ces décrets seront soumis à la ratification des Chambres avant le 31 décembre 1926, l'effet déjà produit par les mesures qu'ils auront prescrites demeurant définitivement acquis.“ Ebd., Anlage. Der Annex umfaßt sechs Seiten.

343 Von Bonnefous, Histoire 4, S. 156, der lakonisch feststellt, der Ausschuß habe die Vorlage gebilligt, wird dies völlig übersehen. Zur Bewertung der Kommissionsvorlage vgl. auch Note Jean, 17. 7. 1926; AN Paris, F7 12954/1, Bl. 873, wo es pointiert heißt: „C'est, en effet, cette délégation absolue contre laquelle la Commission des Finances, a émis, hier, un vote contraire [...]."

$3+4$ Vgl. hierzu Note Jean, 16. 7. 1926; AN Paris, F7 12954/1, Bl. 867. 
stand darauf, daß die Abgeordnetenkammer zwischen seiner Vorlage und jener der Finanzkommission zu wählen habe ${ }^{345}$. Das Risiko, das der Finanzminister damit einging, war hoch. Bonnet berichtet, daß die Forderung nach „pouvoirs financiers étendus“ in parlamentarischen Kreisen große Aufregung auslöste: „Beaucoup de députés de province s'inquiétaient en conscience de cette atteinte au Parlement.“346 Auch der linksliberale Quotidien, der bereits 1924 an vorderster Front gekämpft hatte, mobilisierte jetzt erneut gegen die décrets-lois ${ }^{347}$.

Die Kammersitzung vom 17. Juli sollte zum Scherbengericht über das Ermächtigungsprojekt werden ${ }^{348}$. Überraschenderweise wurde der Reigen der Kritiker eingeleitet durch Herriot, der ganz gegen die Tradition als Kammerpräsident in die Debatte eingriff ${ }^{349}$. Seine leidenschaftliche Rede war von einem tief verwurzelten republikanischen Idealismus, aber auch von einer heftigen persönlichen Gegnerschaft zu Caillaux getragen ${ }^{350}$. Die Argumentation gegen die Ermächtigungsvorlage nahm nun doch noch prinzipielle Züge an ${ }^{351}$. Allerdings fällt auf, daß auch Herriot sich nicht gegen das Instrument einer Ermächtigung an sich, sondern gegen die eingeschlossene steuerpolitische Delegation wandte ${ }^{352}$. Die Steuerbewilligung sei ein Vorrecht, welches das Parlament nicht aufgeben dürfe. Die beiden Artikel des Ermächtigungsgesetzes hätten zahlreiche Abgeordnete „jusqu'au plus profond de leur conscience républicaine" verletz $t^{353}$. Caillaux solle, so Herriot in einem dramatischen Schlußsatz, mit dem Parlament „zusammenarbeiten“ und es nicht „unterdrücken “ 354 . Für den Fall, daß das Gesetz gebilligt werde, drohte der Kammerpräsident mit seinem Rücktritt.

Nach dieser „rencontre tragique “ 355 der beiden führenden politischen Gestalten der linksliberalen Mitte stieg der Regierungschef als Verteidiger seines Finanzministers ans Rednerpult ${ }^{356}$. Geschickter als Caillaux am Vortag im Finanzausschuß kleidete er seine pragmatische Rechtfertigung der Ermächtigung in eine „republi-

${ }^{345}$ Note Jean, 17. 7. 1926; AN Paris, F7 12954/1, B1. 873, spricht davon, daß Caillaux sich „intransigeant" gezeigt habe.

346 Bonnet, Vingt ans, S. 116. Die Äußerung bezieht sich auf den Vorabend der Sitzung vom 17.7. 1926.

${ }^{347}$ LQ, 17. 7. 1926, S. 1 „Non, non, et non!“ Zunächst war auch Le Quotidien relativ zurückhaltend geblieben.

348 Vgl. zur Debatte auch Bonnefous, Histoire 4, S. 156-158.

${ }^{349}$ Zeitgenössisch und in der Literatur wurde dieser Vorgang stark beachtet. Vgl. v.a. Berstein, Herriot, S. $146 \mathrm{f}$. Zur vorherigen Ankündigung im Büro Herriots vgl. Bonnet, Vingt ans, S. 116. Herriot, Jadis 2, S. 247, gibt an, durch den Kommissionsbeschluß aufgeschreckt worden zu sein: „Informé du vote de la Commission, j'en fus troublé au plus profond de ma conscience politique.".

350 So das Urteil von Berstein, Herriot, S. $146 \mathrm{f}$., wobei der Autor das Schwergewicht wohlwollend im ersten Motiv sieht. Ähnlich in der Bewertung auch schon in Botschaftsbericht-Paris (Hoesch), Tel. Nr. 723, 20. 7. 1926, S. 1: „Ich finde Erklärung in Persönlichkeit Herriots selbst, der dazu neigt, in Aufwallungen seiner doktrinär-idealistischen Auffassung von Republikanismus und Demokratie praktische Erwägungen hintanzusetzen und sich ziellos in seine Ideale zu verrennen." Herriots „bekanntes schlechtes Verhältnis zu Caillaux“ sieht Hoesch als mitbestimmend, ebenso eine "schon seit geraumer Zeit bestehende Animosität gegen Briand“. PA AA Berlin, R 70717.

351 JO, Débats, Chambre 1926, S. 2964-2966.

352 In der Literatur wurde dies bislang nicht bemerkt.

353 JO, Débats, Chambre 1926, S. 2964.

354 „[...] je vous dis ceci, messieurs du Gouvernement: collaborez avec le Parlement, ne le supprimez pas". Ebd., S. 2966.

355 So Briand. Ebd., S. 2967.

356 Ebd., S. 2966-2969. 
kanische" Rhetorik. Die republikanischen Institutionen, so Briand, müßten angesichts der Notwendigkeiten "geschmeidiger" werden: "Je crois sentir autour de mon effort, autour de moi, l'ardent désir de ce pays que les institutions républicaines puissent s'assouplir devant les nécessités, avec les sauvegardes nécessaires" 357 . Das vorgeschlagene Verfahren schade der Republik nicht, sondern stärke sie sogar: „Nous avons la conviction, nous, républicains, qu'en nous permettant d'agir, non seulement vous ne nuirez pas à l'institution républicaine, mais que vous la renforcerez aux yeux du pays. " 358

Scharfe Attacken kamen in der Kammerdebatte vom 17. Juli auch von Marin und Renaudel ${ }^{359}$. Beiden Rednern ging es freilich weniger um das Prinzip einer Ermächtigung als um die Kritik an der Reichweite sowie an der Person von Caillaux. Besonders effektvoll war wieder einmal Tardieu. Um die Absichten des Finanzministers zu diskreditieren, verlas er in einer kurzen Wortmeldung während der Rede Marins unter heftiger Anteilnahme der Kammer die im Rubicon-Projekt von 1917 vorgesehene, extrem breite und auch auf die Änderung der Verfassung bezogene Ermächtigungsklausel 360 . In der dadurch aufgeheizten Stimmung konnten die anschließenden Versuche von Caillaux, die aktuelle Ermächtigung nüchtern finanzpolitisch zu begründen, nur noch wenig Eindruck machen ${ }^{361}$.

Als die Regierung schließlich die Vertrauensfrage stellte, geriet sie mit $288 \mathrm{zu}$ 243 Stimmen in die Minderheit. Der größte Teil der Gegenstimmen kam von den Sozialisten und Kommunisten, die geschlossen votierten, sowie von der Mehrzahl der Abgeordneten der Union républicaine démocratique. Die linke und konservative Gegnerschaft zum Kabinett Briand $X$ wäre allerdings nicht erfolgreich gewesen, wenn sich nicht auch ein beträchtlicher Teil der linken Mitte - über 60 Radicaux und Républicains-socialistes - gegen die Regierung entschieden hätte. Welchen Anteil daran der spektakuläre Auftritt Herriots besaß, läßt sich kaum mit Sicherheit feststellen. Zeitgenössisch ist die Intervention des Kammerpräsidenten aber als entscheidend für den Sturz der Regierung Briand-Caillaux bewertet worden $^{362}$. Allerdings darf nicht übersehen werden, daß das Ergebnis insofern auch eine Niederlage für Herriot darstellte, als ihm nur etwa ein Drittel seiner eigenen Fraktion in der Ablehnung der Regierung folgte ${ }^{363}$. Die Divergenzen innerhalb der Radicaux und die Dekonstruktion des seit Ende 1925 dominierenden Regierungslagers hatten nun spektakuläre Ausmaße angenommen. Die Ansätze zu einer disziplinierten Neugestaltung der regierungstragenden Funktion der Abgeordnetenkammer waren damit endgültig hinfällig geworden.

357 Ebd., S. 2966.

358 Ebd., S. 2968.

359 Ebd., S. 2969-2973 (Marin), S. 2975-2978 (Renaudel).

360 „Pendant une période de $\mathrm{x}$ mois à dater de la promulgation de la présente loi, le Président de la République est investi du droit de prendre en conseil des ministres des décrets ayant force législative et constitutionnelle.“ Ebd., S. 2973. Fehlerhaft zitiert in Bonnefous, Histoire 4, S. 158.

361 JO, Débats, Chambre 1926, S. 2978-2980.

362 So z. B. auch von Caillaux, Mémoires 3, S. 215.

${ }^{363}$ Darauf weist auch Botschaftsbericht-Paris (Hoesch), Nr. 723, 20. 7. 1926, S. 2, hin. Herriot habe sich „zum ersten Mal ein von ihm bisher stets ängstlich vermiedenes ,désaveu“ von einem Teil seiner Anhänger" geholt. PA AA Berlin, R 70717. 
Tab. 20: Votum der Abgeordnetenkammer am 17. 7. 1926: Ablebnung Ermächtigungsgesetz, Sturz Briand $X^{364}$

\begin{tabular}{lrrrrrr}
\hline Fraktion & Abg. & ja & nein & $\begin{array}{l}\text { keine } \\
\text { Teil- } \\
\text { nahme }\end{array}$ & beurl. & $\begin{array}{l}\text { Kohä- } \\
\text { renz }\end{array}$ \\
\hline Communistes & 28 & - & 28 & - & - & $100 \%$ \\
Socialistes (SFIO) & 97 & - & 96 & - & 1 & $100 \%$ \\
Républicains-socialistes & 40 & 21 & 16 & 1 & 2 & $55 \%$ \\
Radicaux et radicaux-socialistes & 136 & 75 & 48 & 7 & 6 & $58 \%$ \\
Gauche radicale & 40 & 29 & 7 & 2 & 2 & $76 \%$ \\
Démocrates & 14 & 12 & 2 & - & - & $86 \%$ \\
Gauche indépendante 365 & 16 & 14 & 1 & 1 & - & $88 \%$ \\
Gauche républicaine démocratique & 34 & 23 & 6 & 4 & 1 & $70 \%$ \\
Républicains de Gauche & 32 & 31 & - & 1 & - & $97 \%$ \\
Union républicaine démocratique & 102 & 33 & 60 & 3 & 6 & $63 \%$ \\
"Aucun Groupe" & 27 & 4 & 22 & 1 & - & - \\
"Non inscrits" & 4 & 1 & 2 & - & 1 & - \\
\hline Gesamt & 570 & 243 & 288 & 20 & 19 & - \\
\hline
\end{tabular}

Als Briand beim Staatspräsidenten seinen Rücktritt einreichte, erklärte er strikt, für eine weitere Ministerpräsidentschaft nicht mehr zur Verfügung zu stehen. Er könne nicht in einer Umgebung „fortgesetzter Feindseligkeit“ leben ${ }^{366}$. Wohl zum ersten Mal in seiner Amtszeit kam nun die Gelegenheit für Doumergue, maßgeblichen Einfluß auf die weitere Entwicklung zu nehmen. Mit dem Argument, Herriot habe den Sturz des Kabinetts Briand herbeigeführt und stehe daher jetzt in der Pflicht einer neuen Regierungsbildung, drängte der Staatspräsident am 18. Juli den zunächst widerwilligen Kammerpräsidenten, einen entsprechenden Antrag anzunehmen ${ }^{367}$. Es scheint gesichert, daß Doumergue dabei wesentlich von dem Gedanken getragen war, ein demonstratives und definitives Scheitern Herriots zu inszenieren ${ }^{368}$.

Dieses auch von Herriot selbst erwartete Debakel vollzog sich in mehreren Phasen. Zunächst gelang es dem radikalen Parteichef nicht, sein Kabinett auf eine

364 Liste der namentlichen Abstimmung in JO, Débats, Chambre 1926, S. $2986 \mathrm{f}$. Aufstellung nach Fraktionen aus LT, 19. 7. 1926, S. 4, "Le scrutin sur la confiance" (abgedruckt auch in Bonnefous, Histoire 4, S. 159).

365 Diese Fraktion hat sich im November 1925 nach links von der Gauche républicaine démocratique abgesplittert. Vgl. Botschaftsbericht-Paris (Hoesch), Tel. Nr. 921, 18. 11. 1925, PA AA Berlin, $\mathrm{R} 70717$. Den Fraktionsvorsitz hatte 1926 Le Trocquer (ursprünglich Gauche républicaine démocratique).

366 Vgl. Zitat in Bonnefous, Histoire 4, S. 159.

367 Vgl. auch Bericht in Herriot, Jadis 2, S. 248: „M. le président de la République me chargea de constituer le cabinet, en me représentant que j'en avais l'obligation. J'étais bien sûr de m'exposer à une chute très prochaine; je le dis au chef de l'Etat qui n'en parut point très ému et refusa de prendre en considération mes arguments." Auch zitiert bei Berstein, Herriot, S. 148.

$368 \mathrm{Vgl}$. Bonnet, Vingt ans, S. 117, „Doumergue attendait avec impatience cette occasion pour couler Herriot." Auch in der Literatur wird diese Sicht geteilt: Vgl. Berstein, Herriot, S. 147. - Die weitergehende These bei Bonnet, Vingt ans, S. 111, 115 und 117, Doumergue habe schon länger auf eine „combinaison Poincaré" hingearbeitet und insbesondere einen „Verschleiß“ der Finanzminister provoziert, wirkt dagegen sehr spekulativ. 
halbwegs breite Basis zu stellen ${ }^{369}$. Angesichts der öffentlichen und parlamentarischen Stimmungslage und der bekannten Positionen in der SFIO muß der anfängliche Versuch, die Sozialisten nicht nur zur Unterstützung, sondern zum Eintritt in die Regierung zu bewegen, als absolut illusionär bewertet werden ${ }^{370}$. Die anschließenden Bemühungen um eine Regierung der Union nationale ${ }^{371}$ scheinen hingegen kurzzeitig auf die Bereitschaft von Louis Marin gestoßen zu sein, einen Kabinettsposten zu übernehmen. Heftige Proteste innerhalb der Fraktion der Union républicaine démocratique machten diesem Vorhaben jedoch ein schnelles Ende ${ }^{372}$. Klare Absagen handelte sich Herriot von Louis Barthou ${ }^{373}$ - ehemaliger Ministerpräsident, einflußreicher Senator der Union républicaine und aktueller Vorsitzender der Reparationskommission - und vor allem von Poincaré ein, der vermutlich bereits auf seine eigene Regierungsbildung wartete ${ }^{374}$. Immerhin drei Modérés konnte Herriot schließlich für Minister- bzw. Staatssekretärsposten gewinnen. Der bekannteste unter ihnen war Maurice Colrat, Justizminister Poincarés in den Jahren 1922-24 und Mitglied der neugegründeten Fraktion der Gauche indépendante ${ }^{375}$. Ausgestattet mit den Ressorts der Justiz und Elsaß-Lothringens sowie der Vice-Présidence du Conseil sollte Colrat eine Verbindung zur parlamentarischen Mitte hin bilden ${ }^{376}$. Dies konnte allerdings nicht verbergen, daß das am 20. Juli von Doumergue ernannte Kabinett kein, wie von Herriot tituliert, „Gouvernement d'union républicaine" darstellte, sondern weitgehend auf radikale Gefolgsleute des Parteichefs - vor allem Camille Chautemps, René Renoult, Edouard Daladier und Georges Bonnet - sowie einige wenige Républicains-socialistes und Angehörige der Gauche radicale zurückgriff. Am Ende stand eine mit 13 Ministern und 11 Staatssekretären extrem aufgeblähte Regierungsmannschaft ${ }^{377}$. Auch die Vermehrung der Kabinettsposten war ein verzweifelter Versuch der parlamentarischen Mehrheitsgewinnung.

Die Regierungsbildung wurde von heftigen Emotionen in der Finanzwelt und in Teilen der bürgerlichen Öffentlichkeit begleitet. Es kam nun zu einer geradezu panikartigen Flucht aus dem Franc und zu zahlreichen Abhebungen bei Banken und Sparkassen ${ }^{378}$. Wilde Gerüchte gingen um: Herriot sei von Deutschland oder Rußland bestochen, die Sozialisten planten eine gewaltsame Aktion gegen den

${ }^{369}$ Zur Regierungsbildung vgl. allgemein Bonnefous, Histoire 4, S. 160f.; Berstein, Herriot, S. $148 \mathrm{f}$. $370 \mathrm{Vgl}$. auch Abdruck der wechselseitigen Briefe in Herriot, Jadis 2, S. $248 \mathrm{f}$.

371 Vgl. auch ebd., S. 249.

${ }^{372} \mathrm{Zu} \mathrm{dem}$ in der Literatur bislang offenbar nicht bekannten Vorgang um Marin vgl. Note Jean, 19. 7.

1926; AN Paris, F7 12954/1, Bl. 881. In dem Vorgang kann man auch ein Indiz für die gewachsene politische Bedeutung der konservativen Fraktion sehen.

${ }_{373} \mathrm{Zu}$ Barthou, der hier neben Poincaré erwähnt wird, vgl. Botschaftsbericht-Paris (Hoesch), Tel. Nr. 723, 20. 7. 1926, S. 2; PA AA Berlin, R 70717.

374 So Bonnet, Vingt ans, S. 117-119. Nach Bonnet sollte Poincaré Finanzminister werden. Unter Führung Malvys kam deshalb eine Delegation zu Poincaré. Dieser zeigte sich bereit, jedes Ministerium zu übernehmen, aber nicht das Finanzministerium. Die Lage sei so ernst, daß der Président $d u$ conseil dieses selbst übernehmen müsse.

${ }_{375}$ Bei Bonnefous, Histoire 4, S. 160 f., wird Colrat fälschlicherweise noch als Mitglied der Gauche républicaine démocratique bezeichnet.

376 Daneben die eher in der zweiten Reihe der Républicains de Gauche stehenden Adrien Dariac als Kolonialminister und Barthélemy Robaglia als Staatssekretär für Luftfahrt.

377 Seit dem Machtwechsel von 1924 hatte die Zahl der Kabinettsmitglieder zwischen 18 und 21 geschwankt. Vgl. auch Anhang, Tab. 6.

378 Bonnefous, Histoire 4, S. 160; Berstein, Herriot, S. 150; Bonnet, Vingt ans, S. 119. 
Senat. Mancher wurde angesichts der unsicheren Lage gar von der Angst vor kommunistischen Revolten gepackt ${ }^{379}$.

Das Ende der neuen Regierung zeichnete sich bereits vor ihrer Präsentation in der Abgeordnetenkammer ab. Wohl auch unter dem Eindruck der öffentlichen Stimmungslage kam es innerhalb des Kabinetts zu Differenzen über das finanzpolitische Vorgehen ${ }^{380}$, während Moreau, der von Caillaux eingesetzte Leiter der Banque de France, wegen Erschöpfung des Staatsschatzes mit Einstellung der Auszahlungen drohte ${ }^{381}$. Als Herriot in der ersten und einzigen Kabinettssitzung am 21. Juli die sofortige Demission in Aussicht stellte, stieß er auf den heftigen Widerstand von Doumergue, der den Vorwurf der "forfaiture" erhob und seinen unglücklichen Regierungschef so vor das Urteil der Abgeordnetenkammer zwang ${ }^{382}$.

Der letzte Akt in der Demontage Herriots folgte noch am selben Tag ${ }^{383}$. Bemerkenswert ist zunächst, daß der neue Ministerpräsident am Ende seiner kurzen Erklärung vor der Abgeordnetenkammer die Parlamentarier dazu aufforderte, etwaige Vorbehalte gegen sein Kabinett sofort zum Ausdruck zu bringen. Der entmutigte radikale Parteichef zog offenbar selbst ein schnelles Ende einer Verlängerung der extremen Krisensituation vor. Nach einer vagen Rede des neuen Finanzministers de Monzie, der noch dazu durch Anschuldigungen gegen das Vor-

Tab. 21: Votum der Abgeordnetenkammer am 21. 7. 1926: Sturz Regierung Herriot $1 I^{384}$

\begin{tabular}{lrrrrrr}
\hline Fraktion & Abg. & ja & nein & $\begin{array}{l}\text { keine } \\
\text { Teil- } \\
\text { nahme }\end{array}$ & beurl. & $\begin{array}{l}\text { Kohä- } \\
\text { renz }\end{array}$ \\
\hline Communistes & 28 & - & 28 & - & - & $100 \%$ \\
Socialistes (SFIO) & 97 & 94 & - & 2 & 1 & $98 \%$ \\
Républicains-socialistes & 40 & 20 & 13 & 3 & 4 & $56 \%$ \\
Radicaux et radicaux-socialistes & 136 & 105 & 11 & 11 & 9 & $83 \%$ \\
Gauche radicale & 40 & 13 & 24 & 1 & 2 & $63 \%$ \\
Démocrates & 14 & - & 14 & - & - & $100 \%$ \\
Gauche indépendante & 16 & 1 & 14 & 1 & - & $88 \%$ \\
Gauche républicaine démocratique & 34 & - & 31 & 2 & 1 & $94 \%$ \\
Républicains de Gauche & 32 & 2 & 28 & 1 & 1 & $90 \%$ \\
Union républicaine démocratique & 102 & - & 102 & - & - & $100 \%$ \\
"Aucun Groupe“ & 27 & 1 & 23 & 3 & - & - \\
"Non inscrits" & 4 & 1 & 2 & - & 1 & - \\
\hline Gesamt & 570 & 237 & 290 & 24 & 19 & - \\
\hline
\end{tabular}

379 Vgl. Note Jean, 19. 7. 1926; AN Paris, F7 12954/1, Bl. 882f.; Note Jean, 21. 7. 1926; ebd., Bl. 891. Botschaftsbericht-Paris (Hoesch), Tel. Nr. 723, 20. 7. 1926, S. 4; PA AA Berlin, R 70717.

380 Note Jean, 21. 7. 1926; AN Paris, F7 12954/1, Bl. 891.

381 Vgl. Herriot, Jadis 2, S. 249 f., mit ausführlichem Zitat des Schreibens. Ebd., S. 250: „C'était le couteau sur la gorge." - Vgl. auch Berstein, Herriot, S. 149f.; Jeanneney, De Wendel, S. $315 \mathrm{f}$.

382 Bonnet, Vingt ans, S. $120 \mathrm{f}$. Demnach hat Doumergue hier erneut betont, daß er Herriot wegen des Sturzes der Vorgängerregierung berufen habe.

383 JO, Débats, Chambre 1926, S. 3013 f. (Herriot); 3017-3020 (de Monzie).

384 Liste der namentlichen Abstimmung ebd., S. 3030 f.; Aufstellung nach Fraktionen aus LT, 23. 7. 1926, S. 2, "Le scrutin“. 
gängerkabinett den bisherigen Regierungschef Briand gegen sich aufbrachte, wurde schließlich die Vertrauensfrage der Regierung mit 290 zu 237 Stimmen bei 24 Enthaltungen überraschend deutlich zurückgewiesen.

Das Ergebnis zeigte gleichsam die Ruinen des Linkskartells: Nur von den Sozialisten - diese in alter Tradition weitgehend geschlossen -, den Radicaux, Républicains-socialistes und der Gauche radicale erhielt das Kabinett in nennenswertem Umfang Ja-Stimmen. Der durch die Aufnahme dreier Modérés erhoffte Brückenschlag in die Mitte war gänzlich fehlgeschlagen. Die drei Stimmen aus den Reihen der Gauche indépendante und der Républicains de Gauche stammten von den dort beheimateten Kabinettsmitgliedern selbst. Entscheidend für die Niederlage aber waren die Verluste im Kernbereich des Kartells, in den Reihen der Républicains-socialistes ${ }^{385}$ und vor allem in Herriots eigener Fraktion. Der rechte Flügel des Parti radical unter der Führung von Franklin-Bouillon votierte sogar offen gegen seinen Parteichef, eine weitere Gruppe enthielt sich, und auch die Zahl der entschuldigten Abwesenden lag relativ hoch. Zweifellos war dies auch die Rechnung für Herriots „ungeahnten Husarenritt" vom 17. Juli, mit dem er sich erheblichen Unwillen in der eigenen Partei zugezogen hatte ${ }^{386}$ und mit dem er zudem seine eigenen jahrelangen Bemühungen um eine Steigerung der Fraktionsdisziplin konterkariert hatte. Prägnant stellte Hoesch am 22. Juli in seinem Bericht über das von Herriot erzielte Ergebnis fest: „Seine eigene Partei ist in sich zerfallen, das Kartell auch als Idee ist zerstört. " 387

Gleichzeitig eskalierte nun die öffentliche Erregung. Während der Kammerdebatte vom 21. Juli 1926 kam es zu Bevölkerungskundgebungen und Demonstrationszügen rund um das Palais Bourbon. Der deutsche Botschafter berichtete von "gut gekleidete[n] junge[n] Leute[n] der jeunesse patriote, die unter Rufen ,dissolution' und ,Herriot au poteau' stundenlang Parlament umlagerten und Stadt durchzogen“. Die Demonstranten hätten zwar "gutartigen Charakter" gehabt, sie „zeigten aber doch, daß Rechtsorganisationen allmählich in die Lage kommen, in größeren Organisationen auf Straße aufzutreten "388. Während die neuformierten Straßentruppen des Champagnerproduzenten und konservativen Kammerabgeordneten Taittinger auf sich aufmerksam machten, war auch die Stimmungslage der vor der Abgeordnetenkammer wartenden Menschenmengen überaus kritisch. Dabei richtete sich der durch parlamentarische Krisen und Währungsverfall erregte Volkszorn ${ }^{389}$ keineswegs allein gegen Herriot, sondern nahm einen grund-

385 Auffallend ist hier auch die Stimmenthaltung Briands.

386 Allgemein zur Stimmungslage innerhalb der radikalen Fraktion vgl. Botschaftsbericht-Paris (Hoesch), Tel. Nr. 723, 20. 7. 1926, S. 4: „Ein kleiner rechter Flügel unter Franklin Bouillon bekämpft Herriots Vorgehen aufs schärfste. Das Gros ist verstimmt über den ungeahnten Husarenritt des Chefs und nur das linke Drittel folgt ihm restlos.“ PA AA Berlin, R 70717.

387 Botschaftsbericht-Paris (Hoesch), Tel. Nr. 729, 22. 7. 1926, S. 4; PA AA Berlin, R 70717.

388 Ebd., S. 5. LH, 22. 7. 1926, S. 2, "Une manifestation ,fasciste“ devant la Chambre“, spricht von etwa 2000 aktiven Demonstranten, die neben den Jeunesses Patriotes auch der Action Française und dem Faisceau zugerechnet werden. Tartakowsky, Les manifestations de rue, geht hierauf nicht ein. Generell zum neuartigen Charakter französischer Straßendemonstrationen seit 1924 ebd., S. $152-154$.

${ }^{389}$ Die inflationsbedingte Erregung zeigte sich auch in diversen Ausschreitungen gegen amerikanische Touristen, die als Profiteure des Franc-Verfalls galten. Im Hintergrund stand wohl auch die harte Haltung der Vereinigten Staaten in der Schulden- und Anleihefrage. Vgl. Bericht in LH, 23. 7. 1926, S. 3, „Place Clichy. La foule malmène des Américains“. 
sätzlichen Tenor an. Ein Polizeibericht vom 22. Juli erwähnte: „Hier soir, à la sortie de la Chambre, les députés de tous les partis ont été conspués par la foule. “390 Gut zwei Jahre nach dem mit großen Hoffnungen verbundenen Wahlsieg des Cartel des Gauches war die Stimmungslage in Paris erstmals in der Zwischenkriegszeit von antiparlamentarischen Affekten der Straße geprägt. Auf dem Höhepunkt der parlamentarischen Krise der Inflationszeit zeigten sich erste Vorboten des 6. Februar 1934391 .

\section{Resümee: Demontage des Staatspräsidenten und mißlungene Modernisierung der regierungstragenden Funktion}

Zwischen dem Wahlsieg und dem endgültigen Scheitern des Cartel des Gauches, von Mitte 1924 bis Mitte 1926, sind zwei sehr unterschiedliche Ansätze zu einer Modifizierung des parlamentarischen Systems Frankreichs gescheitert.

1. Zunächst mußte Staatspräsident Millerand in unmittelbarer Folge des Wahlergebnisses die Quittung für seinen Versuch bezahlen, das seit 1877 tabuisierte präsidentielle Potential der Dritten Republik zu reaktivieren. Mit der erzwungenen Demission Millerands war diese Möglichkeit erneut und in noch weitergehender Form diskreditiert, so daß der große Konflikt von 1877, nun - zumindest für die Dritte Republik ${ }^{392}$ - definitiv abgeschlossen war. Die Regierungen blieben allein dem Parlament verantwortlich, und die regierungstragende Funktion des Parlaments war somit weitestgehend frei von Einmischungen des Staatspräsidenten.

Bei Null lagen dessen Einwirkungen fortan freilich immer noch nicht. So blieben zum einen die Spielräume bei der Einleitung der Regierungsbildung erhalten. Doumergue demonstrierte dies, bei aller sonstigen Zurückhaltung, mit boshaftem Geschick, als er im Juli 1926 Herriot zur Kabinettsbildung drängte und ihn so gleichsam zu einem Offenbarungseid zwang. Zum anderen bekam infolge der parlamentarischen Krisensituation auch das Thema einer präsidentiellen Kammerauflösung wieder eine gewisse Relevanz. Freilich wäre eine Auflösung jetzt kein Kampf- oder Disziplinierungsinstrument des Präsidenten gewesen, sondern ein Hilfsmittel in einer völlig verfahrenen innenpolitischen Lage. Daß dieses Mittel 1925/26 nicht ergriffen und sein Einsatz bis zum Juli 1926 von Doumergue wohl auch nicht ernsthaft erwogen wurde, zeigt jedoch, wie wirksam das 1877 errichtete Tabu gerade seit dem Scheitern Millerands wieder war.

390 Note Jean, 22. 7. 1926; AN Paris, F7 12954, Bl. 899. Vgl. ebd.: „A ce moment, une grande émotion se serait emparée des milieux parlementaires, où le bruit courait que si la prochaine combinaison échouait, M. Doumergue était fermement décidé à dissoudre la Chambre." Vgl. auch Presseberichte: LT, 23. 7. 1926, S. 3, „Manifestations devant la Chambre“, spricht für den Zeitpunkt des Sturzes von etwa 4000-5000 Menschen vor der Kammer. Die Polizei habe einen Zug zum Elyséepalast verhindert. LH, 22. 7. 1926, S. 2, „Une manifestation, fasciste' devant la Chambre“, erwähnt auch Rufe „A bas le Parlement!“ Nach Berstein, Herriot, S. 150, mußte die zurückgetretenen Minister lange warten, bis sie das Palais Bourbon verlassen konnten. In Herriot, Jadis 2, S. 151, werden die Demonstrationen nur sehr allgemein erwähnt.

391 Vgl. hierzu unten S. 559.

392 Die Verfassung der Fünften Republik läßt sich dann auch als später Sieg der Millerandschen Vorstellungen interpretieren. Vgl. hierzu auch unten S. 567. 
Im Vergleich zur deutschen Entwicklung sei in diesem Zusammenhang eine etwas spekulative Überlegung angefügt. Hätte im Mai 1924 der Bloc national und damit auch Millerand bei den Kammerwahlen gesiegt, dann hätte sich die Abgabe der legislativen parlamentarischen Funktion vielleicht auch in Frankreich mit einem Ausbau der präsidentiellen Machtstellung verbunden. Zwar gab es hierfür in den Verfassungsgesetzen von 1875 - im Gegensatz zu Artikel 48 der Weimarer Verfassung - keinen Ansatzpunkt. Auf dem Wege einer parlamentarischen Delegation wäre eine derartige Entwicklung aber durchaus möglich gewesen ${ }^{393}$. Das präsidentielle Debakel von 1924 war somit auch eine Weichenstellung dafür, daß die ab 1934 ausufernde Praxis eines Verordnungsregimes - ganz anders als in den letzten Jahren der Weimarer Republik - unter alleiniger parlamentarischer Kontrolle blieb ${ }^{394}$.

2. Das Scheitern des Linkskartells verband sich mit dem Mißlingen eines in dieser Form für Frankreich neuartigen Modells der regierungstragenden Funktion der Abgeordnetenkammer. Die Kooperation zwischen Parti radical und SFIO trug zunächst parteipolitische Züge, so daß allein schon deshalb ein disziplinierteres Agieren des parlamentarischen Regierungslagers angestrebt wurde als traditionell üblich. Die Zusammenarbeit der Kartellfraktionen kam dem - mit gewissen Abstrichen bei der parteipolitisch ungebundenen Gauche radicale - anfänglich durchaus nach, was sich insbesondere auch im Abstimmungsverhalten zeigte.

Nochmals sei hervorgehoben, daß der erste große und wohl auch schon entscheidende Schlag gegen das Linkskartell im Senat erfolgte, wo sich das Modell eines disziplinierten, parteiengestützten Regierungslagers nicht hatte durchsetzen können, was wiederum in erster Linie an der mangelhaften Kohärenz des Parti radical lag. Die Kartellmehrheit in der Abgeordnetenkammer, deren betont parteipolitisches und blockartiges Agieren an sich schon ein Ärgernis für Anhänger des traditionellen Parlamentarismus war, hatte bis dahin die Regierung Herriot I in relativ stabiler Weise unterstützt.

Erst seit dem Sturz Herriots im April 1925 löste sich der Zusammenhalt des Linkskartells auch in der Abgeordnetenkammer immer mehr auf. In traditioneller Manier der "replâtrage" in der Regierungsbildung wurde nun versucht, die parlamentarische Mehrheit in die politische Mitte der Abgeordnetenkammer zu verschieben, was freilich nur ansatzweise gelang. Die Attraktivität der Kartellidee war immerhin noch stark genug, einen großen Teil des Parti radical und der Républicains-socialistes von einem klaren Kurswechsel abzuhalten. Umgekehrt hatte die symbolbeladene Kartellpolitik und die damit anfänglich verbundene Blockbildung auch die Kooperationsbereitschaft zahlreicher Modérés beeinträchtigt. Unter diesen Umständen kam es, im ständigen Schwanken zwischen einer Mehrheitsbildung nach links und zur politischen Mitte hin, schließlich zu einer Zersplitterung des fraktionellen Stimmverhaltens. Die 1924 vom Kartell angestrebte Praxis eines geschlossenen Regierungslagers wurde damit in ihr Gegenteil verkehrt. Am Ende war die Modernisierung hin zu einer stabilen parteiengestützten

${ }^{393}$ So war im Rubicon-Plan von Caillaux aus dem Jahr 1917 eine Ermächtigung des Staatspräsidenten vorgesehen. Vgl. Bonnefous, Histoire 3, S. 404.

${ }^{344}$ Vgl. unten S. 562-564. 
Regierungsmehrheit gescheitert, doch auch die traditionelle Flexibilität der Regierungsbildung war schwer beeinträchtigt. Das parlamentarische System Frankreichs befand sich Mitte 1926 daher tatsächlich in einer sehr kritischen Situation.

Ähnlich wie in Deutschland hatten die massiven Probleme der regierungstragenden Funktion angesichts der Währungskrise auch fatale Konsequenzen für die Gesetzgebung. Ein Finanzprojekt jagte das andere und blieb dann ganz oder teilweise in den parlamentarischen Diskussionen hängen. Die bewährten Werkzeuge der parlamentarischen Kontrollfunktion gewannen so in einer zentralen Frage eine destruktive Eigendynamik. Der häufige Wechsel der Finanzminister sorgte zudem für ein ständiges Hin und Her unterschiedlicher Lösungsansätze zwischen Kapitalbesteuerung und vertrauensbildenden Maßnahmen gegenüber den Anlegern, zwischen vorsichtiger Akzeptanz der inflationären Prozesse und Festklammern an einer strikt deflationären Politik. $\mathrm{Da}$ die reguläre Gesetzgebung in den großen finanzpolitischen Fragen weitgehend lahmgelegt war, überrascht es nicht, daß im Sommer 1926 das bereits im Frühjahr 1924 erprobte Mittel der parlamentarischen Ermächtigung wieder auf der politischen Tagesordnung stand.

Die Regierung Briand-Caillaux scheiterte zwar in der Abgeordnetenkammer an ihrem Projekt finanzpolitischer pleins pouvoirs, die Diskussion über dieses Vorhaben bildete aber einen weiteren Schritt zur Enttabuisierung von Ermächtigungsgesetzen. Die Forderung nach einer Vollmacht kam diesmal von einer linksliberalen, von Radicaux und Républicains-socialistes dominierten Regierung und damit genau aus jener politischen Richtung, die 1924 die heftigsten Widerstände gegen Poincarés décrets-lois geleistet hatte. Und trotz aller Befürchtungen wegen der Breite der Ermächtigungsklausel und wegen der Möglichkeiten, die sie einem Finanzminister Caillaux eröffnete, hatten sich die Debatten inzwischen weitgehend von den Topoi der "défense républicaine" gelöst. Der furiose Angriff, den der Kammerpräsident und radikale Parteivorsitzende Herriot schließlich gegen das Ermächtigungsvorhaben und damit auch gegen die Regierung Briand-Caillaux unternahm, blieb eine spektakuläre Einzelaktion.

Die lange Agonie des Cartel des Gauches war - auf den ersten Blick überraschend - auch von Problemen der parlamentarischen Alternativfunktion begleitet. Die mühsamen Versuche, die Kammermehrheit in die politische Mitte zu verlagern, lassen sich als wenig erfolgreiche Bemühungen verstehen, auf traditionelle Weise Ad-hoc-Alternativen zu schaffen. Von einer modernen, parteipolitisch definierten und inhaltlich klar profilierten Regierungsalternative konnte ohnehin keine Rede sein, so daß der anfänglichen linken Blockbildung ein Pendant im Mitte-rechts-Spektrum fehlte. Hier lag eine der Voraussetzungen für das zeitweise Erstarken einer außerparlamentarischen Protestbewegung.

Seit dem Sturz der Regierung Briand IX Mitte Juni 1926 wurde offensichtlich, daß - abgesehen von einer theoretisch möglichen Kammerauflösung - der einzige systemimmanente Ausweg aus dieser schwierigen Situation über eine breite Regierung der Union nationale 395 führen würde. Eine derartige Lösung bedeutete angesichts der nationalen Notlage des Währungsverfalls die Rückkehr zu einer Burgfriedenspolitik, wobei weitgehend klar war, daß diese nur das bürgerliche

${ }^{395}$ Zur Geschichte des Begriffs vgl. Roth, Poincaré, S. 483. 
Spektrum umfassen würde. Letztlich handelte es sich also um eine Wiederherstellung des Bloc national in seiner ursprünglichen breiten Konzeption, und damit auch um ein Alternieren der Mehrheitsverhältnisse, das weit über die seit 1925 erfolgten Verschiebungen hinausging. Hierfür aber war unabdingbar, daß die Fraktion des Parti radical eine derartige Wende zumindest mit großer Mehrheit vollziehen würde, was wiederum eine völlige Desillusionierung über die noch bestehenden Möglichkeiten einer eher nach links orientierten Regierungsbildung erforderte. Das traurige Schicksal des Kabinetts Herriot II bei seiner Präsentation in der Abgeordnetenkammer war daher wohl eine notwendige Voraussetzung, um eine Regierung der Union nationale anzubahnen.

Ein derartiges Kabinett konnte sinnvoller Weise nur durch einen Politiker gebildet werden, der über ein breitenwirksames Charisma verfügte. Die drei seit Juni 1924 amtierenden Ministerpräsidenten Herriot, Painlevé und Briand waren hierfür sicherlich keine geeignete Besetzung, wie sich auch bei entsprechenden Versuchen Briands und Herriots im Juni und Juli 1926 gezeigt hatte. Innerhalb des Mitte-rechts-Spektrums aber gab es wohl nur einen ernsthaften Kandidaten: Poincaré, der sich nicht nur als starker Ministerpräsident erwiesen, sondern im "Verdun financier" von 1924 bereits einmal die Rolle des währungspolitischen Retters gespielt hatte. $\mathrm{Da}$ aber eine Rückkehr Poincarés in das Amt des Ministerpräsidenten von vielen Radicaux als endgültige "Annullierung“ des linken Wahlsieges von 1924 empfunden wurde ${ }^{396}$, mußte trotz des Debakels von Herriot immer noch mit erheblichen Widerständen gerechnet werden.

${ }_{396}$ Vgl. Botschaftsbericht-Paris (Hoesch), Tel. Nr. 736, 23. 7. 1926, S. 1. Demnach hatten die Radicaux zunächst - „unter Hinweis darauf, daß Rückkehr Poincarés in Minister-Präsidium wie Annullierung Wahlsiegs von 1924 aussehen würde“ - einen „Ministerpräsidenten der Linken“ gefordert. PA AA Berlin, R 70717 . 